\author{
Mon ograph \\ urn:1sid:zoobank.org:pub:CAC6F8AF-ED37-4989-9672-68316920750B
}

\title{
Basic anatomy of species of Triphoridae (Gastropoda, Triphoroidea) from Brazil
}

\author{
Maurício Romulo FERNANDES ${ }^{1,2, *}$ \& Alexandre Dias PIMENTA ${ }^{2}$ \\ ${ }^{1}$ Departamento de Zoologia, Instituto de Biociências, Universidade Federal do Estado do Rio de \\ Janeiro, Av. Pasteur, 458, Urca, 22290-240, Rio de Janeiro, Brazil. \\ ${ }^{2}$ Departamento de Invertebrados, Museu Nacional, Universidade Federal do Rio de Janeiro, \\ Quinta da Boa Vista, São Cristóvão, 20940-040, Rio de Janeiro, Brazil. \\ *corresponding author: mauriciofernandes14@hotmail.com \\ 22Email: alexpim@mn.ufrj.br \\ ${ }^{1}$ urn:1sid:zoobank.org:author:6D9B33AF-4E10-4C8C-A2F4-EF21BBF829AC \\ ${ }^{2}$ urn:1sid:zoobank.org:author:F25DDF06-C6B5-42BA-9EC0-27E86FAD16A5
}

\begin{abstract}
The alpha-taxonomy of triphorids is still largely based on the study of the shell, and the scarcity of studies dealing with their anatomy is a result of the difficulty of sampling live animals and their very small size. Whereas radula and operculum are important structures in the taxonomy at the generic level, the jaw of triphorids has never been properly studied, being regarded as presenting a morphological homogeneity. The present research explored the basic anatomy (especially internal hard structures: operculum, jaw and radula) of 12 species from Brazil, distributed in 11 genera: Cheirodonta Marshall, 1983 (with a new generic allocation, Cheirodonta dupliniana (Olsson, 1916) comb. nov.), Cosmotriphora Olsson \& Harbison, 1953, Iniforis Jousseaume, 1884, Latitriphora Marshall, 1983, Metaxia Monterosato, 1884, Monophorus Grillo, 1877, Nanaphora Laseron, 1958, Nototriphora Marshall, 1983, Sagenotriphora Marshall, 1983, Similiphora Bouchet, 1985 and Strobiligera Dall, 1924; in addition, the basic anatomy of the Caribbean species "Inella" harryleei Rolán \& FernándezGarcés, 2008 was analysed. Radular examination showed that the majority of species studied is properly allocated in their genera after comparisons in the literature with respective type species, albeit a few species are clearly in need of a new generic allocation. The jaw of triphorids is remarkably heterogeneous, displaying different patterns of scales and micro-pores between outer and inner sides.
\end{abstract}

Keywords. Taxonomy, morphology, radula, jaw, operculum.

Fernandes M.R. \& Pimenta A.D. 2019. Basic anatomy of species of Triphoridae (Gastropoda, Triphoroidea) from Brazil. European Journal of Taxonomy 517: 1-60. https://doi.org/10.5852/ejt.2019.517

\section{Introduction}

Members of the family Triphoridae are sponge feeders, and their enormous radular diversification is believed to constitute an adaptation to the great morphological plasticity in Porifera (Marshall 1983; Wells 1998). Despite being one of the most speciose families of marine molluscs in the world (Bouchet 
et al. 2002; Albano et al. 2011), with 642 Recent valid species (WoRMS 2018) and hundreds of undescribed ones, most of them are known only by their shells. The scarcity of studies dealing with the anatomy of triphorids is a result of the difficulty of sampling live animals, as dredging usually furnishes only empty shells, as well as of their small size; adults of most species reach less than $10 \mathrm{~mm}$ in shell length (Wells 1998).

The sinistral coiling of triphorids (not considering the subfamily Metaxiinae, which is composed of species with dextral coiling) makes them unusual in the common sense of gastropods' anatomy: osphradium and ctenidium lie in the right side of the body, whereas rectum and genital duct lie in the left side (Fretter 1951). They have an usually thin and corneous operculum, circular to elliptical, with two to seven whorls (Marshall 1983). The great variation in number, shape and size of radular teeth makes Triphoridae probably the gastropod family with the highest diversity of radula, well aware that this structure is a very important attribute to generic delimitations (Marshall 1983; Wells 1998). The radular ribbon is long and thin, bearing hundreds of teeth rows, with formula (1-30)-1-1-1-(1-30) (Marshall 1983).

Triphorids have elongated cephalic tentacles, eyes positioned at their bases, and an acrembolic proboscis. They have a narrow foot and a well-developed posterior pedal gland, without pedal tentacles (Wells 1998). Distinct mantle tentacles extend into the posterior canal, and their length may serve to taxonomic purposes (Nützel 1998), although these structures were barely noticed in previous works. Triphorids also show a typical glandular pouch that lies dorsally to the esophagus, opening at the end of the posterior esophagus (Kosuge 1966). They are dioecious but males lack a penis, transferring mobile spermatozeugmata into the pallial cavity of the female, which has an elaborated reproductive system (Kosuge 1966).

The majority of studies comprizing the anatomy of triphorids is related only to their internal hard structures, especially opercula and radula (e.g., Kosuge 1966; Marshall 1983; Bandel 1984; Bouchet 1985; Rolán \& Fernández-Garcés 1994, 1995, 2008; Nützel 1998), with very few studies illustrating or describing jaws (Risbec 1943; Fretter 1951; Kosuge 1966; Bouchet 1985; Nützel 1998). Colored photographs of the external morphology of soft parts of triphorids are scarce (e.g., Bouchet \& Guillemot 1978; Redfern 2013; Stephens \& Vafiadis 2015). There are even rarer studies illustrating particular aspects of the reproductive, digestive or nervous systems (e.g., Risbec 1943; Fretter 1951; Johansson 1953; Marcus \& Marcus 1963; Kosuge 1966; Houston 1985), owing to the limitation of drawings on camera lucida of these small animals. Haszprunar (1985) and Healy (1990) conducted ultrastructural histologic sections on a few triphorids (the former on the osphradium, the latter on the spermatozeugmata), and Golding et al. (2009) provided histological sections of the proboscis of one species.

Recent studies increased the total number of triphorids known from Brazil to 66 (Fernandes \& Pimenta in prep.). All of them were studied only by their shells, precluding comparisons with Caribbean specimens illustrated by the external morphology of soft parts, operculum or radula (Bandel 1984; Rolán \& Fernández-Garcés 1994, 1995, 2008; Redfern 2013). An exception to this is Marshallora cf. nigrocincta (C.B. Adams, 1839), which was studied by Marcus \& Marcus (1963) in southeastern Brazil and was the target of an integrative taxonomic approach (Fernandes et al. in prep.), thus not being evaluated in the present study. A summary of studies dealing with anatomical aspects of the triphorid genera addressed in this work is furnished below (Table 1).

The objective of this research is to examine basic aspects of the anatomy of triphorids occurring in Brazil and to provide comparisons at generic and specific levels. For this purpose, colored photographs of the external morphology of soft parts and scanning electron microscope (SEM) images of internal hard structures, i.e., opercula, radulae and jaws, were conducted. The importance of these structures in the phylogenetic context of Triphoridae is also discussed. 
Table 1 (continued on 2 next pages). Previous morphological studies on Triphoridae, regarded only genera addressed in this work. Some studies illustrated but did not describe the respective morphological feature(s), or the inverse. Type species are indicated by an asterisk (*). Abbreviations: EA = Eastern Atlantic (comprising the Mediterranean); WA $=$ Western Atlantic; WP $=$ Western Pacific.

\begin{tabular}{|c|c|c|c|}
\hline Species & $\begin{array}{l}\text { Geographical } \\
\text { range }\end{array}$ & Morphological features & References \\
\hline \multicolumn{4}{|c|}{ Metaxia Monterosato, 1884} \\
\hline $\begin{array}{l}\text { Metaxia rugulosa } \\
\text { (C.B. Adams, 1850) }\end{array}$ & WA & External morphology & Redfern (2013) \\
\hline $\begin{array}{c}\text { *Metaxia metaxa } \\
\text { (Delle Chiaje, 1828) }\end{array}$ & EA & External morphology; radula & Bouchet (1985) \\
\hline Metaxia exaltata (Powell, 1930) & WP & $\begin{array}{l}\text { External morphology; operculum; } \\
\text { jaw; radula }\end{array}$ & Marshall (1977) \\
\hline Metaxia spp. & WP & Operculum; jaw; radula & Nützel (1998) \\
\hline \multicolumn{4}{|c|}{ Cheirodonta Marshall, 1983} \\
\hline $\begin{array}{c}* \text { Cheirodonta pallescens } \\
\text { (Jeffreys, 1867) }\end{array}$ & EA & $\begin{array}{l}\text { External morphology; operculum; } \\
\text { radula }\end{array}$ & $\begin{array}{l}\text { Fretter (1951), described } \\
\text { as Triphora perversa; } \\
\text { Bouchet \& Guillemot } \\
\text { (1978); Bouchet (1985); }\end{array}$ \\
\hline $\begin{array}{l}\text { Cheirodonta labiata } \\
\text { (A. Adams, 1854) }\end{array}$ & WP & Operculum; radula & Marshall (1983) \\
\hline \multicolumn{4}{|c|}{ Cosmotriphora Olsson \& Harbison, 1953} \\
\hline $\begin{array}{l}\text { *Cosmotriphora melanura } \\
\quad(\text { C.B. Adams, 1850) }\end{array}$ & WA/EA & $\begin{array}{l}\text { External morphology; operculum; } \\
\text { radula }\end{array}$ & $\begin{array}{l}\text { Bouchet (1985); Rolán \& } \\
\text { Fernández-Garcés (1994) }\end{array}$ \\
\hline \multicolumn{4}{|c|}{ Iniforis Jousseaume, 1884} \\
\hline Iniforis turristhomae (Holten, 1802) & WA & $\begin{array}{l}\text { External morphology; operculum; } \\
\text { radula }\end{array}$ & $\begin{array}{l}\text { Bandel (1984); Rolán \& } \\
\text { Fernández-Garcés (1993) }\end{array}$ \\
\hline $\begin{array}{c}\text { *Iniforis malvacea Jousseaume, } \\
1884\end{array}$ & WP & Radula & Marshall (1983) \\
\hline $\begin{array}{c}\text { Iniforis violacea } \\
\text { (Quoy \& Gaimard, 1834) }\end{array}$ & WP & Radula & Marshall (1983) \\
\hline \multicolumn{4}{|c|}{ Latitriphora Marshall, 1983} \\
\hline $\begin{array}{l}\text { Latitriphora albida } \\
\text { (A. Adams, 1854) }\end{array}$ & WA & $\begin{array}{l}\text { External morphology; operculum; } \\
\text { radula }\end{array}$ & $\begin{array}{l}\text { Rolán \& Fernández-Garcés } \\
\text { (1995); Redfern (2013) }\end{array}$ \\
\hline \multicolumn{4}{|c|}{ Monophorus Grillo, 1877} \\
\hline Monophorus olivaceus (Dall, 1889) & WA & External morphology; radula & $\begin{array}{l}\text { Rolán \& Fernández-Garcés } \\
\text { (1994) }\end{array}$ \\
\hline $\begin{array}{l}\quad \text { Monophorus ateralbus } \\
\text { Rolán \& Fernández-Garcés, } 1994\end{array}$ & WA & External morphology; radula & $\begin{array}{l}\text { Rolán \& Fernández-Garcés } \\
\text { (1994) }\end{array}$ \\
\hline $\begin{array}{c}* \text { Monophorus perversus } \\
\text { (Linnaeus, 1758) }\end{array}$ & EA & External morphology; radula & Bouchet (1985) \\
\hline $\begin{array}{l}\text { Monophorus thiriotae } \\
\text { Bouchet, } 1985\end{array}$ & EA & External morphology; radula & Bouchet (1985) \\
\hline $\begin{array}{l}\text { Monophorus erythrosoma } \\
\text { (Bouchet \& Guillemot, 1978) }\end{array}$ & EA & External morphology; radula & $\begin{array}{c}\text { Bouchet \& Guillemot } \\
\text { (1978); Bouchet (1985); } \\
\text { Fernandes \& Rolán (1988) }\end{array}$ \\
\hline $\begin{array}{l}\text { Monophorus verdensis } \\
\text { Fernandes \& Rolán, } 1988\end{array}$ & EA & $\begin{array}{l}\text { External morphology; operculum; } \\
\text { radula }\end{array}$ & Fernandes \& Rolán (1988) \\
\hline
\end{tabular}


Table 1 (continued). Previous morphological studies on Triphoridae.

\begin{tabular}{|c|c|c|c|}
\hline Species & $\begin{array}{l}\text { Geographical } \\
\text { range }\end{array}$ & Morphological features & References \\
\hline $\begin{array}{l}\text { Monophorus pantherinus } \\
\text { Rolán \& Peñas, } 2001\end{array}$ & EA & $\begin{array}{l}\text { External morphology; operculum; } \\
\text { radula }\end{array}$ & Rolán \& Peñas (2001) \\
\hline $\begin{array}{l}\text { Monophorus alboranensis } \\
\text { Rolán \& Peñas, } 2001\end{array}$ & EA & Operculum & Rolán \& Peñas (2001) \\
\hline $\begin{array}{l}\text { Monophorus amicitiae } \\
\text { Romani, } 2015\end{array}$ & EA & Operculum & Romani (2015) \\
\hline Monophorus sp. & EA & External morphology; radula & Rolán \& Peñas (2001) \\
\hline $\begin{array}{c}\text { Monophorus angasi } \\
\text { (Crosse \& Fischer, 1865) }\end{array}$ & WP & Operculum; radula & Marshall (1983) \\
\hline $\begin{array}{l}\text { Monophorus nigrofuscus } \\
\quad \text { (A. Adams, 1854) }\end{array}$ & WP & Operculum; radula & Marshall (1983) \\
\hline $\begin{array}{l}\text { Monophorus fascelinus } \\
\text { (Suter, 1908) }\end{array}$ & WP & External morphology & Nützel (1998) \\
\hline \multicolumn{4}{|c|}{ Nanaphora Laseron, 1958} \\
\hline $\begin{array}{c}\text { Nanaphora verbernei } \\
\text { (Moolenbeek \& Faber, 1989) }\end{array}$ & WA & $\begin{array}{l}\text { External morphology; operculum; } \\
\text { radula }\end{array}$ & $\begin{array}{l}\text { Rolán \& Fernández-Garcés } \\
\text { (1994) }\end{array}$ \\
\hline $\begin{array}{l}\quad \text { Nanaphora decollata } \\
\text { (Rolán \& Fernández-Garcés, 1994) }\end{array}$ & WA & $\begin{array}{l}\text { External morphology; operculum; } \\
\text { radula }\end{array}$ & $\begin{array}{l}\text { Rolán \& Fernández-Garcés } \\
\text { (1994) }\end{array}$ \\
\hline $\begin{array}{c}\text { Nanaphora albogemmata } \\
\text { (Laseron, 1958) }\end{array}$ & WP & Operculum; radula & Marshall (1983) \\
\hline $\begin{array}{l}\text { Nanaphora aff. albogemmata } \\
\text { (Laseron, 1958) }\end{array}$ & WP & Radula & Nützel (1998) \\
\hline \multicolumn{4}{|c|}{ Nototriphora Marshall, 1983} \\
\hline $\begin{array}{l}\text { Nototriphora decorata } \\
\text { (C.B.Adams, 1850) }\end{array}$ & WA & $\begin{array}{l}\text { External morphology; operculum; } \\
\text { radula }\end{array}$ & $\begin{array}{l}\text { Garcia \& Luque (1986); } \\
\text { Rolán \& Fernández-Garcés } \\
\text { (1994) }\end{array}$ \\
\hline $\begin{array}{c}\text { Nototriphora canarica } \\
\text { (Nordsieck \& Talavera, 1979) }\end{array}$ & EA & $\begin{array}{l}\text { External morphology; operculum; } \\
\text { radula }\end{array}$ & $\begin{array}{c}\text { Fernandes \& Rolán (1988); } \\
\text { Bouchet (1997) }\end{array}$ \\
\hline Nototriphora vestita Marshall, 1983 & WP & Operculum & Marshall (1983) \\
\hline $\begin{array}{c}\text { *Nototriphora aupouria } \\
\text { (Powell, 1937) }\end{array}$ & WP & Operculum; radula & Marshall (1983) \\
\hline \multicolumn{4}{|c|}{ Sagenotriphora Marshall, 1983} \\
\hline $\begin{array}{c}\text { Sagenotriphora osclausum } \\
\text { (Rolán \& Fernández-Garcés, 1995) }\end{array}$ & WA & Operculum; radula & $\begin{array}{l}\text { Rolán \& Fernández-Garcés } \\
\text { (2008) }\end{array}$ \\
\hline $\begin{array}{l}\text { Sagenotriphora candidula } \\
\text { Rolán \& Lee, } 2008\end{array}$ & WA & Operculum; radula & $\begin{array}{l}\text { Rolán \& Fernández-Garcés } \\
\qquad(2008)\end{array}$ \\
\hline $\begin{array}{l}\text { *Sagenotriphora ampulla } \\
\text { (Hedley, 1903) }\end{array}$ & WP & Operculum; radula & Marshall (1983) \\
\hline \multicolumn{4}{|c|}{ Similiphora Bouchet, 1985} \\
\hline $\begin{array}{l}\text { Similiphora intermedia } \\
\text { (C.B. Adams, 1850) }\end{array}$ & WA & External morphology & $\begin{array}{l}\text { Rolán \& Fernández-Garcés } \\
\qquad(1995)\end{array}$ \\
\hline $\begin{array}{l}\text { *Similiphora similior } \\
\text { (Bouchet \& Guillemot, 1978) }\end{array}$ & EA & External morphology; radula & $\begin{array}{c}\text { Bouchet \& Guillemot } \\
\text { (1978); Bouchet (1985, } \\
\text { 1997) }\end{array}$ \\
\hline
\end{tabular}


Table 1 (continued). Previous morphological studies on Triphoridae.

\begin{tabular}{cccc}
\hline Species & $\begin{array}{c}\text { Geographical } \\
\text { range }\end{array}$ & Morphological features & References \\
\hline Similiphora triclotae Bouchet, 1997 & EA & $\begin{array}{c}\text { External morphology; operculum; } \\
\text { radula }\end{array}$ & Bouchet (1997) \\
$\begin{array}{c}\text { Strobiligera lubrica } \\
\text { Bouchet \& Warén, 1993 }\end{array}$ & EA & Operculum; radula & Bouchet \& Warén (1993) \\
$\begin{array}{c}\text { Strobiligera brychia } \\
\text { (Bouchet \& Guillemot, 1978) }\end{array}$ & EA & Radula & Bouchet (1985)
\end{tabular}

\section{Material and methods}

Some lots herein examined were obtained from malacological collections in Brazil and USA. Other specimens were sampled by the authors after 2014, with field works specifically devoted to obtain triphorids along the Brazilian coast. A few illustrated specimens are from Caribbean or adjacencies, but always related to species that also occur in Brazil.

\section{Acronyms of institutions}

\begin{tabular}{|c|c|}
\hline BMSM & The Bailey-Matthews National Shell Museum, Sanibel, USA \\
\hline FLMNH & Florida Museum of Natural History, Gainesville, USA \\
\hline MNRJ & Museu Nacional, Universidade Federal do Rio de Janeiro, Rio de Janeiro, Brazil \\
\hline MZUSP/MZSP & Museu de Zoologia da Universidade de São Paulo, São Paulo, Brazil \\
\hline NMNH/USNM & National Museum of Natural History, Washington DC, USA \\
\hline ZUEC-GAS & $\begin{aligned}= & \text { collection of Gastropoda of the Museu de Zoologia of Universidade Estadual de } \\
& \text { Campinas - UNICAMP, Campinas, Brazil }\end{aligned}$ \\
\hline
\end{tabular}

Sampling was conducted by snorkeling or SCUBA. Triphorids are too small to be seen and handcollected in great amounts underwater, thus techniques adopted were: brushing of sponges, considered the most suitable method to sample triphorids (Albano et al. 2011); brushing of the underside of stones; and sieving of algae. The mesh size was $0.7 \mathrm{~mm}$, with shallow sieves employed during snorkeling and a basket composed of PVC used during SCUBA dives. The material was anesthetized with $3.5 \% \mathrm{MgCl}_{2}$. Specimens were fixed in ethanol $80 \%$ to $100 \%$ and stored at MNRJ. Unfortunately, this material was lost after the fire at MNRJ on September 2018 (Zamudio et al. 2018).

Shells were photographed prior to anatomical studies. They were initially cracked to allow the image record of the external morphology of soft parts (hereafter, the term 'external morphology' will be applied exclusively to soft parts). Some shells were dissolved using Railliet-Henry's fluid (1L: $930 \mathrm{~mL}$ of distilled water $+6 \mathrm{~g}$ of sodium chloride $+50 \mathrm{~mL}$ of formaldehyde $37 \%+20 \mathrm{~mL}$ of glacial acetic acid). The external morphology was photographed in a camera Zeiss AxioCam ICc5 coupled to the stereo microscope Zeiss Discovery.V20.

To illustrate the operculum, it was removed from the foot of the animal with a pair of fine forceps/ needles and mechanically cleaned. The operculum was positioned on the carbon tape by partly (not completely) touching its surface, in order to facilitate the vizualization of the whorls (Geiger et al. 2007), and was subsequently analyzed in a SEM model JEOL JSM-6390LV. To illustrate radulae and jaws, diluted bleach was applied in the anterior body; after visualizing them, they were mechanically 
cleaned and subsequently extracted with fine forceps, inserting them on a piece of cover slip glued on a carbon tape. Once placed on the cover slip, radulae and jaws were cleaned by consecutive minute drops of ethanol, thus avoiding the loss of these small structures during handling with forceps.

Critical point drying (CPD) was applied in some cases to the head-foot and to ctenidia. Structures were placed in a diluted solution of a neutral detergent to remove mucus of the animal, softly shaking the soft parts during 30 minutes. Subsequent ethanol dehydration series was $25 \%, 50 \%, 75 \%, 93 \%, 100 \%$ (twice), each one carried out for 15 to 30 minutes, finally leading to CPD.

The color of the soft parts was described only of specimens in which distinct color patterns were observed, i.e., when the storage in ethanol did not remove the original coloration of the animal. The diameter of the operculum usually exceeded that of the opercular pouch, and the relative difference between their diameter was measured through a photograph of the foot in dorsal view; the dislodgement of the nucleus in relation to the center of the operculum regarded its radius length (measured through SEM image). Arbitrary categories of nucleus: central (nucleus dislocated $0 \%$ to $10 \%$ ), subcentral (11\% to $29 \%$ ), slightly eccentric ( $30 \%$ to $44 \%$ ) and considerably eccentric ( $45 \%$ or more).

Scales of jaws were named according to their shape, even regarding transition forms between some of them (Fig. 1): rectangular/squared (resembling bricks), rectangular-bilobed (resembling bricks/tiles, not constricted at the middle, but extremities somewhat bilobed), bone-shaped (width constricted at the middle, extremities rounded), boomerang-shaped, lanceolate, leaf-shaped (one extremity oblong, the other slightly asymmetrical and acute), rhombus-shaped, hexagonal, gem-like (angles more rounded than hexagonal scales), X-shaped (with four asymmetrical tips, lobed or hooked), puzzle-shaped (more stretched than $\mathrm{X}$-shaped scales), fusiform, or irregular (undefined shape, usually seen at the border of the jaw).

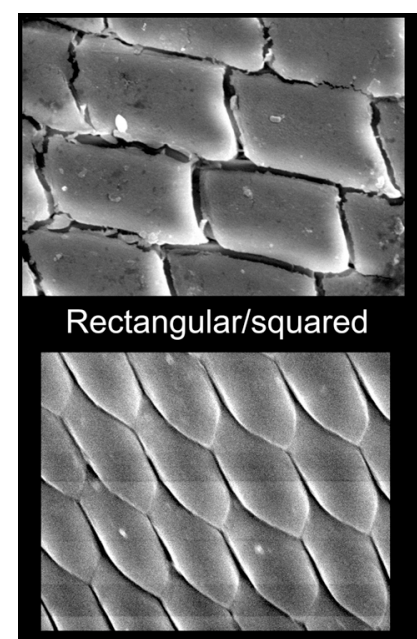

Lanceolate

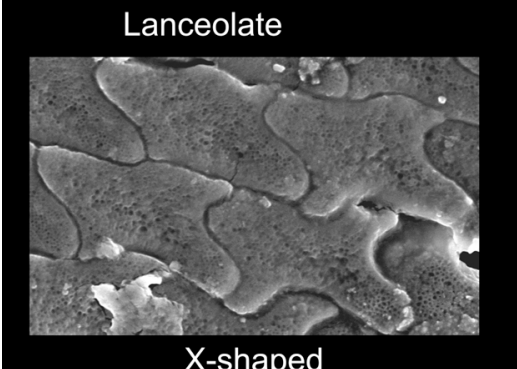

X-shaped
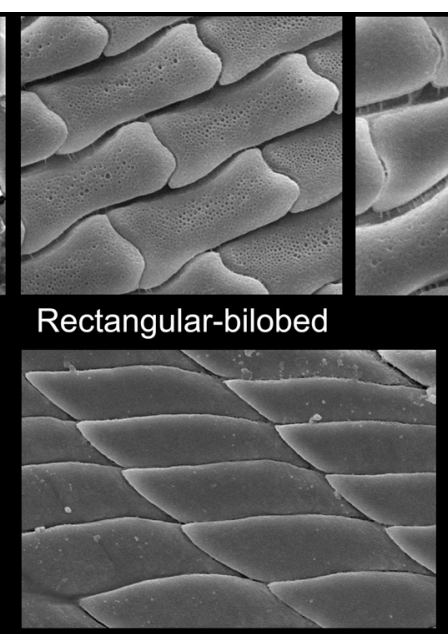

Leaf-shaped

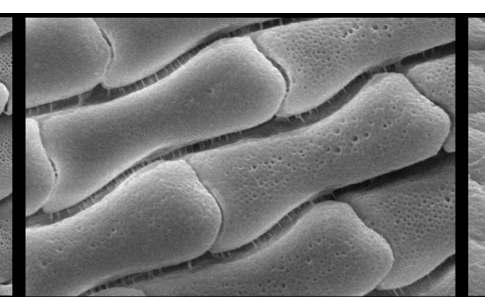

Bone-shaped

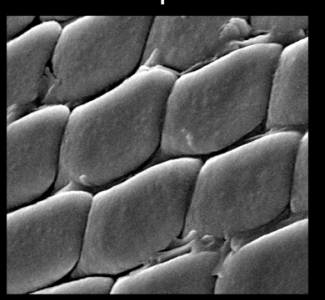

Rhombus-shaped

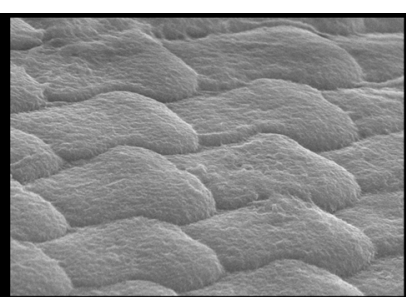

Boomerang-shaped

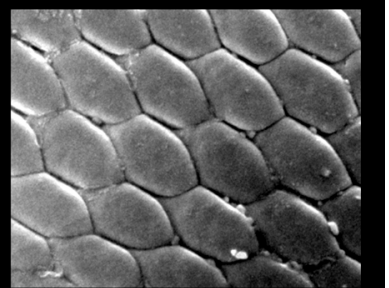

Hexagonal/gem-like

Fig. 1. Main types of jaw scales of Triphoridae. 
Particularly regarding the cusps of the radula, preliminary descriptions followed the main tendency in the literature to name cusps instead of numbering them; as a consequence, a problematic scenario emerged when dealing with multicuspid teeth. When necessary, cusps are herein numbered from the innermost cusp (cusp 1), close to the rachidian/central tooth, toward the outermost cusp, distant from the central tooth. A multicuspid central tooth has cusps arbitrarily numbered from left to right. In rare cases when extra cusps emerge along teeth rows, they are assigned a number and a letter, e.g., cusp 7A (the one emerging between cusps 7 and 8).

When enough material was available, up to three specimens per species were studied in order to evaluate intraspecific variation. Five to 20 units were measured per feature (e.g., width of central tooth), depending on the availability of images. Some structures (e.g., jaw) or views (e.g., inner side of the jaw) could not be observed for certain species. Numbers inside square brackets indicate how many specimens were originally present in the lot, and 'd' refers to the number of partially or totally destroyed specimens for anatomical or molecular studies (unpublished data). Central, lateral and marginal teeth are respectively referred by letters ' $\mathrm{C}$ ', 'L' and ' $\mathrm{M}$ ' (in this case, for example, 'M1' refers to the first marginal tooth) in the figures.

\section{Results}

Some specimens broken for the study of soft parts are shown (Fig. 2). The studied specimen of Cheirodonta dupliniana (Olsson, 1916) comb. nov. was not photographed prior to shell breaking, thus not being illustrated.

Class Gastropoda Cuvier, 1795

Subclass Caenogastropoda Cox, 1960

Superfamily Triphoroidea Gray, 1847

Family Triphoridae Gray, 1847

Subfamily Metaxiinae Marshall, 1977

Genus Metaxia Monterosato, 1884

\section{Type species}

Cerithium rugulosum Sowerby, 1855 = Metaxia metaxa (Delle Chiaje, 1828); see Bouchet et al. (2017) for a detailed explanation. Subsequent designation by Cossmann (1906). Recent, northeastern Atlantic and Meditteranean.

Metaxia excelsa Faber \& Moolenbeek, 1991

Figs $2 \mathrm{~A}, 3$

\section{Material examined}

BRAZIL - [2, 1 d] specs; Fernando de Noronha Archipelago, canal between islands Ressureta and Rata;

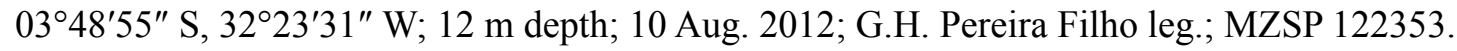

\section{Description of basic anatomy}

OperCuLum. Elliptical, thin, semi-transparent, membranous, nucleus and number of whorls not discernible; diameter of operculum exceeds diameter of opercular pouch in $17 \%$.

JAW. Wing-shaped; outer side with scales usually rectangular/squared, sometimes rhombus-shaped or even oblong-lanceolate; some scales covered by micro-pores up to $270 \mathrm{~nm}$ in diameter; rectangular scales $10.5-15.4 \mu \mathrm{m}$ long, 4.8-7.7 $\mu \mathrm{m}$ wide, ratio length/width 1.8-2.9, rhombus-shaped scales 17.9- 
$24.5 \mu \mathrm{m}$ long, 5.9-10.0 $\mu \mathrm{m}$ wide, ratio length/width 2.4-3.1, oblong-lanceolate scales 14.6-16.5 $\mu \mathrm{m}$ long, 4.0-5.0 $\mu \mathrm{m}$ wide, ratio length/width 2.9-3.6.

RAdULA. Formula 4-1-1-1-4; central tooth with four to five elongated and claw-like cusps, median cusp present or not but always thinner, with the basal plate of tooth assuming a concave format (i.e., outer cusps in an upper position than median one), outer cusps usually distinctly oriented outwards and reaching slightly larger dimensions (equal or up to $1.2 \times$ more elongated) than inner cusps; lateral teeth with four elongated claw-like cusps, basal plate of tooth slightly concave (not as much as central tooth), all cusps approximately with the same length, but cusp 1 considerably broader and sometimes slightly shorter than remaining cusps; marginal teeth gradually diminishing in size outwards; M1 and M2 with four cusps very similar to lateral teeth, with all cusps similar in length or width; M3 with three similar, moderately elongated, pointed and claw-like cusps; M4 small, with three curved

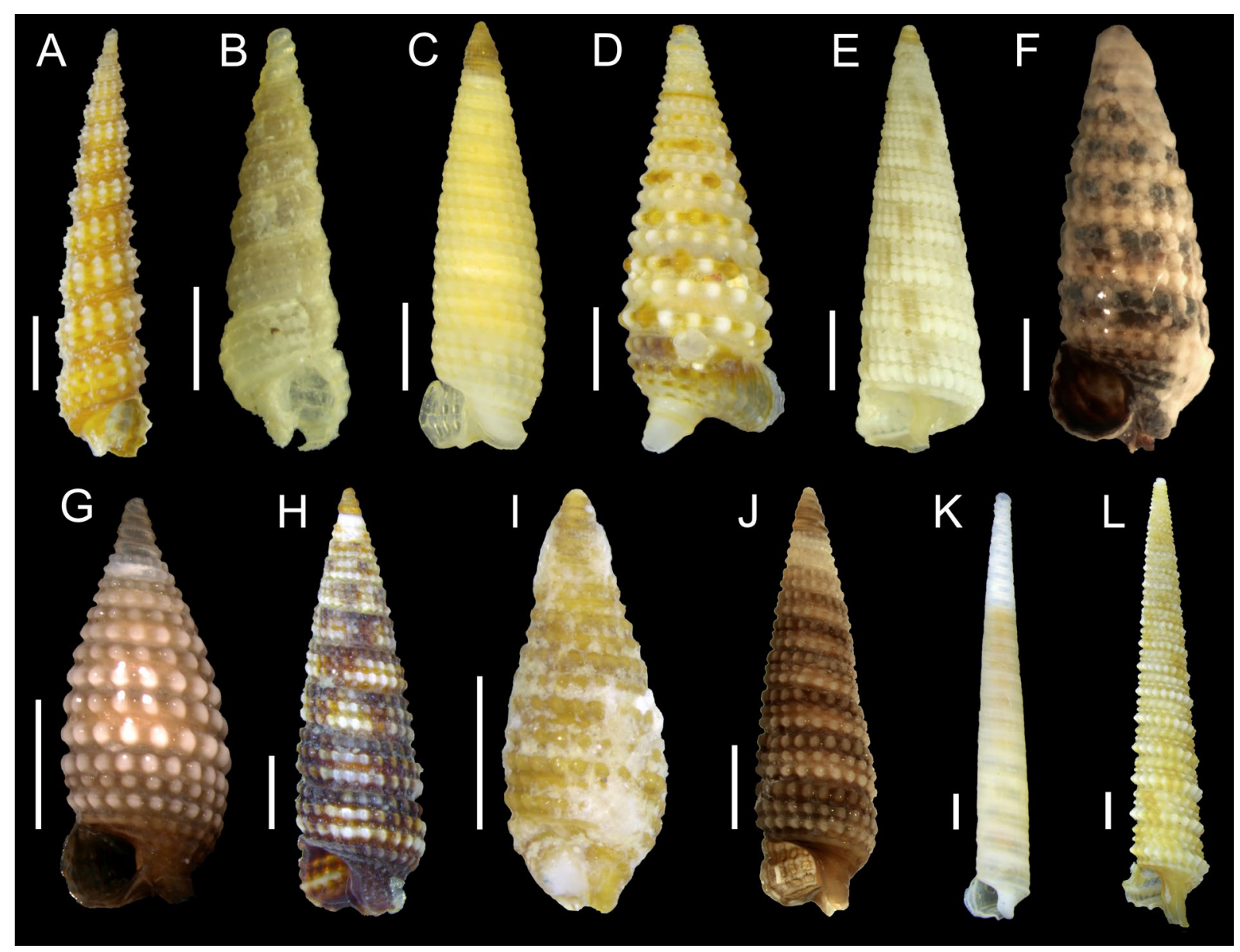

Fig. 2. Specimens studied. A. Metaxia excelsa Faber \& Moolenbeek, 1991 (MZSP 122353). B. Metaxia rugulosa (C.B. Adams, 1850) (BMSM 56034). C. Cosmotriphora melanura (C.B. Adams, 1850) (MNRJ 33980). D. Iniforis pseudothomae Rolán \& Fernández-Garcés, 1993 (MZSP 100957). E. Latitriphora albida (A. Adams, 1854) (BMSM 55442). F. Monophorus olivaceus (Dall, 1889) (MNRJ 34615). G. Nanaphora verbernei (Moolenbeek \& Faber, 1989) (MZSP 85022). H. Nototriphora decorata (C.B. Adams, 1850) (MNRJ 28941). I. Sagenotriphora osclausum (Rolán \& Fernández-Garcés, 1995) (MNRJ 35061). J. Similiphora intermedia (C.B. Adams, 1850) (MNRJ 29763). K. Strobiligera gaesona (Dall, 1927) (MZSP 53685). L. “Inella” harryleei Rolán \& Fernández-Garcés, 2008 (FLMNH 450495). Scale bars: $1 \mathrm{~mm}$. 


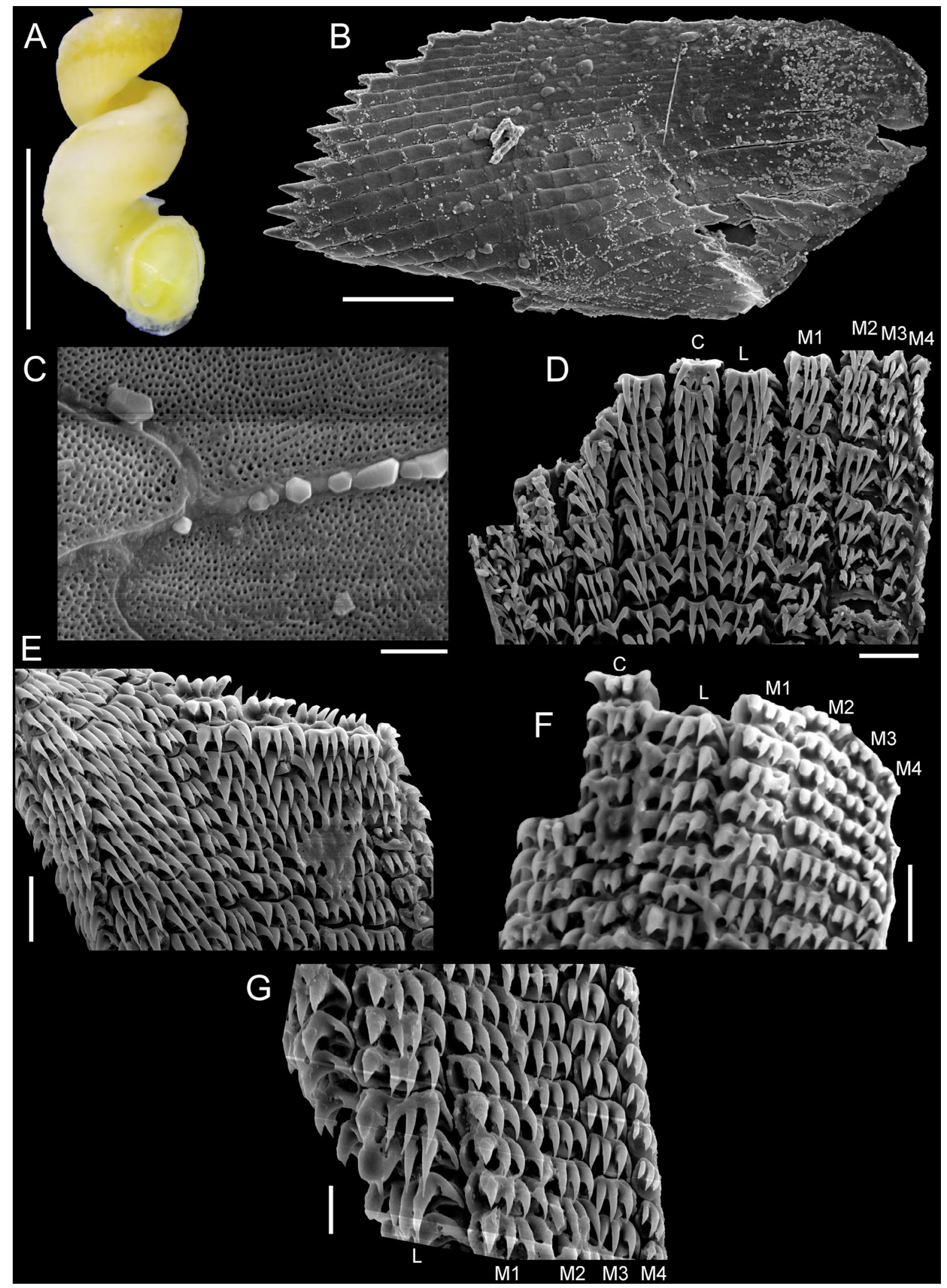

Fig. 3. Metaxia excelsa Faber \& Moolenbeek, 1991. A-G. MZSP 122353. A. External morphology. B-C. Jaw, outer side. D-G. Radula. Scale bars: A $=1 \mathrm{~mm}$; B $=50 \mu \mathrm{m} ; \mathrm{C}=2 \mu \mathrm{m}$; D-F $=10 \mu \mathrm{m}$; $\mathrm{G}=$ $5 \mu \mathrm{m}$. 
and pointed cusps, median one 1.2 to 1.6 times more elongated than remaining cusps; central tooth 6.4-9.2 $\mu \mathrm{m}$ wide, lateral teeth 7.1-9.9 $\mu \mathrm{m}$ wide, M1 5.8-8.7 $\mu \mathrm{m}$ wide, M2 4.1-6.7 $\mu \mathrm{m}$ wide, M3 3.2-4.4 $\mu \mathrm{m}$ wide, M4 2.3-3.1 $\mu \mathrm{m}$ wide.

\section{Remarks}

The radula of M. excelsa shares several features with that of M. exaltata (Powell, 1930) (Marshall 1977), such as the general tooth morphology and the gradual decrease of size towards the outermost marginal teeth, confirming their affinity at genus-level. The distinction lies in the number of marginal teeth (only four in $M$. excelsa, but nine or ten in M. exaltata), the median cusp of the central tooth (apparently more reduced or vestigial in $M$. exaltata) and the number of cusps in the outermost marginal teeth (three in M4 of M. excelsa, two in M9 or M10 of M. exaltata). The radula of M. metaxa described by Bouchet (1985) shows slight differences compared to M. excelsa, like a central tooth with four cusps (instead of five in M. excelsa), lateral teeth and M1-M2 with five cusps (four in M. excelsa) and the presence of five marginal teeth (four in $M$. excelsa). Radulae of both species are similar in general tooth morphology, with claw-like cusps, and in the number of cusps of the outermost marginal teeth (i.e., three cusps). The tooth morphology of M. excelsa is also quite similar to the two unnamed species from the southwestern Pacific studied by Nützel (1998), especially to Metaxia sp. 1, albeit these two species have six and five marginal teeth (but four in $M$. excelsa). The predominance of rectangular scales in the jaw of Metaxia sp. 1 looks identical to the observed in M. excelsa (Fig. 3B).

Metaxia rugulosa (C.B. Adams, 1850)

Figs 2B, 4

\section{Material examined}

BAHAMAS • [2, 1 d] specs; Abaco; 0.2 m depth; 11 Jul. 1994; C. Redfern leg.; BMSM 56034.

\section{Description of basic anatomy}

Operculum. Elliptical, thin, semi-transparent, membranous, paucispiral, 2.25 whorls, nucleus considerably eccentric, dislocated $47 \%$ from center towards margin; diameter of operculum exceeds diameter of opercular pouch in $10 \%$.

JAW. Wing-shaped; outer side with scales rectangular or rhombus-shaped, some of them covered by micro-pores up to $330 \mathrm{~nm}$ in diameter; rectangular scales $13.4-25.2 \mu \mathrm{m}$ long, $5.0-11.1 \mu \mathrm{m}$ wide, ratio length/width 2.3-3.1, rhombus-shaped scales 19.8-22.2 $\mu \mathrm{m}$ long, 6.8-9.4 $\mu \mathrm{m}$ wide, ratio length/ width 2.3-3.2.

RADULA. Formula 3-1-1-1-3; central tooth with four main cusps, triangular and curved (claw-like), outer cusps slightly broader and occupying an upper position in relation to inner ones, in addition to a fifth, median and thin cusp up to $60 \%$ the length of remaining cusps; lateral teeth with four cusps, of which 1, 3 and 4 are claw-like and cusp 2 is vestigial or very reduced (up to $56 \%$ the length of remaining cusps); M1 with three to four cusps, cusps 1 and 4 slightly broader, cusp 2 often considerably reduced but even reaching the same length of remaining cusps; M2 with three to four small cusps; M3 very reduced, usually with three small cusps; central tooth $7.7-8.7 \mu \mathrm{m}$ wide, lateral teeth $6.7-7.4 \mu \mathrm{m}$ wide, M1 5.4-7.6 $\mu \mathrm{m}$ wide, M2 4.0-5.0 $\mu \mathrm{m}$ wide, developed M3 2.1-3.0 $\mu \mathrm{m}$ wide.

\section{Remarks}

The white color of the soft parts of M. rugulosa was illustrated by Redfern (2013), and the specimen herein figured was poorly preserved inside the shell, giving a false aspect of cream color to the external morphology (Fig. 4A-B). The operculum of M. rugulosa resembles that of M. exaltata, despite 


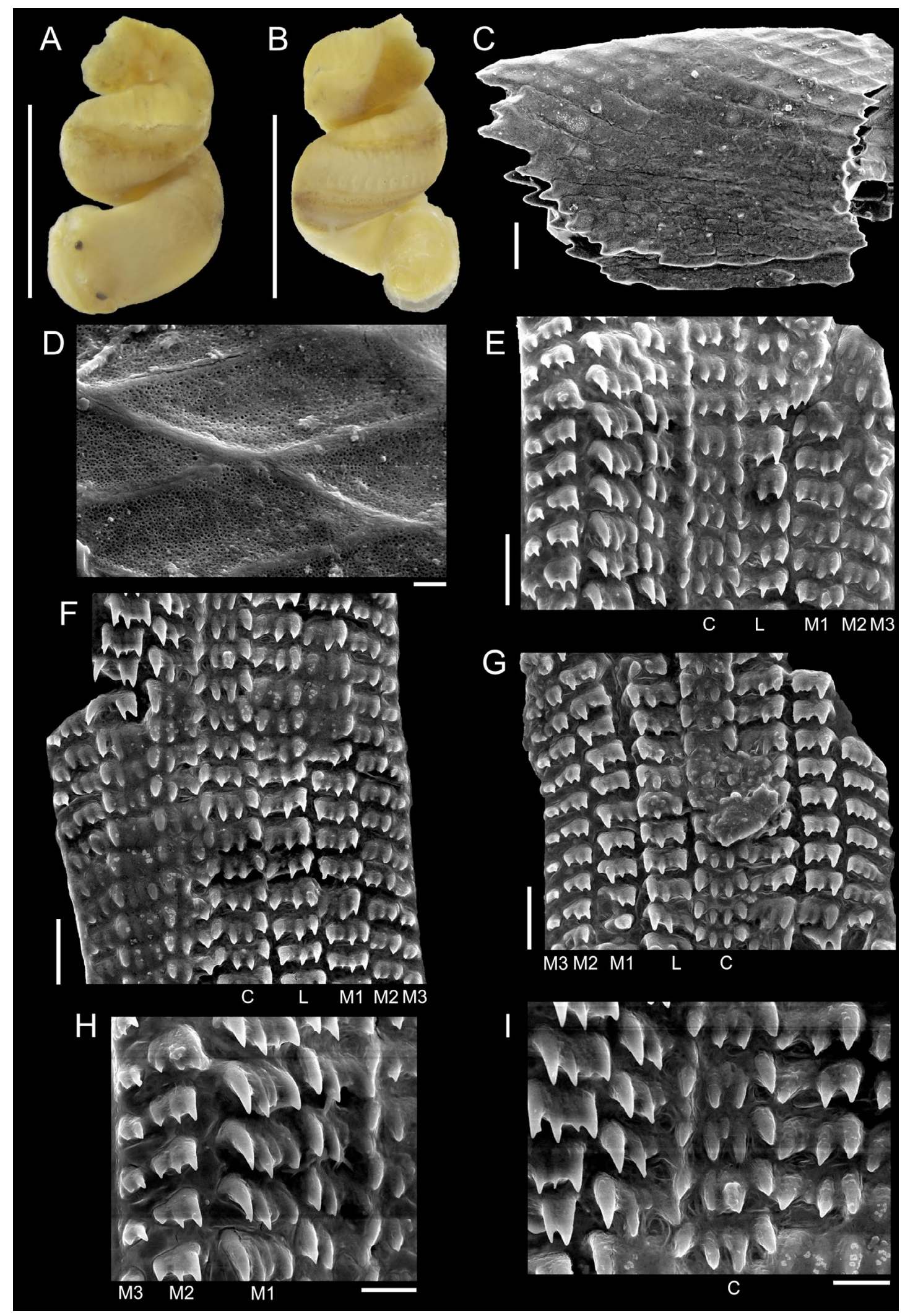

Fig. 4. Metaxia rugulosa (C.B. Adams, 1850). A-I. BMSM 56034. A-B. External morphology. C-D. Jaw, outer side. E-I. Radula. Scale bars: A-B $=1 \mathrm{~mm} ; \mathrm{C}=20 \mu \mathrm{m} ; \mathrm{D}=2 \mu \mathrm{m} ; \mathrm{E}-\mathrm{G}=10 \mu \mathrm{m}$; $\mathrm{H}-\mathrm{I}=5 \mu \mathrm{m}$. 
the former showing a shorter whorl expansion (Fig. 4B) instead of the wide whorl expansion of the latter and its consequent more eccentric nucleus (Marshall 1977).

Metaxia rugulosa has a paucispiral protoconch with a few spiral threads in the embryonic whorl, and has a radula (Fig. 4E-I) with tooth morphology similar to that of species with a multispiral protoconch with several spiral threads in the embryonic whorl, e.g., M. excelsa, M. exaltata and the type species M. metaxa. A remarkable aspect of the radula of M. rugulosa is the reduced number of marginal teeth (three), which is followed by M. excelsa (four), M. metaxa and Nützel's Metaxia sp. 2 (five), Nützel's Metaxia sp. 1 (six) and M. exaltata (nine or ten). The increment of teeth at the margins of the radular ribbon was indicated by Marshall (1977) for M. exaltata, and could be the reason for the deviation of this genus from the taenioglossate radula (with two marginal teeth) typical of Cerithiopsidae.

Subfamily Triphorinae Gray, 1847

Genus Cheirodonta Marshall, 1983

\section{Type species}

Cerithium perversum var. pallescens Jeffreys, 1867. Original designation. Recent, northeastern Atlantic and Mediterranean.

Cheirodonta dupliniana (Olsson, 1916) comb. nov.

Figs 5-6

Cheirodonta mizifio Fernandes \& Pimenta, 2015; see Fernandes \& Pimenta in prep. for synonymy.

\section{Material examined}

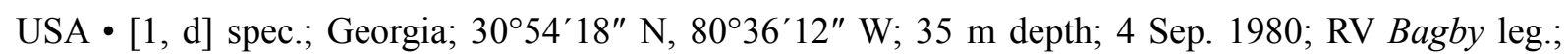
USNM 1438722.

\section{Description of basic anatomy}

Operculum. Ovate-elliptical, thin, semi-transparent, membranous, poorly distinct whorls, nucleus subcentral, dislocated $22 \%$ from center toward margin.

$\mathrm{J}_{\mathrm{AW}}$. Wing-shaped; outer side with scales rectangular/squared, rectangular-bilobed, acute-lanceolate or puzzle-like; rectangular scales $9.0-10.3 \mu \mathrm{m}$ long, 5.2-6.1 $\mu \mathrm{m}$ wide, ratio length/width 1.6-1.9, rectangular-bilobed scales 9.9-10.3 $\mu \mathrm{m}$ long, 4.6-5.2 $\mu \mathrm{m}$ wide, ratio length/width 2.0-2.2, acutelanceolate scales $16.7-18.1 \mu \mathrm{m}$ long, 5.6-6.7 $\mu \mathrm{m}$ wide, ratio length/width $2.6-3.2$, puzzle-like scales 12.9-15.6 $\mu \mathrm{m}$ long (largest lobe to largest lobe), 5.6-9.9 $\mu \mathrm{m}$ wide (perpendicular to the length at the center of scale), ratio length/width 1.4-2.8.

RADULA. Formula 8-1-1-1-8; central tooth usually with seven cusps, median one (cusp 4) is the smallest or even absent, cusps 1, 3, 5 and 7 medium-sized, cusps 2 and 6 considerably broader and robust (1.9$3.0 \times$ longer than cusp 4); lateral teeth with seven main cusps, all with similar length, and an additional small one (cusp 1); M1 with eight to nine cusps, with an increasing length from cusp 1 to cusp 7 (or cusp 8 , when nine cusps are present), the latter usually being very elongated, up to $1.7 \times$ longer than median cusps, and with a filiform distal half(cusp 6 or 7 may also have a filiform elongation); remaining marginal teeth hand-like, with a long basal plate, usually with nine or ten cusps, also increasing in size from cusp 1 to cusps 7 (or 8 ) and 8 (or 9), the latter cusps usually having a filiform elongation in the distal half, up to $2.3 \times$ longer than median cusps; central tooth 4.9-5.0 $\mu \mathrm{m}$ wide, lateral teeth $4.1-4.6 \mu \mathrm{m}$ wide, M1 4.1-4.9 $\mu \mathrm{m}$ wide, M2 usually $5.4 \mu \mathrm{m}$ wide, M3 4.8-5.3 $\mu \mathrm{m}$ wide, outer marginal teeth $5.2-5.4 \mu \mathrm{m}$ wide. 


\section{Remarks}

The operculum of $C$. dupliniana comb. nov. agrees with that of the type species C. pallescens (described in Bouchet 1985). Its radula has a superficial resemblance with the description of C. pallescens by Bouchet \& Guillemot (1978) and Bouchet (1985), despite significant differences: C. dupliniana comb. nov. has more marginal teeth (eight, instead of five or six), a completely different central tooth (seven cusps with varied sizes, instead of six to eight homogeneous cusps separated in two groups of three or four cusps by an internal diastema), lateral teeth with seven main cusps plus a smaller one (instead of six cusps in Bouchet 1985 - but seven or eight cusps were similarly indicated in Bouchet \&

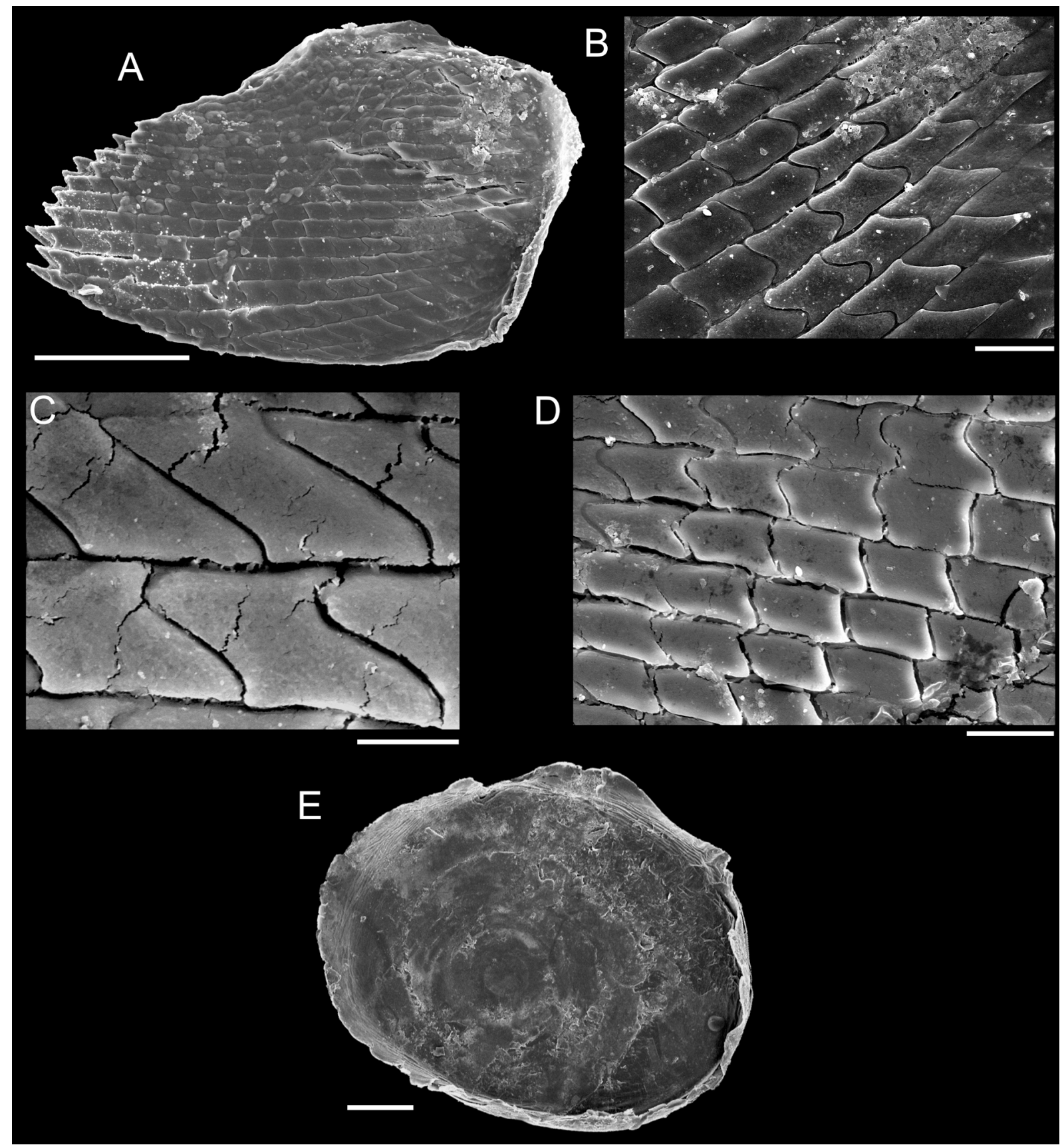

Fig. 5. Cheirodonta dupliniana (Olsson, 1916) comb. nov. A-E. USNM 1438722. A-D. Jaw, outer side. E. Operculum. Scale bars: $\mathrm{A}=50 \mu \mathrm{m} ; \mathrm{B}, \mathrm{D}=10 \mu \mathrm{m} ; \mathrm{C}=5 \mu \mathrm{m} ; \mathrm{E}=100 \mu \mathrm{m}$. 
Guillemot 1978), and marginal teeth hand-like with a maximum of 10 long cusps distributed along their length (instead of 'broad spoon-like' teeth with 12 to 20 cusps concentrated in the rounded end of teeth in C. pallescens).

There are significant differences in the illustrated radulae of $C$. pallescens from French material (based on specimens from the eastern Atlantic and Mediterranean) described by Bouchet \& Guillemot (1978: fig. 19) and Bouchet (1985: figs 10-11), especially regarding the central and lateral teeth. More differences emerge when considering the drawn radula of specimens from southern England by Fretter (1951), bearing lateral teeth with nine cusps and marginal teeth with much longer cusps than those illustrated by Bouchet, in addition to a presumably different axis orientation of marginal teeth (downward instead of sideward). With the current limited amount of information, it is uncertain whether C. pallescens represents a single species with a variable radular morphology, or whether the Mediterranean population and perhaps also the population from England constitute one or two new species. The morphology of

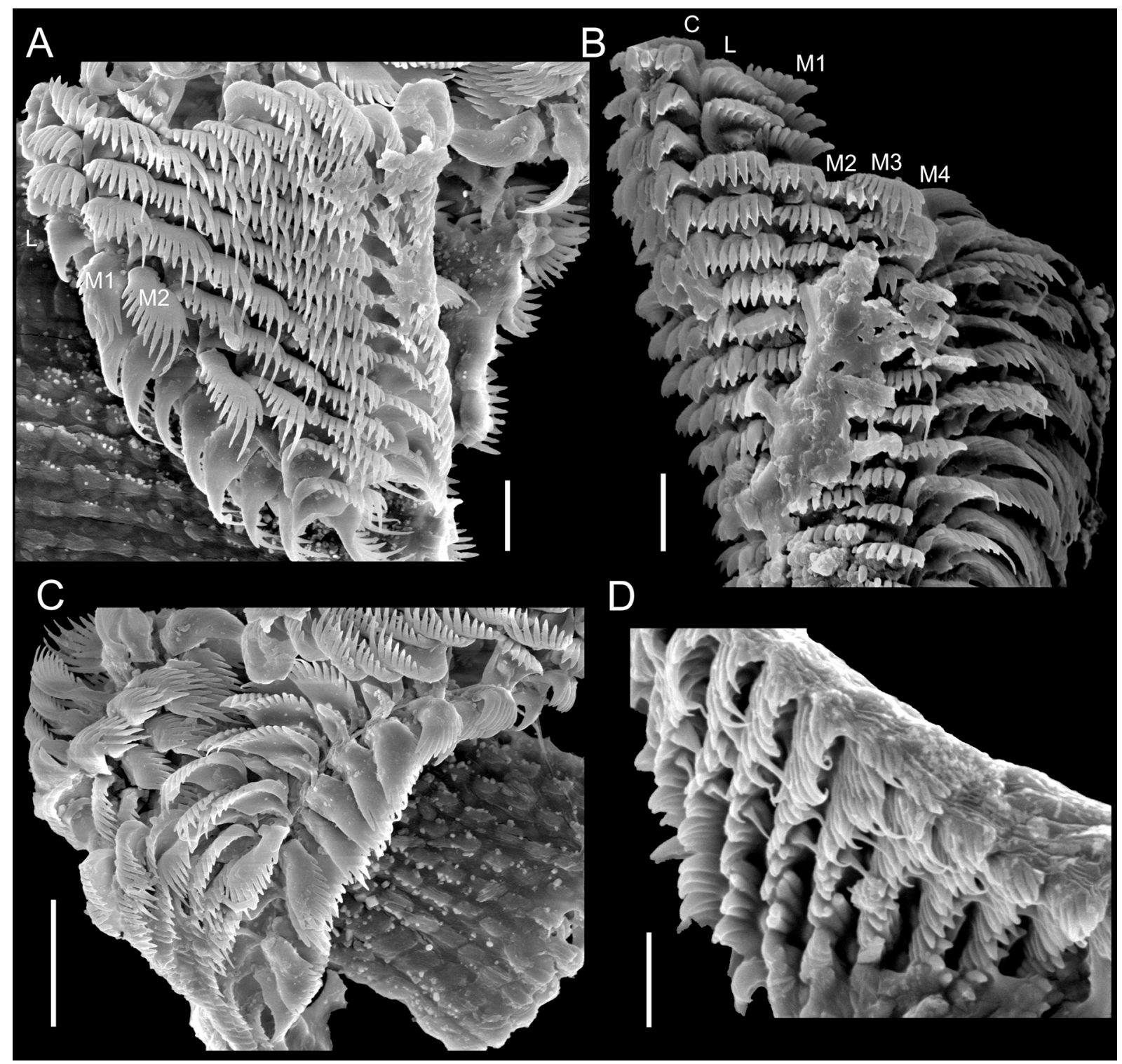

Fig. 6. Cheirodonta dupliniana (Olsson, 1916) comb. nov. A-D. Radula (USNM 1438722). Scale bars: $\mathrm{A}-\mathrm{B}, \mathrm{D}=5 \mu \mathrm{m} ; \mathrm{C}=10 \mu \mathrm{m}$. 
the central and marginal teeth of specimens from France (especially from Mediterranean) is slightly similar to that of Sagenotriphora osclausum (Rolán \& Fernández-Garcés, 1995) (see below), in spite of consistent differences mainly related to the lateral teeth. Considering only species from the Atlantic, both genera show similarities in shell (e.g., supranumerical cords, smooth subperipheral and basal cords, similar protoconch sculpture) and radula, as herein indicated. They may be proved to be phylogenetically close after a comprehensive phylogeny.

The radula of the southwestern Pacific species Cheirodonta labiata (A. Adams, 1854), described and illustrated by Marshall (1983), is much similar to that of C. dupliniana comb. nov. They have the same number of marginal teeth (eight), a similar number of cusps and dimensions of the central tooth $(C$. dupliniana comb. nov. usually with seven heterogeneous cusps, $5.0 \mu \mathrm{m}$ wide; $C$. labiata with seven to nine heterogeneous cusps, $6.8 \mu \mathrm{m}$ wide), idem for lateral teeth (both usually with eight cusps; 4.1-4.6 $\mu \mathrm{m}$ wide in $C$. dupliniana comb. nov., $6.8 \mu \mathrm{m}$ wide in C. labiata) and marginal teeth (M1-M3 with eight to ten cusps in C. dupliniana comb. nov., 4.1-5.4 $\mu \mathrm{m}$ wide; M1-M3 with eight to nine cusps in $C$. labiata, about $5.0 \mu \mathrm{m}$ wide). In this sense, the radula of $C$. dupliniana comb. nov. is much more similar to C. labiata than to $C$. pallescens, despite the opposite can be affirmed to shell features.

Radulae of Caribbean species of Nanaphora Laseron, 1958 illustrated in Rolán \& Fernández-Garcés (1994), at that time under the name Cheirodonta, are also superficially similar to those of C. dupliniana comb. nov., particularly regarding the elongation of the basal plate of marginal teeth. Another species of Nanaphora from the Pacific was already indicated as similar to Cheirodonta in terms of marginal tooth morphology (Marshall 1983). However, shell and operculum are consistently different between both genera (Marshall 1983; Fernandes \& Pimenta 2015). Phylogenetic hypotheses will reveal whether these genera are analogous in radular morphology owing to feeding on similar sponge hosts, or whether they share a common and recent ancestral lineage.

Genus Cosmotriphora Olsson \& Harbison, 1953

\section{Type species}

Cerithium melanura C.B. Adams, 1850. Original designation. Recent, western Atlantic.

Cosmotriphora melanura (C.B. Adams, 1850)

Figs $2 \mathrm{C}, 7-8$

\section{Material examined}

BRAZIL - Espírito Santo State • [1, d] spec.; Ilha Escalvada, Guarapari; $20^{\circ} 42^{\prime} 00^{\prime \prime} \mathrm{S}, 40^{\circ} 24^{\prime} 28^{\prime \prime} \mathrm{W}$; 10-15 m depth; 12 Dec. 2014; M.R. Fernandes and L.S. Souza leg.; MNRJ 33980. - Rio de Janeiro State • [3, 2 d] specs; Campos Basin; 22 ${ }^{\circ} 42^{\prime}$ S, 4040'W; 2006; MNRJ 18750 • [3, 2 d] specs; same data as for preceding; MNRJ 33138.

\section{Description of basic anatomy}

EXTERNAL MORPHOLOGY. Body mainly white, but a distinct, sinuous, black stripe occupies the upper-mid portion of the whorl during a little less than half whorl of length, one to two whorls posteriorly to the operculum; roof of mantle cavity can be yellowish in fresh specimens.

OperCuLum. Yellowish, ovate-elliptical, thin, semi-transparent, membranous, poorly distinct whorls, nucleus subcentral, dislocated $14 \%$ to $23 \%$ from center toward margin; denticles in the inner border of operculum; diameter of operculum exceeds diameter of opercular pouch in $22 \%$ to $30 \%$. 
$\mathrm{J}_{\mathrm{AW}}$. Wing-shaped; outer side with scales rectangular, rectangular-bilobed or acute-lanceolate; scales with micro-pores up to $260 \mathrm{~nm}$ in diameter; inner side with hexagonal scales, surface smooth; outer side with rectangular scales 12.1-12.3 $\mu \mathrm{m}$ long, 2.7-2.9 $\mu \mathrm{m}$ wide, ratio length/width 4.2-4.4, acutelanceolate scales 21.0-26.7 $\mu \mathrm{m}$ long, 6.9-7.9 $\mu \mathrm{m}$ wide, ratio length/width 3.0-3.7; scales of inner side 13.7-17.3 $\mu \mathrm{m}$ long, 3.9-5.0 $\mu \mathrm{m}$ wide, ratio length/width 2.9-3.8.

RADULA. Formula not discernible because of overcrowded outer marginal teeth; central and lateral teeth head-fork shaped with four triangular cusps, inner ones 1.3-1.6× more elongated than outer ones; inner marginal teeth (i.e., M1 to M5) with three cusps, width of teeth gradually decreasing towards outer marginal teeth, median cusp more prominent and elongated, 1.2-2.1× longer than outer cusps, becoming increasingly elongated towards outer marginal teeth; outer marginal teeth (i.e., after M6) with two elongated and filiform cusps, somewhat hook-shaped, inner cusp much shorter (usually 2.2-2.9× shorter than outer cusp, but even 4.5-5.0× shorter in teeth under development); central tooth 2.9-3.5 $\mu \mathrm{m}$ wide, lateral teeth $2.9-3.6 \mu \mathrm{m}$ wide, inner marginal teeth $1.7-2.7 \mu \mathrm{m}$ wide, outer marginal teeth 6.0 $10.6 \mu \mathrm{m}$ long.

\section{Remarks}

Rolán \& Fernández-Garcés (1994) described the external morphology of $C$. melanura as having numerous white/yellowish spots in the anterior portion of the body, which was not observed in the

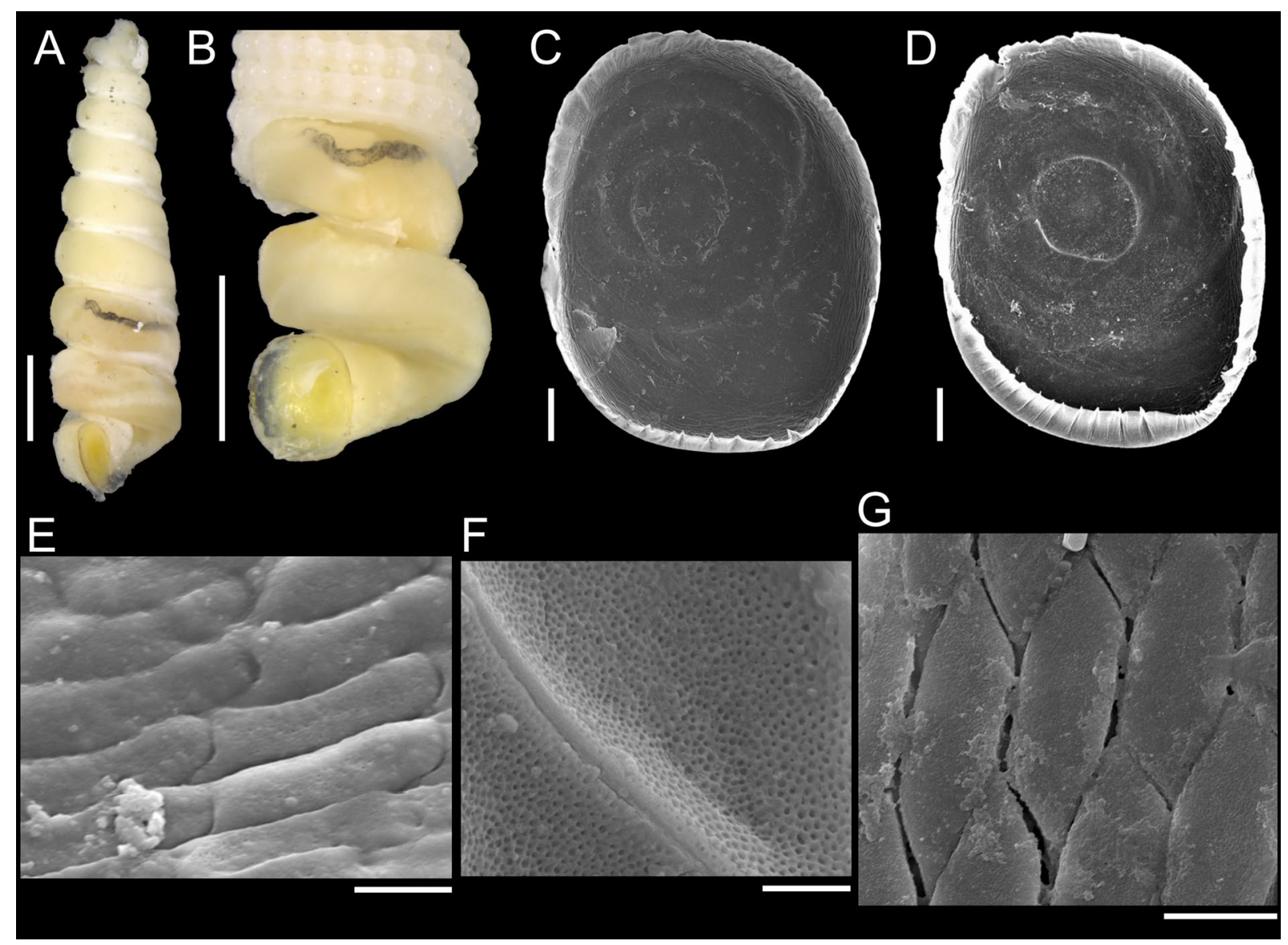

Fig. 7. Cosmotriphora melanura (C.B. Adams, 1850). A, E, G. MNRJ 33138. B-D, F. MNRJ 18750. A-B. External morphology, different specimens. C-D. Operculum. E-G. Jaw, outer (E-F) and inner (G) sides. Scale bars: $A-B=1 \mathrm{~mm} ; C-D=100 \mu \mathrm{m} ; \mathrm{E}, \mathrm{G}=5 \mu \mathrm{m} ; \mathrm{F}=2 \mu \mathrm{m}$. 
present study probably due to a faint coloration after a long storage in ethanol. However, all specimens had a distinct and previously unnoticed black stripe situated at one to two whorls posteriorly to the operculum (Fig. 7A-B), not present in any other triphorid studied so far; this stripe is continuous and does not seem to be related to fecal pellets. Opercula of specimens from Brazil (Fig. 7C-D) are identical to those of Caribbean specimens (Bouchet 1985: fig. 2).

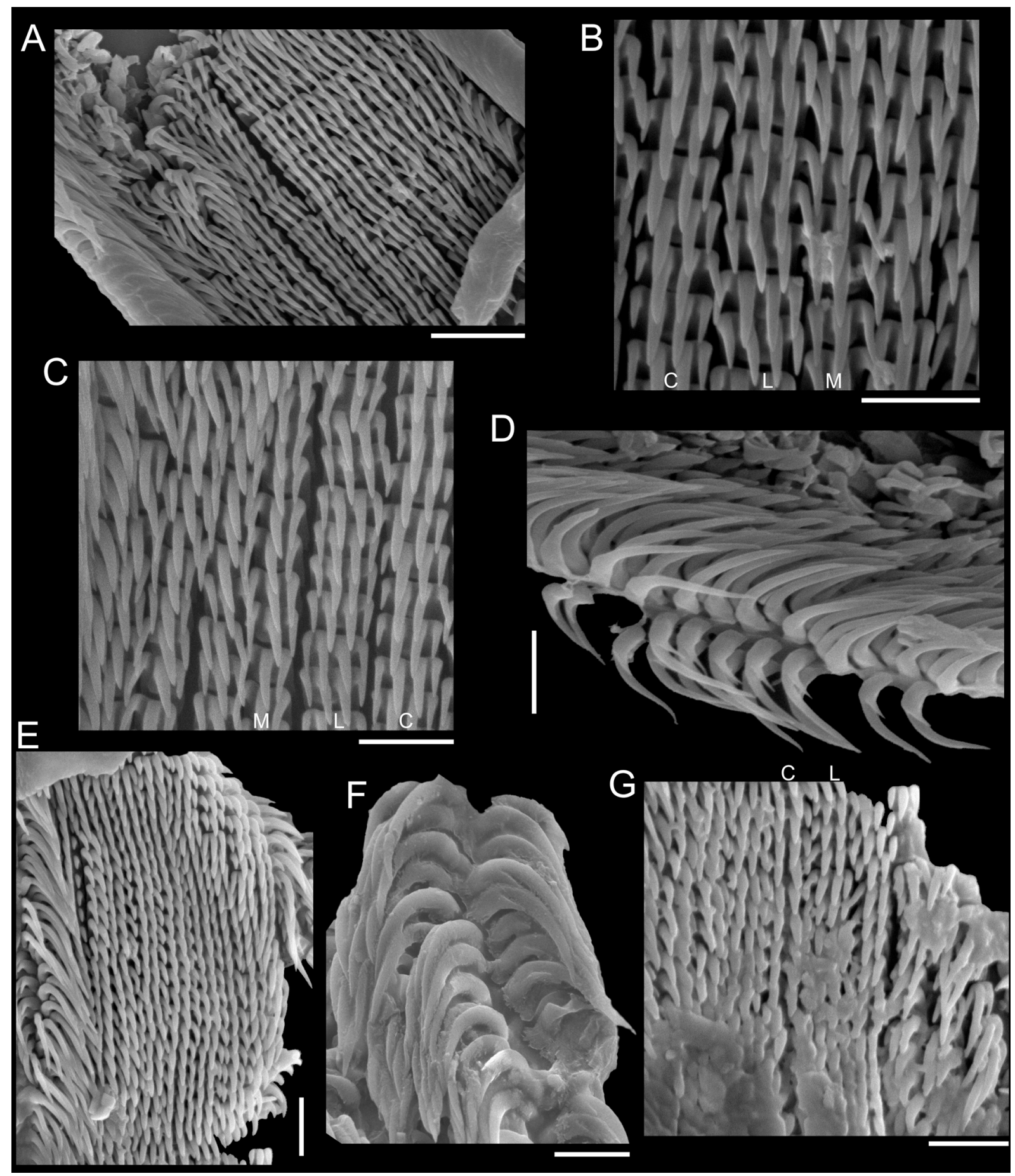

Fig. 8. Cosmotriphora melanura (C.B. Adams, 1850). A-G. Radula (MNRJ 18750). Scale bars: A = $10 \mu \mathrm{m} ; \mathrm{B}-\mathrm{G}=5 \mu \mathrm{m}$. 
The radula of specimens from Brazil (Fig. 8) is almost identical to that of Caribbean specimens (Bouchet 1985; Rolán \& Fernández-Garcés 1994), with the exception that the central tooth of Brazilian specimens is more similar to the lateral teeth of Caribbean ones (outer cusps considerably shorter than inner ones), but lateral teeth of Brazilian specimens are more similar to the central tooth of Caribbean ones (outer cusps not so shorter than inner ones). Although not illustrated, Bouchet (1985) noted differences in the marginal teeth of a juvenile from the eastern Atlantic when compared to the pattern seen in adults from the western Atlantic, warning for the necessity of fine radular comparisons from adult specimens from both sides of the Atlantic. After examining several specimens from Cuba (Caribbean) and Ghana (eastern Atlantic), Rolán \& Fernández-Garcés (1994) concluded that there were no significant differences in their radulae, despite not having illustrated those from the eastern Atlantic.

Genus Iniforis Jousseaume, 1884

\section{Type species}

Iniforis malvaceus Jousseaume, 1884. Original designation. Recent, New Caledonia.

Iniforis pseudothomae Rolán \& Fernández-Garcés, 1993

Figs 2D, 9-11

\section{Material examined}

BRAZIL - Bahia State • [1, d] spec.; Garapuá, Morro de São Paulo, Cairu; Dec. 2008; MNRJ 32881 • [1, d] spec.; Praia de Garapuá, Morro de São Paulo, Cairu; 5 m depth; 2011; P. Coelho-Filho leg; MZSP 100957.

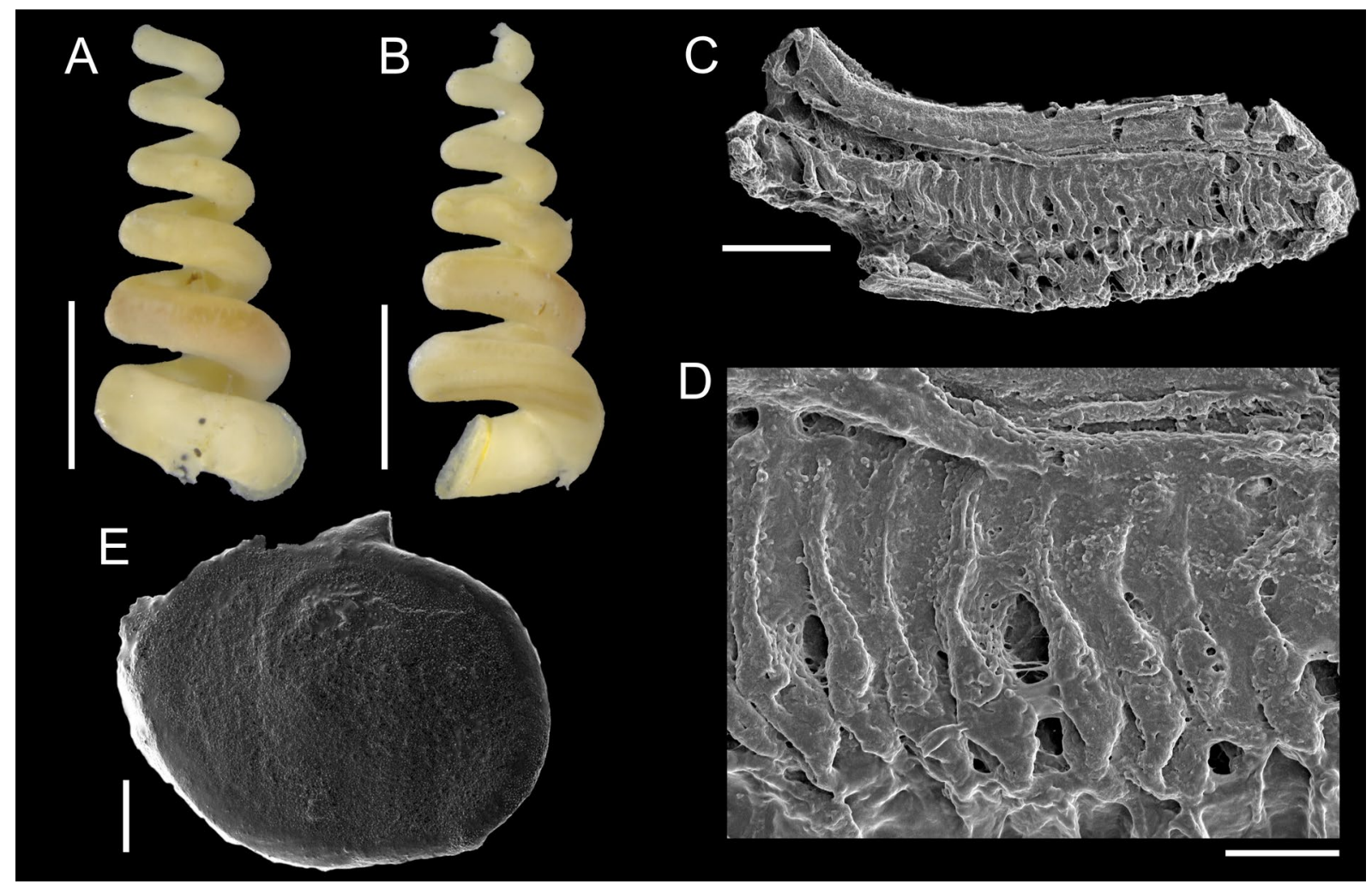

Fig. 9. Iniforis pseudothomae Rolán \& Fernández-Garcés, 1993. A-B, E. MNRJ 32881. C-D. MZSP 100957. A-B. External morphology. C-D. Ctenidium. E. Operculum. Scale bars: A-B $=1 \mathrm{~mm} ; \mathrm{C}=$ $200 \mu \mathrm{m} ; \mathrm{D}=50 \mu \mathrm{m} ; \mathrm{E}=100 \mu \mathrm{m}$. 


\section{Description of basic anatomy}

OPERCULUM. Ovate, thin, semi-transparent, membranous, with a yellow border, poorly distinct whorls and nucleus; small triangular projection at the border, its length being $14 \%$ of diameter of operculum; diameter of operculum exceeds diameter of opercular pouch in $\sim 20 \%$.

$\mathrm{J}_{\mathrm{AW}}$. Wing-shaped; outer side with scales acute-lanceolate, rectangular/squared, rectangular-bilobed or irregular; scales with micro-pores up to $350 \mathrm{~nm}$ in diameter, concentrated in the posterior region (close to the radula); inner side with scales moderately lanceolate, hexagonal or rhombus-shaped, surface smooth; scales of outer side 16.3-22.6 $\mu \mathrm{m}$ long, 5.2-8.7 $\mu \mathrm{m}$ wide, ratio length/width 2.4-3.4 (acute-lanceolate scales), 9.7-12.4 $\mu \mathrm{m}$ long, 3.9-6.1 $\mu \mathrm{m}$ wide, ratio length/width 1.7-3.1 (rectangular), 8.8-15.3 $\mu \mathrm{m}$ long (squared), 10.2-11.3 $\mu \mathrm{m}$ long, 4.3-4.9 $\mu \mathrm{m}$ wide, ratio length/width 2.2-2.5 (rectangular-bilobed); scales

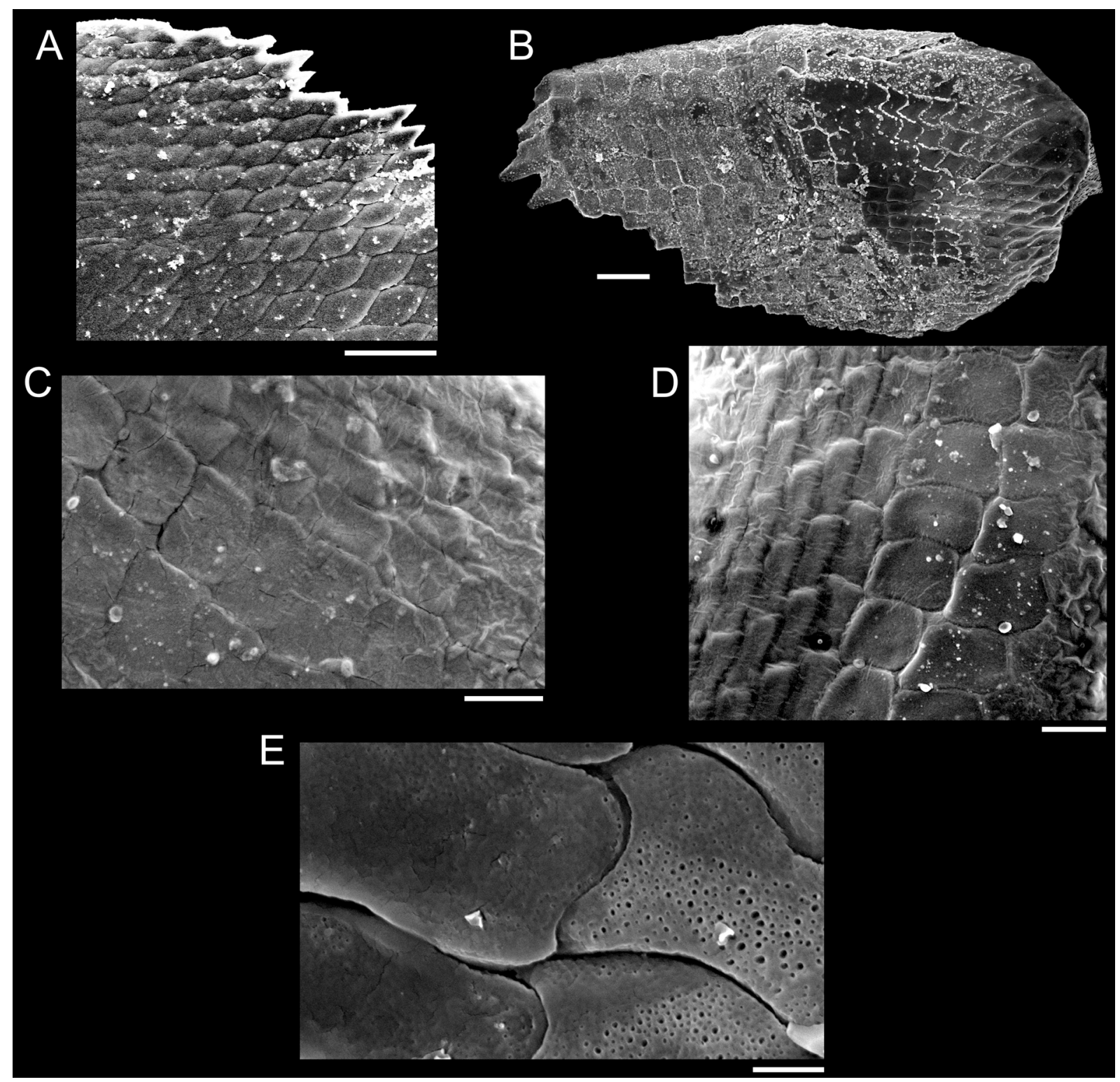

Fig. 10. Iniforis pseudothomae Rolán \& Fernández-Garcés, 1993. A-E. Jaw, inner (A) and outer (B-E) sides. A-B, E. MZSP 100957. C-D. MNRJ 32881. Scale bars: A-B $=20 \mu \mathrm{m} ; \mathrm{C}-\mathrm{D}=10 \mu \mathrm{m} ; \mathrm{E}=2 \mu \mathrm{m}$. 


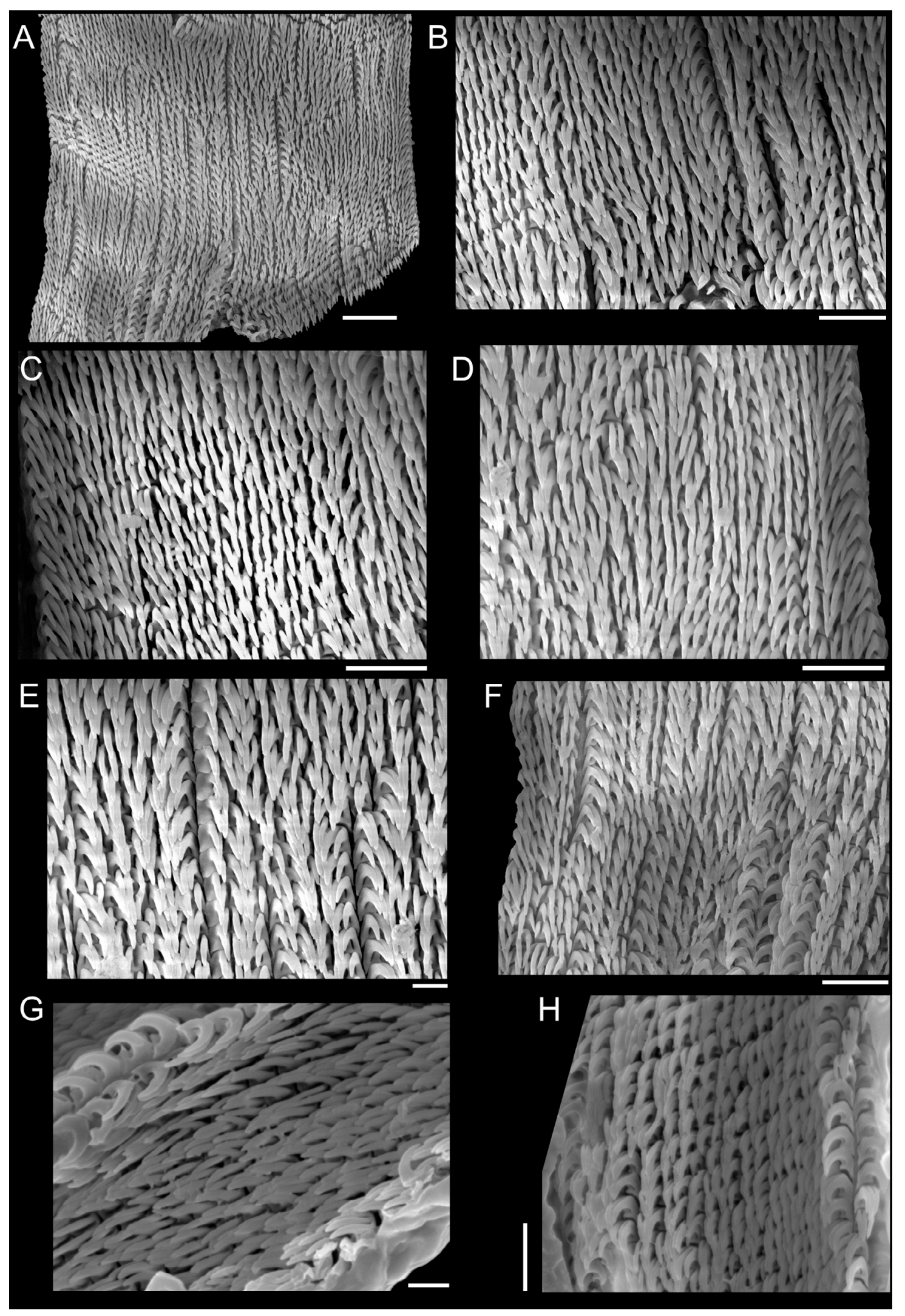

Fig. 11. Iniforis pseudothomae Rolán \& Fernández-Garcés, 1993, radula. A-F. MZSP 100957. G-H. MNRJ 32881. Scale bars: A = $10 \mu \mathrm{m}$; B-D, F, H $=5 \mu \mathrm{m}$; E, $\mathrm{G}=2 \mu \mathrm{m}$. 
of inner side 13.0-14.2 $\mu \mathrm{m}$ long, 4.3-5.4 $\mu \mathrm{m}$ wide, ratio length/width 2.5-3.2 (lanceolate), 14.7-19.4 $\mu \mathrm{m}$ long, 6.3-8.9 $\mu \mathrm{m}$ wide, ratio length/width 2.0-2.4 (hexagonal/rhombus-shaped).

RADULA. Up to 41 undifferentiated and overcrowded teeth per row; narrow teeth, usually hook-shaped, with three elongated or slightly curved/claw-like cusps, median cusp equal or up to $1.5 \times$ more elongated than outer ones; outer marginal teeth with three elongated cusps, median cusp usually increases towards last marginal teeth and is $1.3-1.6 \times$ more elongated than outer cusps; undifferentiated teeth $1.4-1.8 \mu \mathrm{m}$ wide, outer (last) marginal teeth $1.3-1.6 \mu \mathrm{m}$ wide.

\section{Remarks}

Despite the loss of pigmentation in specimens herein studied due to their long storage in ethanol, I. pseudothomae still shows distinct yellow border in the operculum (Fig. 9B). Rolán \& FernándezGarcés (1993) also observed a yellow pigmentation in the propodium and metapodium of I. turristhomae (Holten, 1802). They cited, but did not illustrate, the presence of an 'ovoid insertion surface form' in a lateral position of the operculum, which may resemble the small triangular projection present in the border of the operculum of I. pseudothomae (Fig. 9E).

The tooth morphology of I. pseudothomae seems identical to that of I. turristhomae (Bandel 1984; Rolán \& Fernández-Garcés 1993), with many undifferentiated teeth that usually bear three hooked cusps (Fig. 11). A complete radular row of I. pseudothomae contains 41 teeth, instead of 28 in I. turristhomae (Bandel 1984). Similar teeth with three hooked cusps are also present in I. malvacea Jousseaume, 1884 and I. violacea (Quoy \& Gaimard, 1834) (Marshall 1983). The Japanese species Mastoniaeforis albogranosa (Kosuge, 1961) was traditionally allocated to Iniforis, leading to Rolán \& Fernández-Garcés (1993) erroneously interpret that this genus has a variable number of cusps per teeth based on Kosuge (1966); Marshall (1983: 45) already indicated the allocation of the latter species in Mastoniaeforis Jousseaume, 1884, although not explicitly as a new combination.

Genus Latitriphora Marshall, 1983

\section{Type species}

Triphora latilirata Verco, 1909. Original designation. Recent, southern Australia.

Latitriphora albida (A. Adams, 1854)

Figs 2E, 12-13

\section{Material examined}

BAHAMAS • [2, 1 d] specs; Abaco; 0.5 m depth; 17 Feb. 2004; C. Redfern leg.; BMSM 55442.

\section{Description of basic anatomy}

OPERCULUM. Yellowish, ovate, moderately thick, poorly distinct whorls, nucleus subcentral, dislocated $25 \%$ from center toward margin; diameter of operculum exceeds diameter of opercular pouch in $\sim 19 \%$.

JAW. Wing-shaped; outer side with scales rectangular/squared, leaf-shaped, rectangular-bilobed, boneshaped or irregular; scales with micro-pores up to $400 \mathrm{~nm}$ in diameter; inner side with scales lanceolate, fusiform, or hexagonal in a lesser extent, surface smooth; scales of outer side 10.8-12.6 $\mu \mathrm{m}$ long, 3.9$5.2 \mu \mathrm{m}$ wide, ratio length/width 2.3-2.9 (rectangular scales), 10.7-11.8 $\mu \mathrm{m}$ long, $4.2-5.2 \mu \mathrm{m}$ wide, ratio length/width 2.2-2.8 (leaf-shaped), 11.0-11.9 $\mu \mathrm{m}$ long, 4.5-6.4 $\mu \mathrm{m}$ wide, ratio length/width $1.8-2.5$ (rectangular-bilobed), 10.4-11.6 $\mu \mathrm{m}$ long, 2.4-3.2 $\mu \mathrm{m}$ wide, ratio length/width 3.5-4.9 (bone-shaped); scales of inner side 13.3-17.4 $\mu \mathrm{m}$ long, 3.4-4.4 $\mu \mathrm{m}$ wide, ratio length/width 3.3-4.0 (lanceolate), 9.5- 
$13.3 \mu \mathrm{m}$ long, 1.7-2.4 $\mu \mathrm{m}$ wide, ratio length/width 4.7-6.4 (fusiform), 11.5-14.5 $\mu \mathrm{m}$ long, 4.3-4.8 $\mu \mathrm{m}$ wide, ratio length/width 2.6-3.1 (hexagonal).

RADULA. Formula 12-1-1-1-12; central tooth with three or four triangular and pointed cusps, cusp 3 absent in some rows, up to $63 \%$ of length of remaining cusps; lateral teeth comb-like, right lateral teeth with five equally-sized cusps, left lateral teeth with five or six cusps, cusp 1 absent or much smaller $(28-53 \%$ of

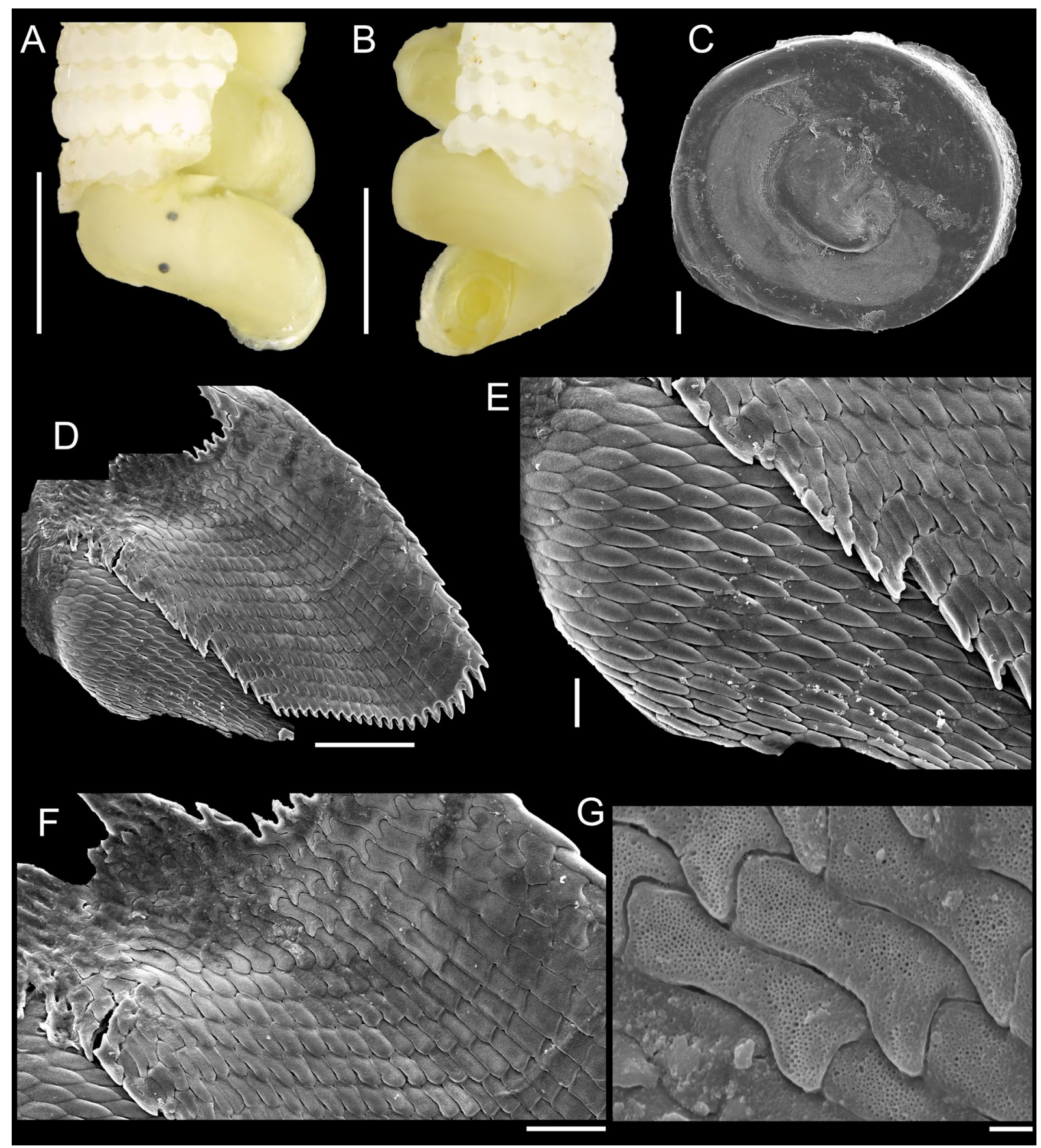

Fig. 12. Latitriphora albida (A. Adams, 1854). A-G. BMSM 55442. A-B. External morphology. C. Operculum. D-G. Jaw, both sides (D-E) and outer side (F-G). Scale bars: A-B = $1 \mathrm{~mm} ; \mathrm{C}=100 \mu \mathrm{m}$; $\mathrm{D}=50 \mu \mathrm{m} ; \mathrm{E}=10 \mu \mathrm{m} ; \mathrm{F}=20 \mu \mathrm{m} ; \mathrm{G}=2 \mu \mathrm{m}$. 
length of larger cusps) and cusp 3 with 56-70\% of length of larger cusps; M1 with four cusps, cusps 1 and 4 robust, triangular and pointed, cusps 2 and 3 extremely elongated and filiform, 1.8-2.7× more elongated than remaining cusps; M2-M12 with three cusps (abnormal teeth with four cusps may occur), median one extremely elongated and filiform, 2.3-3.8× more elongated than outer cusps; central tooth 4.3-4.8 $\mu \mathrm{m}$ wide; lateral teeth 4.6-5.2 $\mu \mathrm{m}$ wide; M1 3.3-3.6 $\mu \mathrm{m}$ wide; M2-M12 1.9-2.9 $\mu \mathrm{m}$ wide.

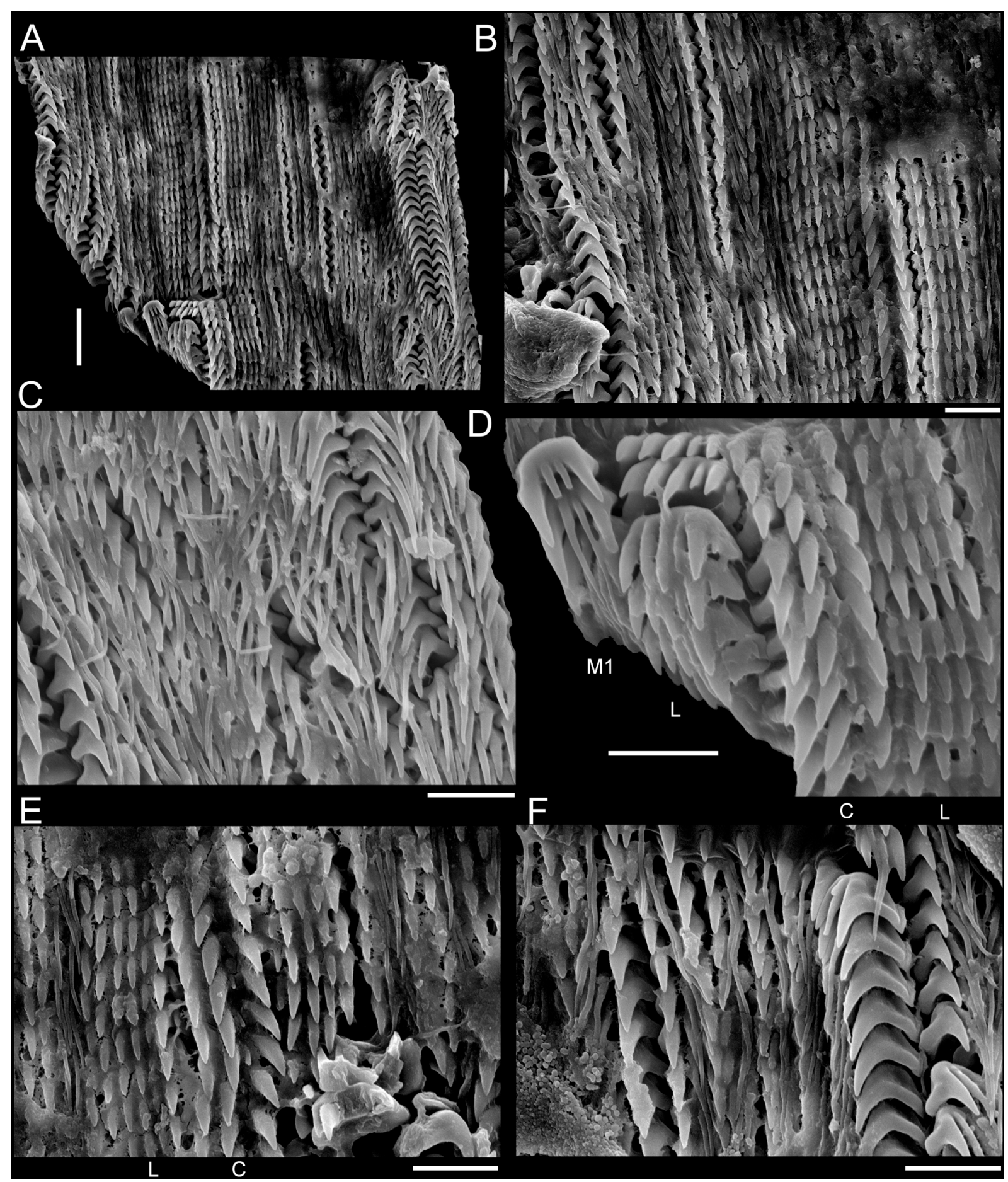

Fig. 13. Latitriphora albida (A. Adams, 1854), radula. A-F. BMSM 55442. Scale bars: $A=10 \mu \mathrm{m}$; $\mathrm{B}-\mathrm{F}=5 \mu \mathrm{m}$. 


\section{Remarks}

Live specimens of L. albida were hitherto studied only from Bahamas (Rolán \& Fernández-Garcés 1995; Redfern 2013). In addition to the description of the jaw (Fig. 12D-G), the present study provides important details of the radula that were unnoticed by Rolán \& Fernández-Garcés (1995): (1) the central tooth was indicated to have only three cusps in Rolán \& Fernández-Garcés (1995), but it is herein shown that cusp 3 (of a total of four cusps) is present in some teeth (Fig. 13D-E); (2) lateral teeth indeed have typically five cusps, but an additional smaller cusp can be seen in some left lateral teeth (Fig. 13D), possibly hidden or not yet developed in the right teeth; (3) the median filiform cusps of M1-M9 drawn by Rolán \& Fernández-Garcés (1995: fig. 46) are much more reduced than those illustrated herein (Fig. 13C, F); (4) these authors affirmed that M1-M3 present four cusps, which is actually true for M1 but rare for M2-M3 (which often exhibit three cusps). In addition, they indicated that 13 (instead of 12) marginal teeth are present in L. albida, reflecting a possible intraspecific variation or merely a mistake therein or herein in the counting of teeth owing to considerable difficulties in such cases of overcrowded teeth.

Based on the previous description of the radula of L. albida, Rolán \& Fernández-Garcés (1995) considered it to be very similar to the radula of the western Pacific and type species Nototriphora aupouria (Powell, 1937). Actually, the tooth morphology of L. albida resembles that of Atlantic species of Nototriphora Marshall, 1983 (discussed below), with a slight difference related to the number of cusps in the central tooth (three or four in L. albida, three in Atlantic species of Nototriphora). A molecular investigation is required to determine the degree of divergence between both genera in the Atlantic, besides evaluating the affinity between L. albida and Pacific species of Latitriphora, owing to substantial differences in the shell; e.g., the former does not constantly bear two spiral cords in the protoconch, but instead has a pattern of 2-1-2-(1) cords (Fernandes \& Pimenta 2017b), and does not exhibit a simultaneous emergence of the three spiral cords of teleoconch (Fernandes \& Pimenta in prep.).

Genus Monophorus Grillo, 1877

\section{Type species}

Trochus perversus Linnaeus, 1758. Designation by monotypy. Recent, northeastern Atlantic and Mediterranean.

Monophorus olivaceus (Dall, 1889)

Figs $2 \mathrm{~F}, 14-18$

\section{Material examined}

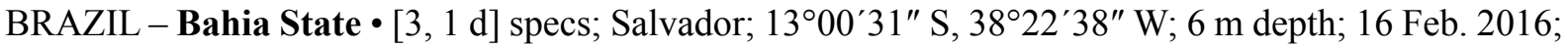
M.R. Fernandes leg.; MNRJ 35075. - Espírito Santo State • [1, d] spec.; Ilha Escalvada, Guarapari; 15 Feb. 2014; W. Vieira leg.; MNRJ 34028 • [1] spec.; exit of Guarapari Canal, Guarapari; Apr. 1992; J. Coltro leg.; MZSP 78376. - Rio de Janeiro State - [3] specs; Campos Basin; 22 ${ }^{\circ} 42^{\prime} \mathrm{S}, 40^{\circ} 40^{\prime} \mathrm{W}$; 2006; MNRJ 18741 • [1] spec.; Arraial do Cabo; 25-30 m depth; Aug. 2003; P. Gonçalves leg.; MZSP 133322 - [2, 2 d] specs; Enseada do Cardeiro, Arraial do Cabo; 6 m depth; 12 Sep. 2015; M.R. Fernandes and L.S. Souza leg.; MNRJ 34615 • [1, d] spec.; Ilhas Maricás, Maricá; $23^{\circ} 00^{\prime}$ S, $42^{\circ} 55^{\prime}$ W, 8 m depth; 12 Feb. 2015; M.R. Fernandes and L.S. Souza leg.; MNRJ 34240.

\section{Description of basic anatomy}

EXTERNAL MORPHOLOGY. Body mainly cream-white, roof of mantle cavity with distinct brown or red spiral patches (occasionally with discrete lilac patches and small white dots), extending up to one whorl; pedal slit covering about $75 \%$ of foot length. 
OperCulum. Rounded, flat, moderately thin but rigid, semi-transparent, poorly distinct whorls, nucleus subcentral or even slightly eccentric, dislocated $27 \%$ to $30 \%$ from center toward margin.

JAW. Wing-shaped; outer side with scales rectangular/squared, rectangular-bilobed, bone-shaped, hexagonal, acute-lanceolate, X-shaped, puzzle-shaped or irregular; scales with micro-pores up to $400 \mathrm{~nm}$ in diameter, concentrated in the posterior region (close to the radula), abruptly disappearing in the anterior region; inner side with scales moderately lanceolate, hexagonal/gem-like or rhombus-shaped, surface smooth; scales of outer side 10.1-14.7 $\mu \mathrm{m}$ long, 6.2-7.0 $\mu \mathrm{m}$ wide, ratio length/width 1.4-2.3 (rectangular/squared), 12.9-15.4 $\mu \mathrm{m}$ long, 2.6-4.1 $\mu \mathrm{m}$ wide, ratio length/width 2.6-2.7 (rectangularbilobed), 15.2-15.5 $\mu \mathrm{m}$ long, 4.7-5.9 $\mu \mathrm{m}$ wide, ratio length/width 3.8-5.8 (bone-shaped), 16.3-19.8 $\mu \mathrm{m}$ long, 6.9-10.4 $\mu \mathrm{m}$ wide, ratio length/width 1.7-2.4 (hexagonal scales), 18.3-19.0 $\mu \mathrm{m}$ long, 5.9-6.7 $\mu \mathrm{m}$ wide, ratio length/width 2.7-3.2 (acute-lanceolate), 12.4-14.1 $\mu \mathrm{m}$ long, 2.7-4.0 $\mu \mathrm{m}$ wide, ratio length/ width 3.1-5.3 (puzzle-shaped); scales of inner side 17.8-19.4 $\mu \mathrm{m}$ long, 5.7-6.4 $\mu \mathrm{m}$ wide, ratio length/ width 2.9-3.4 (lanceolate), 13.7-18.7 $\mu \mathrm{m}$ long, 6.2-7.8 $\mu \mathrm{m}$ wide, ratio length/width 1.9-2.6 (hexagonal), 11.3-13.2 $\mu \mathrm{m}$ long, 5.7-6.6 $\mu \mathrm{m}$ wide, ratio length/width 1.9-2.2 (rhombus-shaped).

RADULA. Up to 43 teeth per row, but formula hardly defined owing to dozens of teeth very similar and close to each other (especially in median portion of rows), in addition to frequent bilateral asymmetry; undifferentiated teeth, comb-like and usually having five to six cusps (outer cusps, 1 and 5/6, often reduced in size), but even up to seven cusps; outer marginal teeth somewhat head-fork shaped or clawlike with two to four irregular cusps (inner cusps can be more elongated, and some cusps may be fingerlike with a rounded end) to comb-like with five cusps (i.e., when typical outer marginal teeth are not

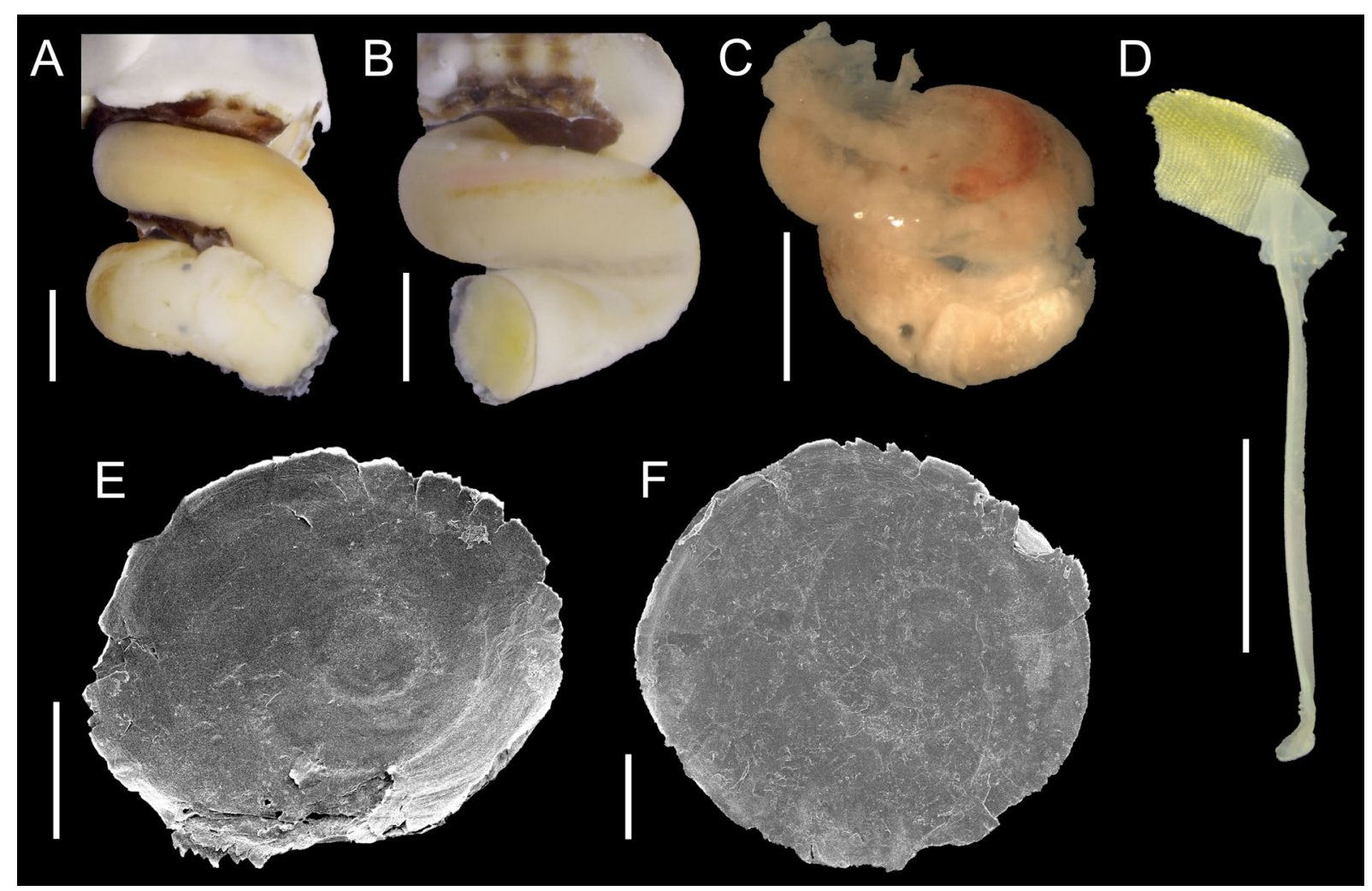

Fig. 14. Monophorus olivaceus (Dall, 1889). A-C, E-F. MNRJ 34615. D. MNRJ 34028. A-C. External morphology. D. Jaw (gold) and radula (white). E-F. Operculum. Scale bars: A-C = $1 \mathrm{~mm} ; \mathrm{D}=500 \mu \mathrm{m} ; \mathrm{E}-\mathrm{F}=250 \mu \mathrm{m}$. 
developed); teeth with five cusps 3.5-4.6 $\mu \mathrm{m}$ wide, teeth with six cusps $4.3-4.5 \mu \mathrm{m}$ wide, teeth with seven cusps $4.6-5.1 \mu \mathrm{m}$ wide, outer marginal teeth with three cusps 1.7-2.7 $\mu \mathrm{m}$ wide, outer marginal teeth with four cusps $2.0-3.1 \mu \mathrm{m}$ wide.

\section{Remarks}

Monophorus is often associated with species showing an intense red coloration in the anterior body (e.g., Bouchet \& Guillemot 1978: fig. 3). Agreeing with Rolán \& Fernández-Garcés (1994), who studied specimens from Cuba, M. olivaceus differs from other congeneric species by not having a red coloration, although the roof of the mantle cavity can present such feature in some cases (Fig. 14C). The lack of

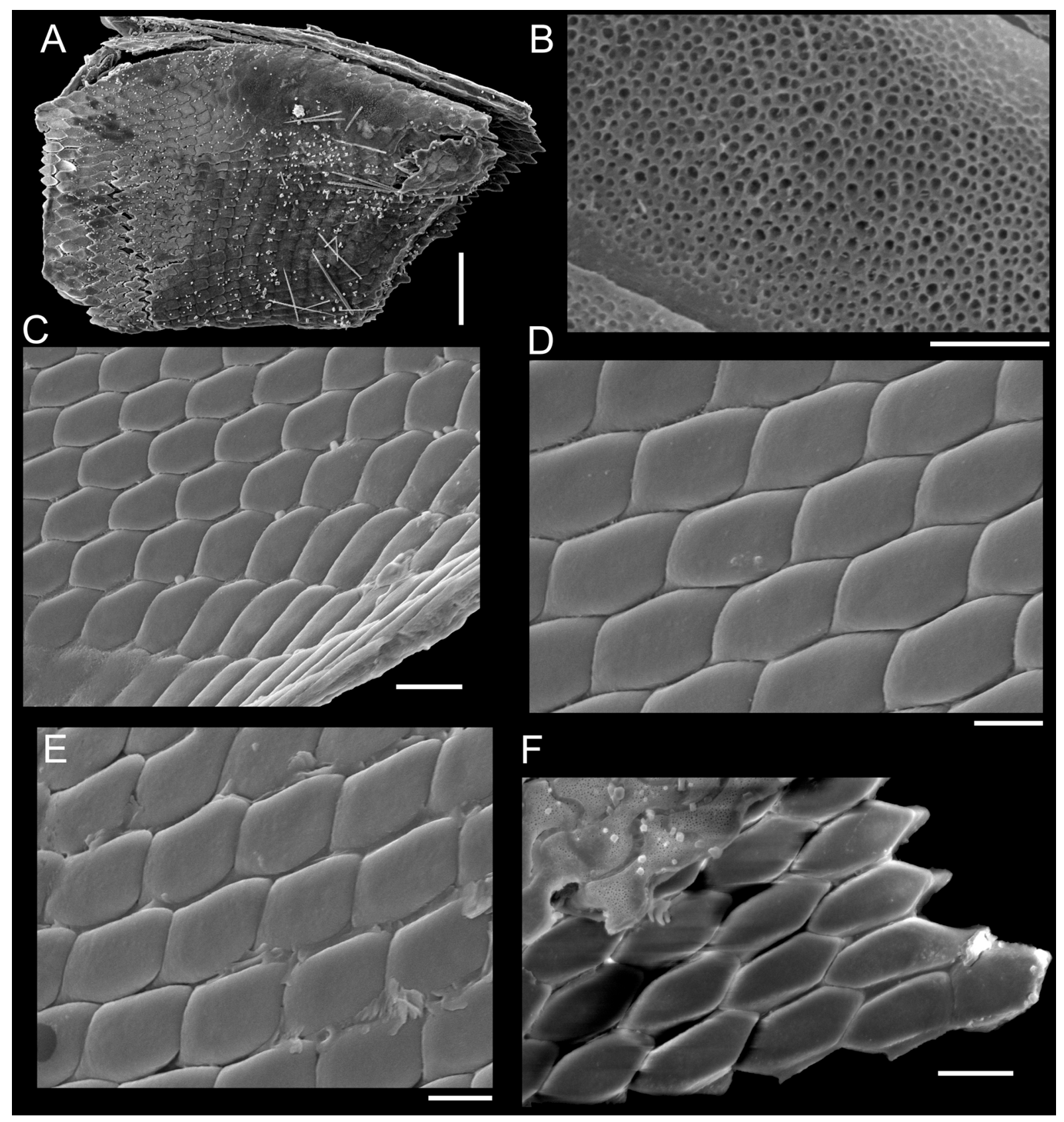

Fig. 15. Monophorus olivaceus (Dall, 1889). A-B, F. MNRJ 34240. C-E. MNRJ 35075. A-F. Jaw, outer $(A-B)$ and inner $(C-F)$ sides. Scale bars: $A=50 \mu \mathrm{m} ; B=2 \mu \mathrm{m} ; C, F=10 \mu \mathrm{m}$; D-E $=5 \mu \mathrm{m}$. 


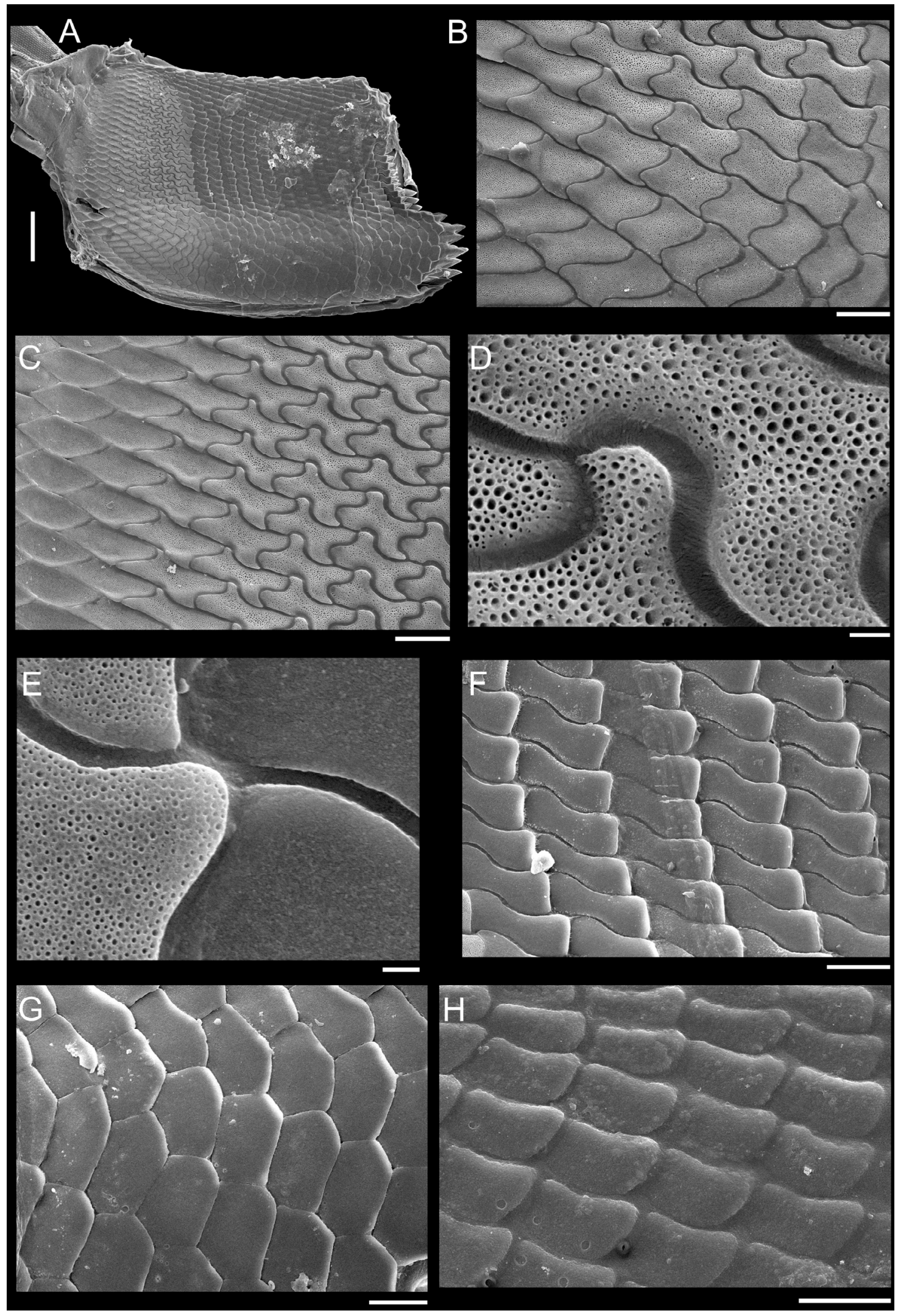

Fig. 16. Monophorus olivaceus (Dall, 1889). A-H. MNRJ 34028, jaw (outer side). Scale bars: A = $50 \mu \mathrm{m} ; \mathrm{B}-\mathrm{C}, \mathrm{F}-\mathrm{H}=10 \mu \mathrm{m} ; \mathrm{D}-\mathrm{E}=1 \mu \mathrm{m}$. 
a vivid red pigmentation may be merely associated with feeding on sponges different from the usual ones for the genus, possibly not having any major phylogenetic significance, or this coloration severely vanishes soon after the storage in ethanol (see remarks on N. verbernei (Moolenbeek \& Faber, 1989)), in this case pending further photographs of live specimens.

The operculum of M. olivaceus is herein illustrated for the first time (Fig. 14E-F). The simple morphology of the operculum is similar to that described for the genus (e.g., Marshall 1983; Fernandes \& Rolán 1988; Romani 2015), although with an expanded last whorl owing to a proportionally larger shell and aperture of M. olivaceus compared to congeneric species.

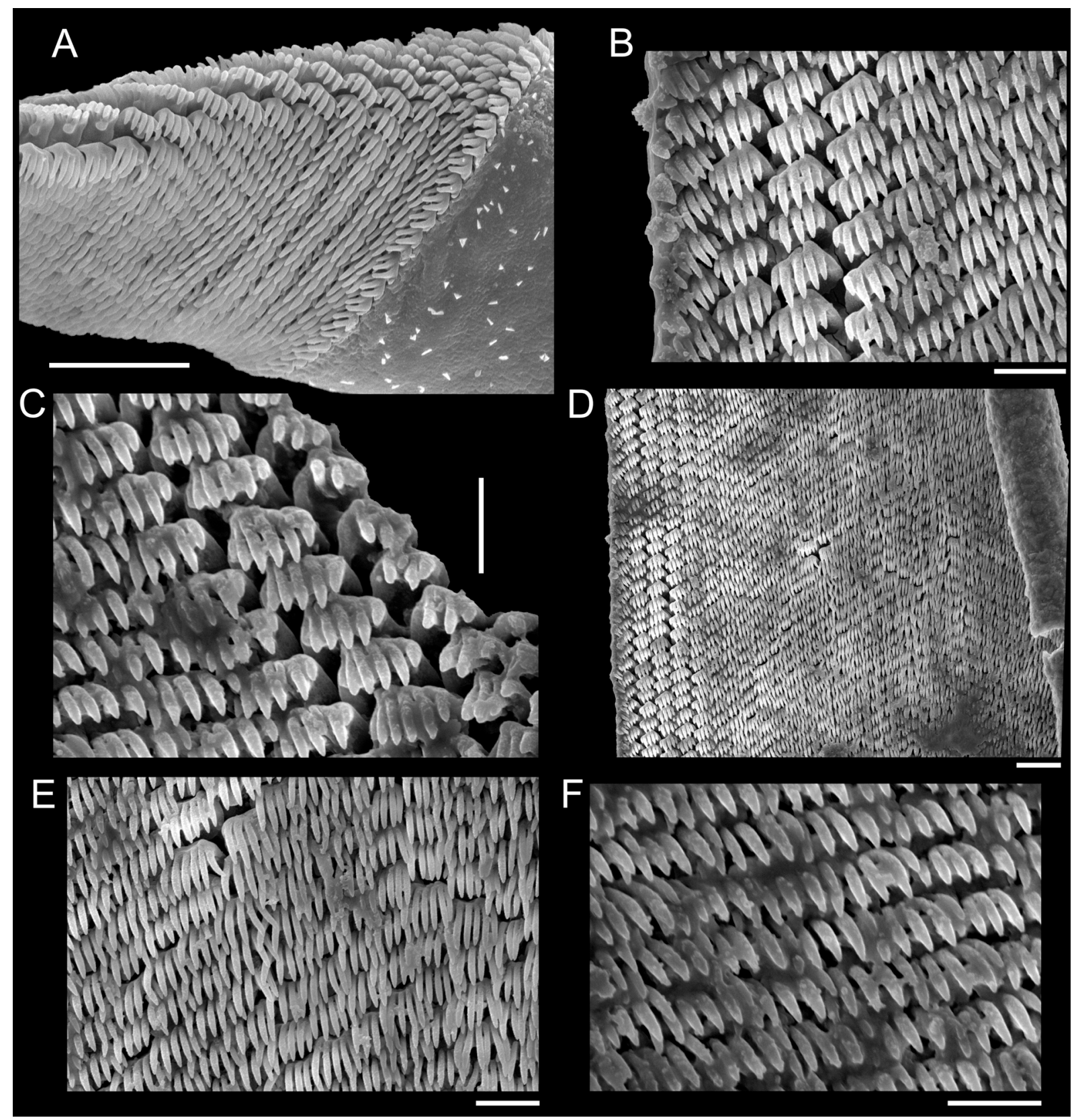

Fig. 17. Monophorus olivaceus (Dall, 1889), radula. A. MNRJ 35075. B-F. MNRJ 34240. Scale bars: $\mathrm{A}, \mathrm{D}=10 \mu \mathrm{m} ; \mathrm{B}-\mathrm{C}, \mathrm{E}-\mathrm{F}=5 \mu \mathrm{m}$. 
The radula of $M$. olivaceus has by far the highest number of teeth per row in the genus, with up to 43. Monophorus perversus (Linnaeus, 1758) has the second highest number of teeth per row, i.e., 29 (Bouchet 1985), whereas the smallest number of teeth per row in Monophorus is 11, observed in a species from Chile (Fernandes \& Araya in prep.).

The single radular preparation of M. olivaceus from Cuba (Rolán \& Fernández-Garcés 1994) masked some important features of this species. For example, these authors found only teeth with five cusps and

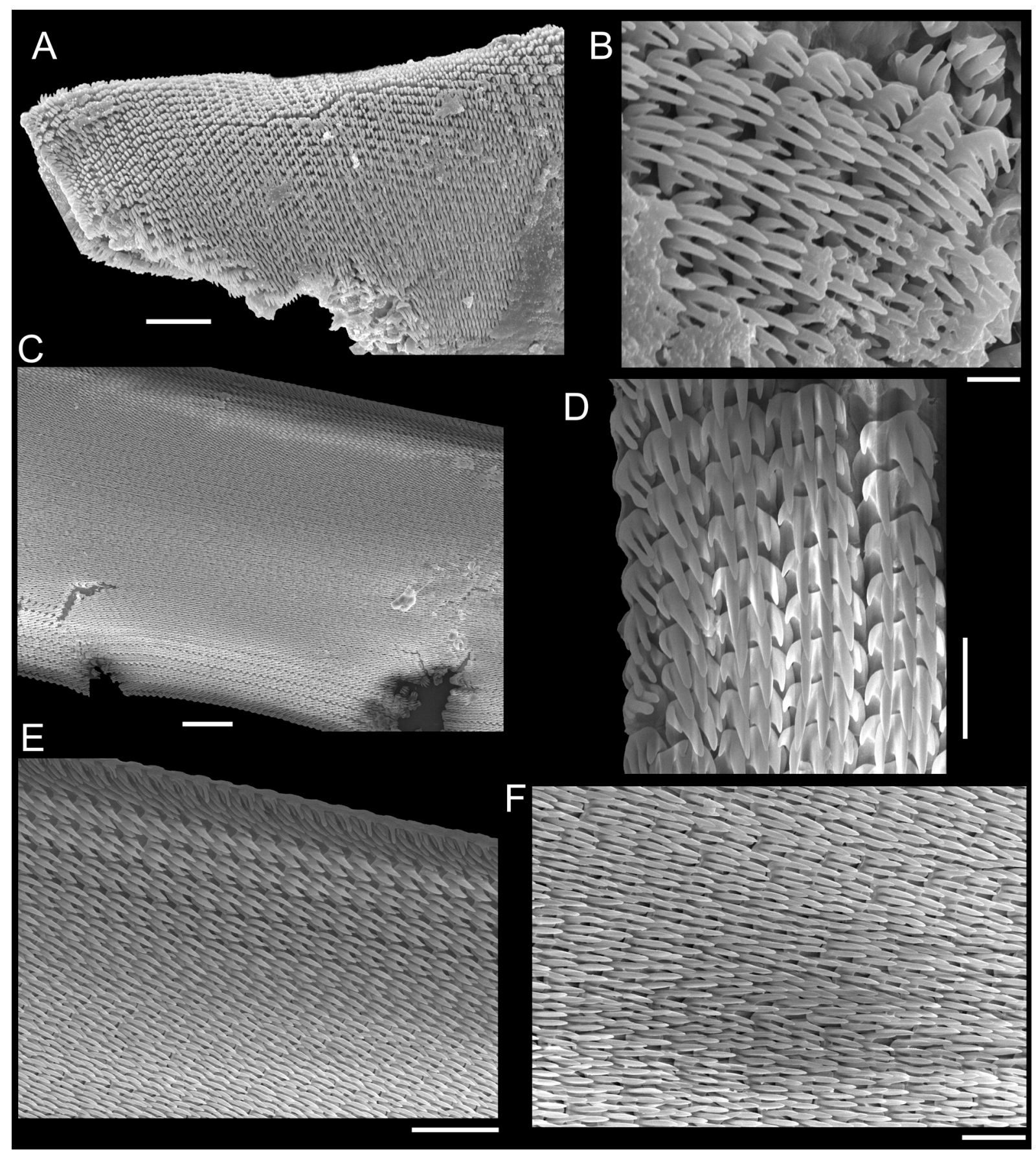

Fig. 18. Monophorus olivaceus (Dall, 1889), radula. A-B. MNRJ 35075. C-F. MNRJ 34028. Scale bars: $\mathrm{A}, \mathrm{E}=10 \mu \mathrm{m} ; \mathrm{B}=2 \mu \mathrm{m} ; \mathrm{C}=20 \mu \mathrm{m} ; \mathrm{D}, \mathrm{F}=5 \mu \mathrm{m}$. 
a total number of 33 teeth per row, instead of teeth with two to seven cusps and up to 43 teeth per row in the present study. This highlights the importance of illustrating more than one radula per species when dealing with triphorids, especially in cases of abnormal local bilateral asymmetry (Marshall 1983), which is the case of M. olivaceus. As understood from Marshall (1983), the abnormal local bilateral asymmetry occurs when any significant discrepancy is observed between the two sides (left or right of central tooth) of the same radula, e.g., in tooth shape, number of cusps or relative cusp size. This process was firstly observed for the western Pacific species M. angasi (Crosse \& P. Fischer, 1865) in Marshall (1983).

The most similar radula to M. olivaceus is that of the eastern Atlantic population of M. erythrosoma (Bouchet \& Guillemot, 1978), with undifferentiated teeth bearing three to six cusps (Bouchet \& Guillemot 1978). The Mediterranean population of M. erythrosoma has a remarkably different radula (Bouchet 1985) than the eastern Atlantic population, with differentiated tooth morphology (especially the central tooth) and more marginal teeth, demanding investigation of intraspecific variation vs the existence of cryptic but distinct species. Another case is that of M. perversus, which presents two radular types in the same Mediterranean population, probably reflecting a considerable intraspecific variation. They are distinguished by the morphology of central, lateral and M1 teeth, and one type (Bouchet 1985: figs 5,7 ) is somewhat similar to M. olivaceus.

Genus Nanaphora Laseron, 1958

\section{Type species}

Nanaphora torquesa Laseron, 1958. Original designation. Recent, eastern Australia.

Nanaphora verbernei (Moolenbeek \& Faber, 1989)

Figs $2 \mathrm{G}, 19-20$

\section{Material examined}

BRAZIL - Rio de Janeiro State • [4, 1 d] specs; Campos Basin, 22 $42^{\prime}$ S, 40 40' W; 2006; MNRJ 18756 • [1, d] spec.; same data as for preceding; MNRJ 33139. - São Paulo State • [2, 1 d] specs; Ilha da Queimada Pequena, Itanhaém; 0-12 m depth; MZSP 85022. - Santa Catarina State • [1] spec.; Praia

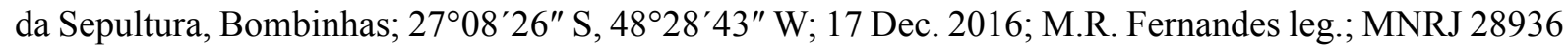

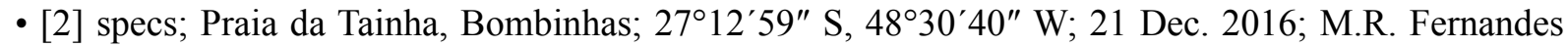
leg.; MNRJ 28951 • [5, 2 d] specs; same data as for preceding; MNRJ 28956.

\section{Description of basic anatomy}

EXTERNAL MORPHOLOGY. Body cream-yellowish, head-foot reddish, but the vivid pigmentation on headfoot vanishes after fixation; pedal slit covering about $68 \%$ of foot length; some black encapsulated fecal pellets present along intestine, with a vesicular shape and $82-100 \mu \mathrm{m}$ long.

OperCulum. Rounded, flat, moderately thin, semi-transparent, multispiral, 4.75 whorls, nucleus subcentral, dislocated $15 \%$ from center toward margin; diameter of operculum exceeds diameter of opercular pouch in $13-23 \%$.

RADULA. Formula 8-1-1-1-8; teeth row arranged in a 'V-shape, with adjacent teeth aligned in a somewhat diagonal position to each other; central tooth with three main broad and triangular cusps, outer cusps 1.1-1.3 $\times$ more elongated than median one, in addition to two marginal cusps very reduced in size; in one radula (Fig. 20A-D), lateral teeth with three (left of central tooth) or four (right of central tooth) main broad and triangular cusps, in addition to two marginal cusps reduced in size, resulting in lateral teeth with five (left) or six (right) cusps; left lateral teeth with cusps 1 and 5 with length 39-63\% of cusps 
2 and 4, cusp 3 with length $70-88 \%$ of cusps 2 and 4; right lateral teeth with cusps 1 and 6 with length $29-47 \%$ of remaining cusps, which are similarly sized; in another radula (Fig. 20E-F), lateral teeth always with four cusps; left M1 with three broad and triangular cusps, median one 1.3-1.5× more elongated than outer cusps; right M1 with four triangular cusps, cusp 1 much reduced, with length $49-60 \%$ of remaining cusps, which are similarly sized; M2-M6 with three main triangular, claw-like and equally-sized cusps in a posterior portion of radula, in addition to a fourth small cusp (cusp 1) that gradually strengthens towards the anterior portion of radula and may become equal in size to remaining cusps (at least in M3-M6), with right M5 being supposedly the first tooth to show a fully developed cusp 1; an additional fifth cusp may appear in M3 and M4 as an abnormal local asymmetry; M7 with four triangular, curved and similarly-sized cusps in a posterior region of radula, with cusp 1 gradually reducing in size and finally disappearing in the anterior region of radula, resulting in M7 with three cusps; M8 very narrow, with three finger-like cusps (median one $1.3-1.5 \times$ more elongated than outer cusps), fully formed only in the anterior region of radula; central tooth 3.6-3.8 $\mu \mathrm{m}$ wide, lateral teeth 3.8-4.1 $\mu \mathrm{m}$ wide, M1-M2 2.4-2.8 $\mu \mathrm{m}$ wide, M3-M6 (with three main cusps) 2.6-3.1 $\mu \mathrm{m}$ wide, M3-M6 (with four main cusps) 6.6-9.2 $\mu \mathrm{m}$ wide, M7 (with four cusps) 2.7-3.2 $\mu \mathrm{m}$ wide, M7 (with three cusps) 4.4-4.8 $\mu \mathrm{m}$ wide, fully developed M8 2.9-3.3 $\mu \mathrm{m}$ wide.

\section{Remarks}

Figured specimens show a gradual loss of coloration of the reddish-pigmented soft parts in N. verbernei after many years conserved in ethanol, from fresh specimens (Fig. 19A-B) to old ones (Fig. 19C-D).

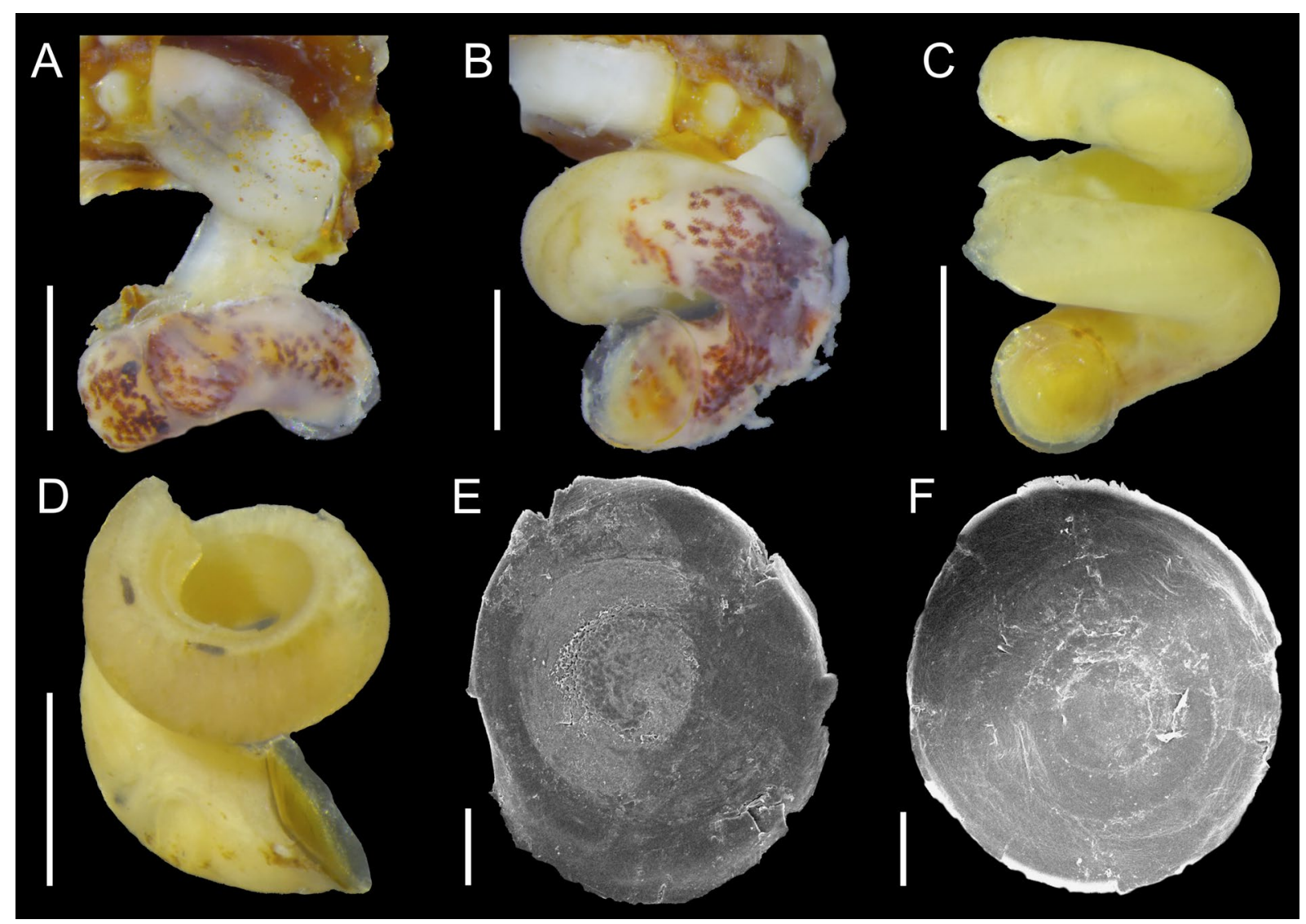

Fig. 19. Nanaphora verbernei (Moolenbeek \& Faber, 1989). A-B, F. MNRJ 28956. C. MZSP 85022. D-E. MNRJ 33139. A-D. External morphology. E-F. Operculum. Scale bars: A-D = $500 \mu \mathrm{m}$; E-F = $100 \mu \mathrm{m}$. 
Rolán \& Fernández-Garcés (1994) described the external morphology of $N$. verbernei and $N$. decollata (Rolán \& Fernández-Garcés, 1994) from Cuba as being translucent white with milk-white spots distributed on the dorsum. This could be a result of long-time storage of animals and consequent loss

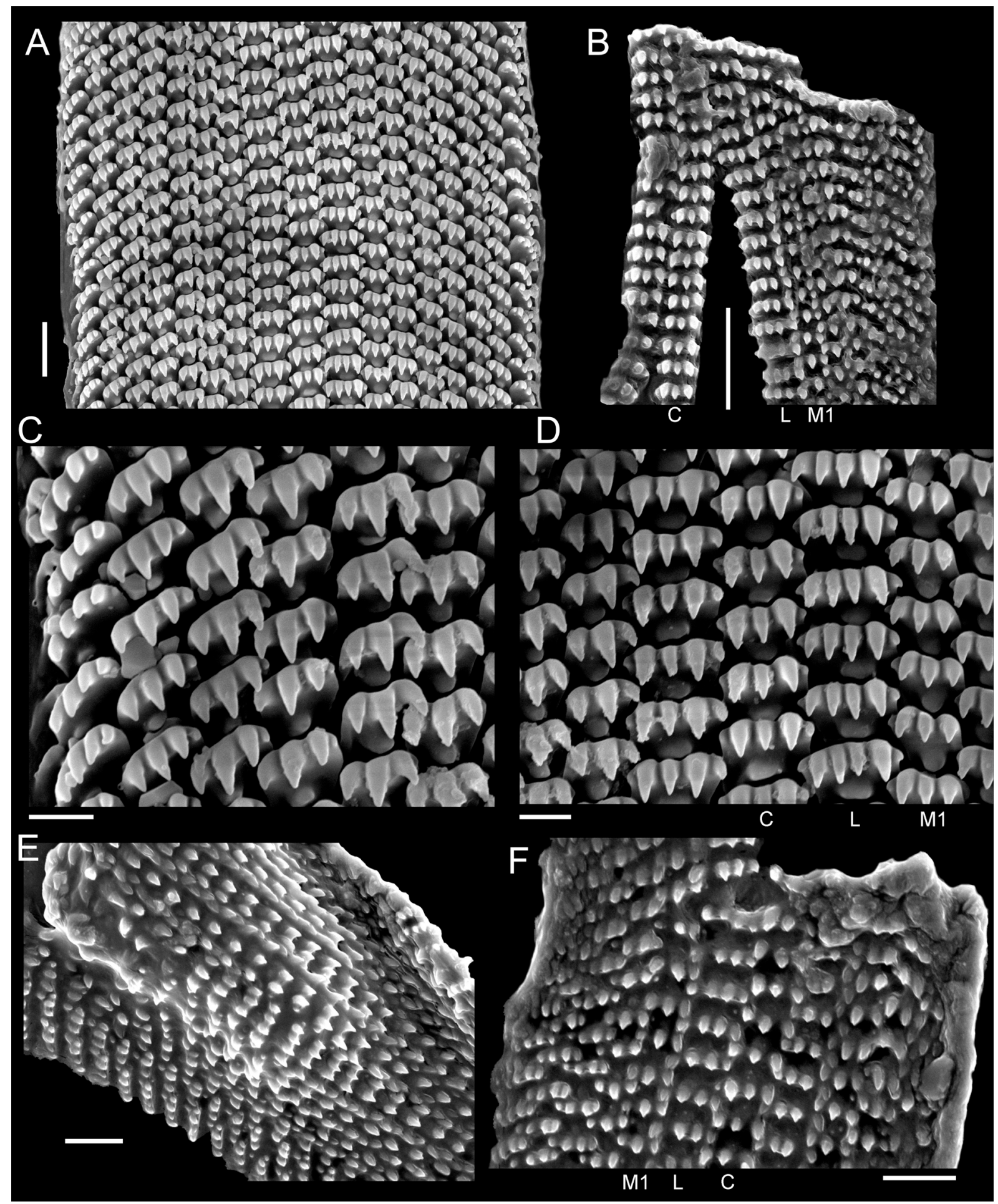

Fig. 20. Nanaphora verbernei (Moolenbeek \& Faber, 1989), radula. A-D. MNRJ 28956. E-F. MZSP 85022. Scale bars: A, $E-F=5 \mu \mathrm{m} ; \mathrm{B}=10 \mu \mathrm{m} ; \mathrm{C}-\mathrm{D}=2 \mu \mathrm{m}$. 
of pigmentation, or even suggest that $N$. verbernei from Brazil constitutes a different species than the Caribbean one (see below).

Rolán \& Fernández-Garcés (1994) briefly described, but did not illustrate, opercula of $N$. verbernei and $N$. decollata, which are similar to those herein illustrated (Fig. 19E-F) by being multispiral and having a subcentral nucleus. The operculum of $N$. albogemmata Laseron, 1958, illustrated by Marshall (1983), possesses a remarkably prominent peg accessory, which was not observed in $N$. verbernei from Brazil.

The radula of $N$. verbernei from Brazil has a variable number of cusps in some teeth, in addition to an abnormal local asymmetry. The peculiar arrangement of teeth rows in a distinct 'V-shape' generates a pattern in which one tooth is exactly situated in the center of the six teeth adjacent to it (Fig. 20D). Other genera of Triphoridae also seem to present a slight level of ' $V$-shape' arrangement of rows, but apparently never like the observed herein.

The most surprising feature of the radula of $N$. verbernei from Brazil is its radically different tooth morphology when compared to $N$. verbernei from Cuba and other species ( $N$. decollata, $N$. albogemmata and $N$. aff. albogemmata). Main differences comprise the central tooth of $N$. verbernei from Brazil bearing three main cusps (instead of two, four, six or nine cusps), lateral teeth with up to five or six cusps (instead of seven or more cusps in remaining species) and the main three claw-like cusps of marginal teeth (which completely differ from the several elongated cusps of the hand-shaped marginal teeth in other species). The radular formula of $N$. decollata is 7-1-1-1-7 (Rolán \& Fernández-Garcés 1994), similar to the eight marginal teeth observed in $N$. verbernei from Brazil, whereas the radula of $N$. albogemmata and $N$. aff. albogemmata is 1-1-1-1-1 (as argued by Marshall 1983) or 2-0-1-0-2 (as argued by Nützel 1998). This extreme variation in the composition of the radula indicates that Nanaphora shows an atypical evolutionary flexibility in order to colonize new sponge hosts or, alternatively, it is constituted by different monophyletic lineages that are masked by a convergence of inflated and reduced shells (Marshall 1983).

Genus Nototriphora Marshall, 1983

\section{Type species}

Notosinister aupouria Powell, 1937. Original designation. Recent, New Zealand.

Nototriphora decorata (C.B. Adams, 1850)

Figs $2 \mathrm{H}, 21-23$

\section{Material examined}

BRAZIL - Rio de Janeiro State • [1] spec.; Campos Basin; 2242' S, 4040’ W; MNRJ 33137 • [5, 3 d] specs; Ilha do Aleijado, Angra dos Reis; MNRJ 32763 - [2, 1 d] specs; Ilha Cunhambebe Grande,

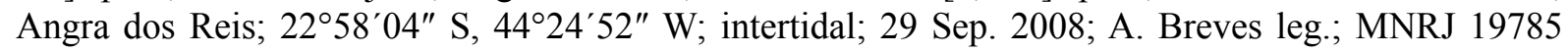
- [4, 1 d] specs; Ilha da Gipóia, Angra dos Reis; 2003; MNRJ 28854. - São Paulo State • [9, most juvs, 2 d] specs; Ilhabela; 29 Mar. 2007; P. Longo leg.; in Sargassum sp.; ZUEC-GAS 1803-1811.

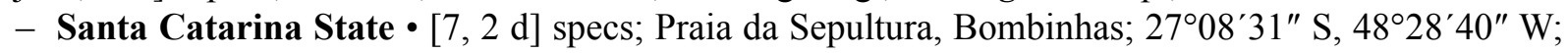
20 Dec. 2016; M.R. Fernandes leg.; MNRJ 28941 - [1] spec.; Praia da Tainha, Bombinhas; 27012'59" S, 48³0'40" W; 21 Dec. 2016; M.R. Fernandes leg.; MNRJ 28957.

\section{Description of basic anatomy}

OperCuLum. Rounded to slightly elliptical, thick, slightly opaque, yellowish, corneous, multispiral, up to 4.75 distinct whorls, nucleus subcentral, dislocated $21-27 \%$ from center toward margin; diameter of operculum exceeds diameter of opercular pouch in $\sim 20 \%$. 

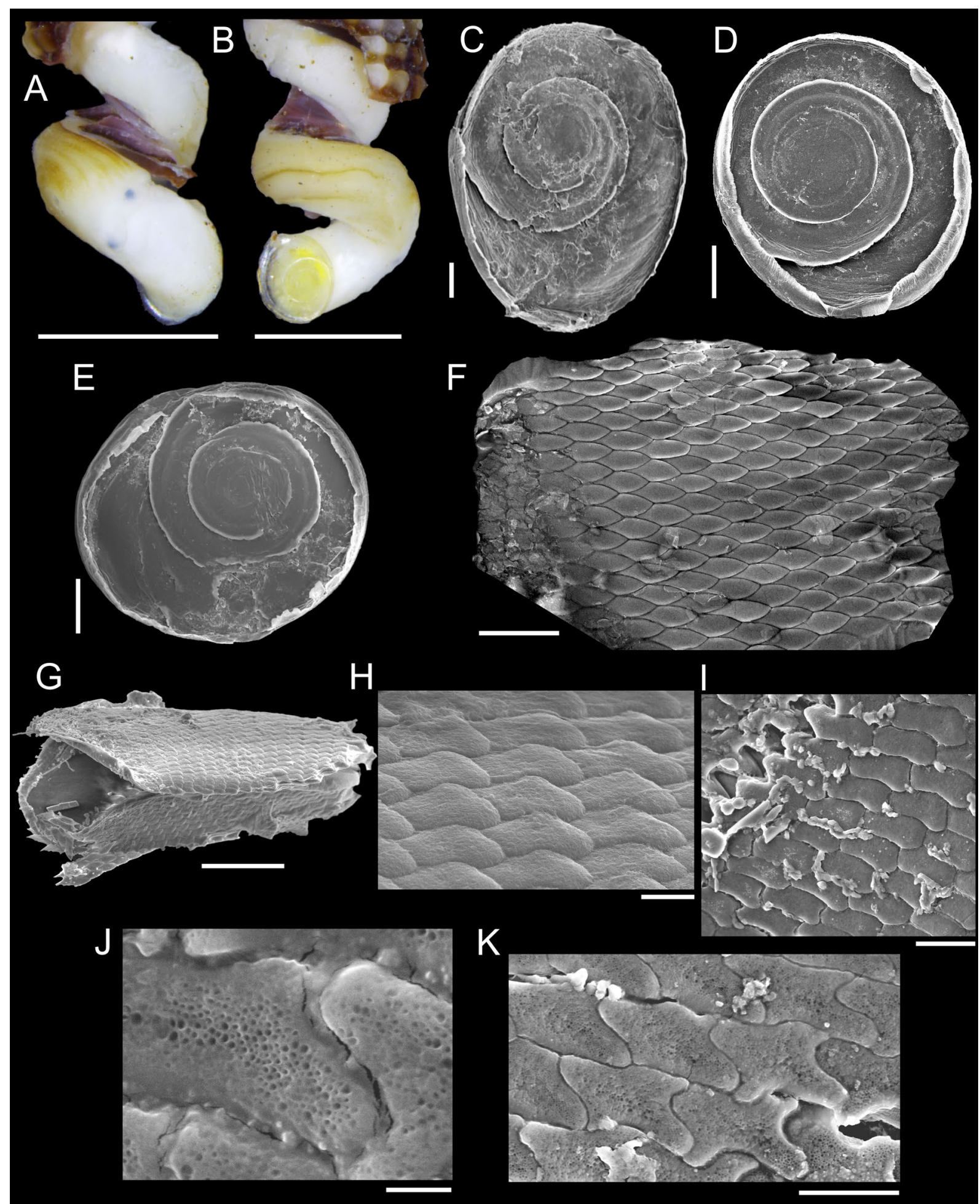

Fig. 21. Nototriphora decorata (C.B. Adams, 1850). A-B. MNRJ 28941. C. MNRJ 19785. D-E. MNRJ 32763. F, I-K. MNRJ 28854. G-H. ZUEC-GAS 1804. A-B. External morphology. C-E. Operculum. $\mathbf{F}-\mathbf{K}$. Jaw, inner $(\mathbf{F})$ and outer $(\mathbf{G}-\mathbf{K})$ sides. Scale bars: A-B $=1 \mathrm{~mm} ; \mathrm{C}-\mathrm{E}=100 \mu \mathrm{m} ; \mathrm{F}=20 \mu \mathrm{m} ; \mathrm{G}=$ $50 \mu \mathrm{m} ; \mathrm{H}=5 \mu \mathrm{m} ; \mathrm{I}, \mathrm{K}=10 \mu \mathrm{m} ; \mathrm{J}=2 \mu \mathrm{m}$. 
JAW. Wing-shaped; outer side with scales boomerang-shaped, rectangular, rhombus-shaped, puzzleshaped or X-shaped; scales of outer side 9.1-9.9 $\mu \mathrm{m}$ long, 3.0-4.0 $\mu \mathrm{m}$ wide, ratio length/width 2.5-3.2 (boomerang-shaped), 10.2-10.9 $\mu \mathrm{m}$ long, 4.3-4.9 $\mu \mathrm{m}$ wide, ratio length/width $2.1-2.5$ (rectangular), 14.1-15.7 $\mu \mathrm{m}$ long, 5.5-6.4 $\mu \mathrm{m}$ wide, ratio length/width 2.4-2.6 (rhombus-shaped), 11.3-12.8 $\mu \mathrm{m}$ long,
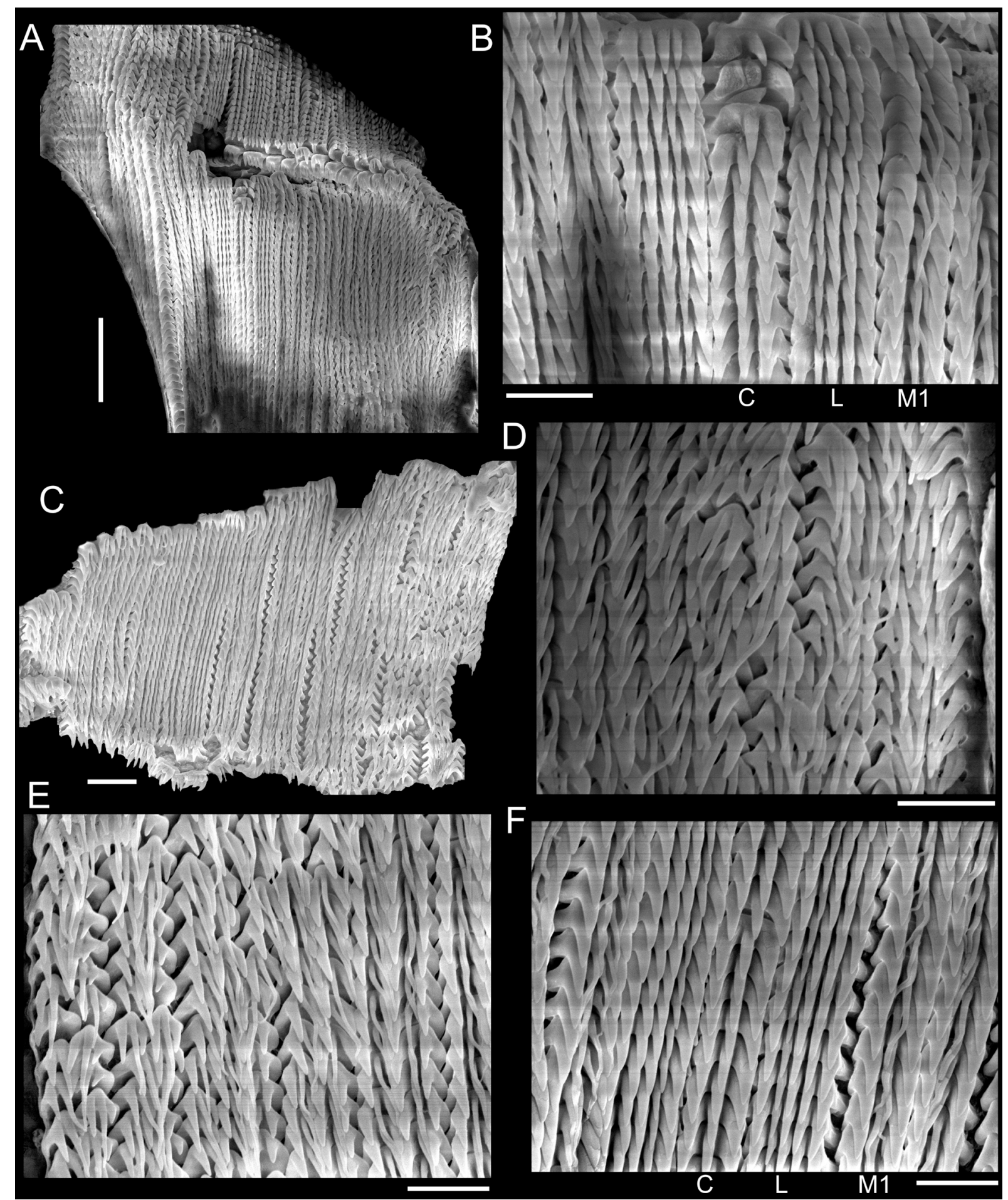

Fig. 22. Nototriphora decorata (C.B. Adams, 1850), radula. A-F. MNRJ 28854. Scale bars: $A=20 \mu \mathrm{m}$; $\mathrm{B}, \mathrm{D}-\mathrm{F}=5 \mu \mathrm{m} ; \mathrm{C}, 10 \mu \mathrm{m}$. 
1.9-2.2 $\mu \mathrm{m}$ wide, ratio length/width 5.6-6.4; scales with micro-pores up to $500 \mathrm{~nm}$ in diameter; inner side with smooth lanceolate scales, $12.4-15.9 \mu \mathrm{m}$ long, 3.9-5.8 $\mu \mathrm{m}$ wide, ratio length/width 2.7-3.8.

RADULA. Formula 18-1-1-1-18; central tooth claw-like, with three nearly similar cusps, median cusp thinner, outer cusps more prominent and broader in the middle of its length, assuming a somewhat

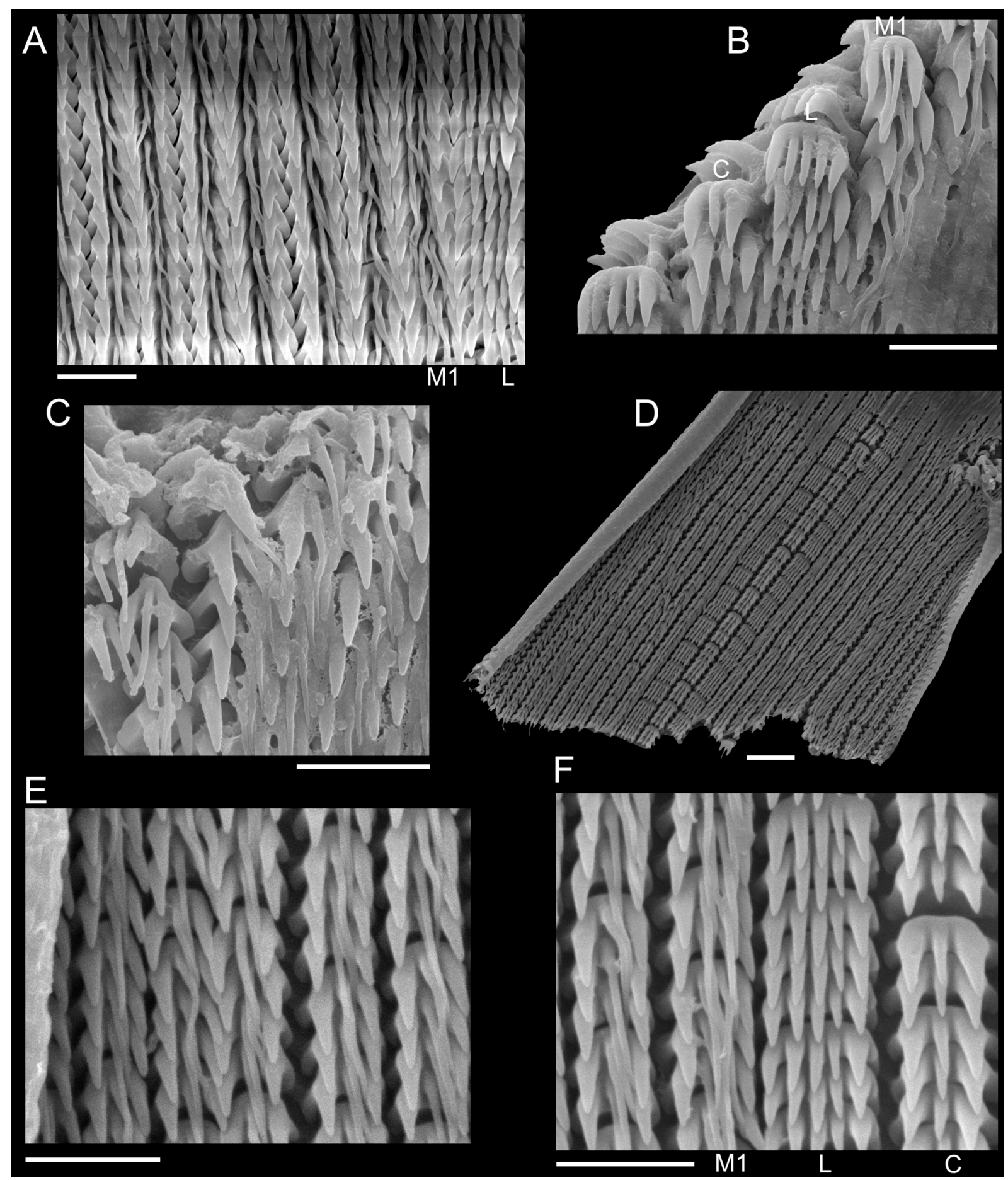

Fig. 23. Nototriphora decorata (C.B. Adams, 1850), radula. A. MNRJ 28854. B-C. ZUEC-GAS 1804. D-F. MNRJ 32763. Scale bars: A-C, E-F $=5 \mu \mathrm{m}$; D $=10 \mu \mathrm{m}$. 
rhombus-shape; lateral teeth comb-like, with five similar cusps, but outer ones (cusps 1 and 5) slightly broader and more prominent, cusp 2 often slightly more reduced; M1 with four cusps, inner ones (cusps 2 and 3) much thinner and elongated (1.5-2.7× longer than cusps 1 and 4$)$, resembling malleable filaments, cusps 1 and 4 curved, somewhat similar to outer cusps of central and lateral teeth; remaining marginal teeth similar to M1, but with three cusps, median one much elongated (1.5-2.5× longer than outer cusps); central tooth 3.1-4.1 $\mu \mathrm{m}$ wide, lateral teeth 3.4-4.7 $\mu \mathrm{m}$ wide, marginal teeth between $1.8 \mu \mathrm{m}$ (outer teeth) to $3.7 \mu \mathrm{m}$ wide (M1).

\section{Remarks}

García \& Luque (1986) cited the existence of red spots on the flanks, near the operculum, of Caribbean specimens of $N$. decorata, which was not observed in specimens from Cuba studied by Rolán \& Fernández-Garcés (1994) nor herein. Specimens analyzed by García \& Luque (1986) could actually be wrongly identified as $N$. decorata, because a red pigmentation can be seen in other genera, such as Monophorus and Nanaphora.

Although briefly described by Rolán \& Fernández-Garcés (1994), the thick and yellowish operculum of $N$. decorata is herein illustrated for the first time (Fig. 21C-E), superficially resembling those previously described for the genus, despite the operculum of $N$. decorata having fewer whorls and not being so tall as in the type species N. aupouria (Marshall 1983).

The radula herein described is identical to the Caribbean one described by Rolán \& Fernández-Garcés (1994). Another similar radula is that of the eastern Atlantic species Nototriphora canarica (Nordsieck \& Talavera, 1979), with 17 marginal teeth (Bouchet 1997). Both species also share a remarkably similar shell, being considered in the past as a single species (for detailed comparisons, see Bouchet 1985), and they have probably diverged recently.

Bouchet (1997) compared the radula of $N$. canarica with that of type species $N$. aupouria (Marshall 1983), finding discrete differences such as the latter species with four cusps in lateral teeth (instead of five), four cusps in M2 and M3 (instead of three), and a reduced number of marginal teeth (only nine). Such differences also apply to $N$. decorata, which has a similar radula to $N$. canarica. Even with the evident closer relationship of the two Atlantic species, their radula cannot be seen as diverging in a generic level to the type species owing to a very similar tooth morphology, except by the species-level differences listed above.

Genus Sagenotriphora Marshall, 1983

\section{Type species}

Triphora ampulla Hedley, 1903. Original designation. Recent, southwestern Pacific.

Sagenotriphora osclausum (Rolán \& Fernández-Garcés, 1995)

Figs 2I, 24

\section{Material examined}

BRAZIL - Bahia State - [2, 2 d] specs; Forte Santa Maria, Salvador; 0-10 m depth; $13^{\circ} 00^{\prime} 15^{\prime \prime}$ S, 38³2'03" W; 18 Feb. 2016; M.R. Fernandes leg.; MNRJ 35061.

\section{Description of basic anatomy}

RADULA. Formula 7-1-1-1-7; central tooth and lateral teeth disposed around a central axis, marginal teeth lie in a kind of membrane, oblique to almost perpendicular to the central axis; central tooth resembles a pair of small curved paws, having a single common axis that bifurcates in about $56-62 \%$ of tooth length, 
originating the two halves of tooth, which are separated by an internal diastema (distance between extremities of inner cusps and distance between basal plates constitute respectively $16-24 \%$ and $9-14 \%$ of total width of tooth), each half of tooth bearing a globose base and four (or even five) short, triangular and sharp-pointed cusps similarly sized, comprising $21-34 \%$ of length of the entire tooth half; lateral teeth resemble one half of central tooth, with a robust base and four to five short, triangular and sharp-

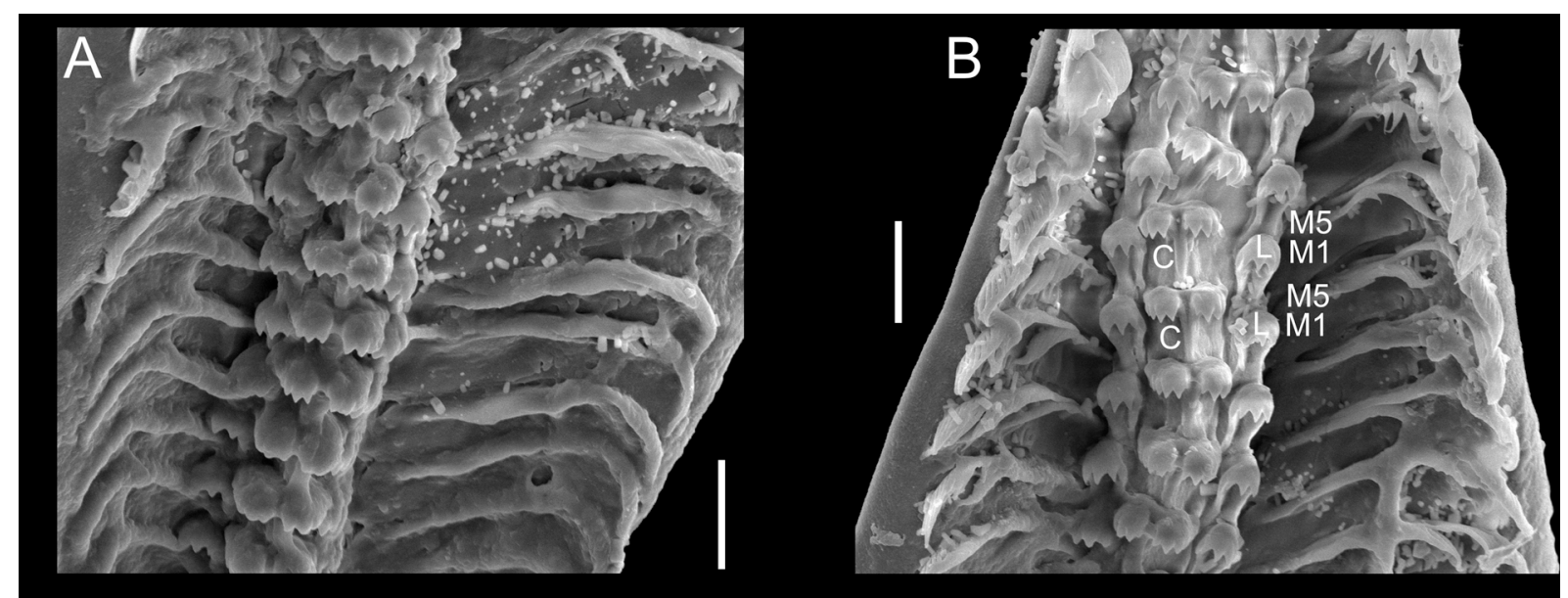

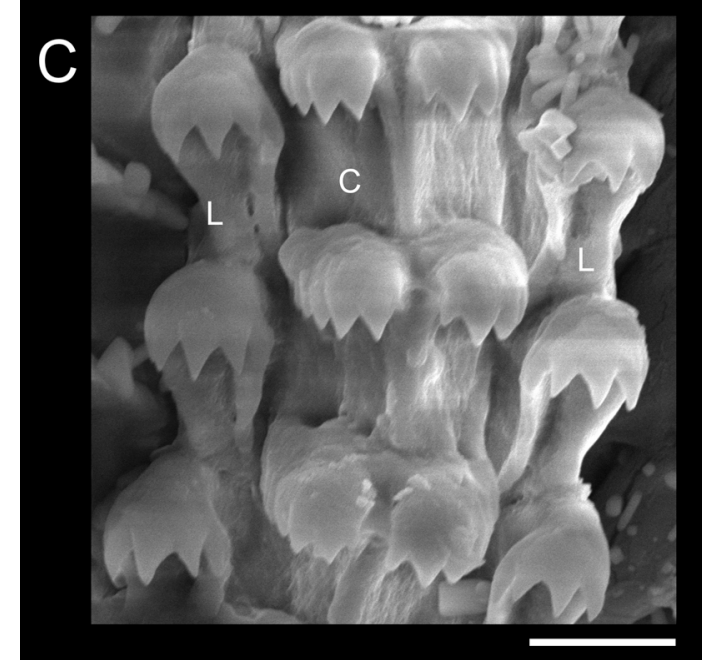

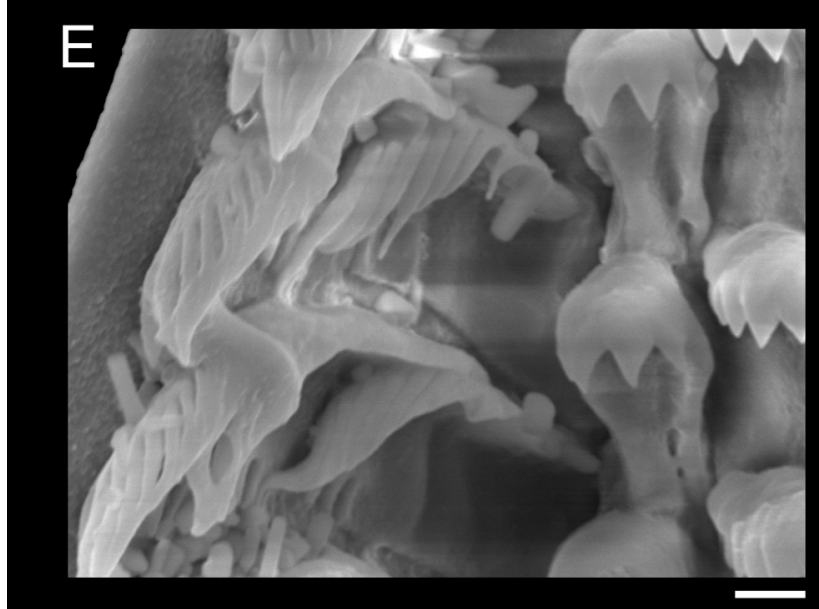

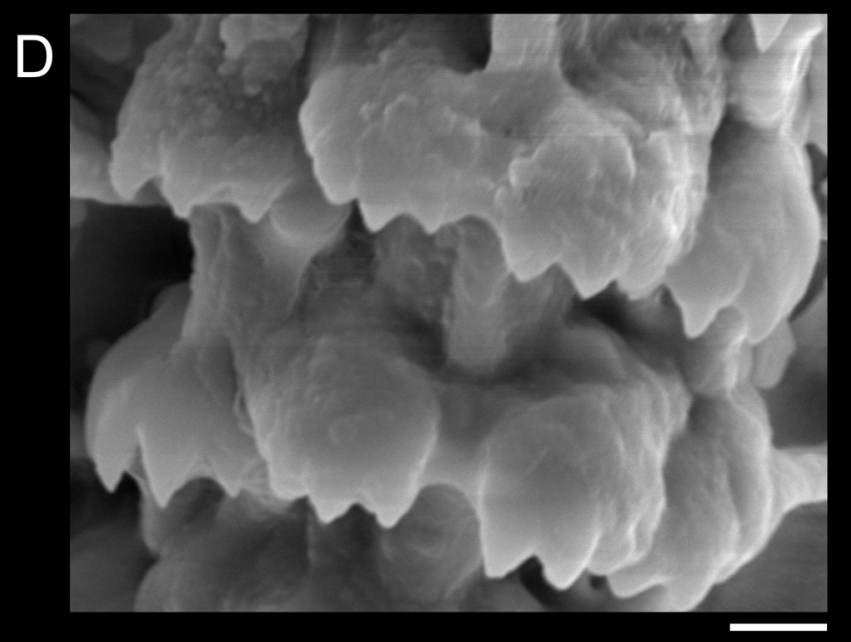

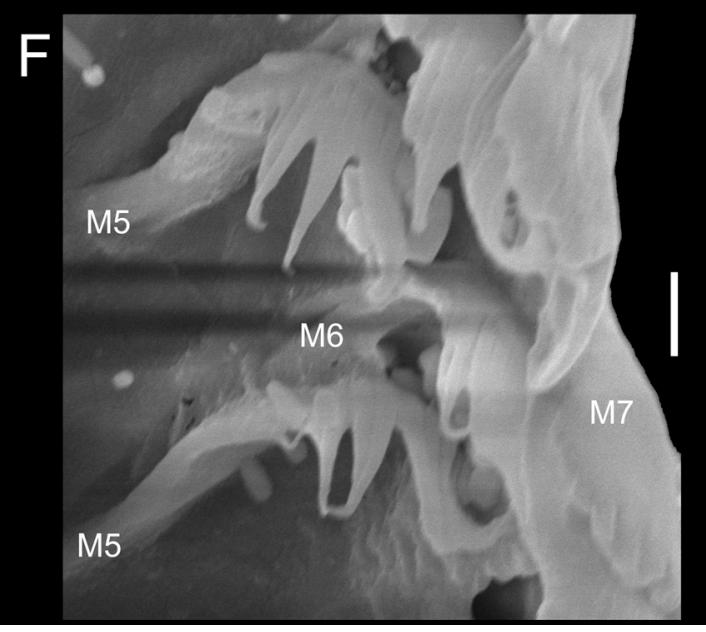

Fig. 24. Sagenotriphora osclausum (Rolán \& Fernández-Garcés, 1995), radula. A-F. MNRJ 35061. Scale bars: A-B $=10 \mu \mathrm{m} ; \mathrm{C}=5 \mu \mathrm{m}$; D-F $=2 \mu \mathrm{m}$. 
pointed cusps similarly sized, comprising $34-40 \%$ of length of the entire tooth; marginal teeth elongated and developing one behind or above the other in the same row, hindering a proper visualization; M1 to M4 resembling chainsaws, with curved cusps of very small size (in the lower part) or a little longer (upper part) concentrated in the distal portion (16-21\% of tooth length) of the long and robust basal plate; M5 and M6 resembling brackens, with at least seven elongated finger-like cusps in the distal portion (25-50\% of tooth length) of the long and thin basal plate; M7 with apparently nine or ten cusps very close to each other, almost inseparable; central tooth 8.0-9.0 $\mu \mathrm{m}$ wide, lateral teeth 3.9-4.4 $\mu \mathrm{m}$ wide, M1 to M4 15.6-16.5 $\mu \mathrm{m}$ long, M5 and M6 16.9-18.1 $\mu \mathrm{m}$ long, M7 14.8-17.8 $\mu \mathrm{m}$ long.

\section{Remarks}

This is a very unusual radula among triphorids. Rolán \& Fernández-Garcés (2008) described six to seven cusps in the lateral teeth of a specimen of S. osclausum from Florida (southeastern USA), more than the four to five cusps herein described (Fig. 24C-D), possibly because of better angle views of this globose structure in that work. They described and illustrated only inner marginal teeth that resemble chainsaws (M1 to M4), not having noticed the elongated marginal teeth M5 to M7, which are described in the present study (Fig. 24F). In fact, marginal teeth of S. osclausum are extremely difficult to be discerned and quantified, owing to the great overlap among each other.

Despite having similar shell sculpture and protoconch morphology, the radula of $S$. candidula Rolán \& Fernández-Garcés, 2008, drawn by Rolán \& Fernández-Garcés (2008), is quite different from that of $S$. osclausum, as the authors correctly stated. The marginal teeth of $S$. candidula are similar to M5 and M6 of S. osclausum (Fig. 24F), although apparently with fewer cusps.

The radula of the southwestern Pacific and the type species Sagenotriphora ampulla (Hedley, 1903), described in Marshall (1983), is radically different from that of S. osclausum, considering both the morphology (shape and number of cusps) of all teeth and the number of marginal teeth (seven in S. osclausum, only one in S. ampulla). Rolán \& Fernández-Garcés (2008) were conservative when avoiding to give a new generic name for the western Atlantic species, arguing for that similarity of the central tooth being divided into two parts in both species might be a convergent feature of minor importance considering the discrepant morphology of the central and remaining teeth. Shell differences are also observed between them, like the embryonic shell sculpture (with vesicular granules in S. osclausum, but reticulated in S. ampulla) and sculpture of subperipheral/basal cords (mainly smooth in $S$. osclausum, nodulose in $S$. ampulla). Future phylogenies are necessary prior to the creation of a new generic name.

Genus Similiphora Bouchet, 1985

\section{Type species}

Triphora similior Bouchet \& Guillemot, 1978. Original designation. Recent, northeastern Atlantic and Mediterranean.

Similiphora intermedia (C.B. Adams, 1850)

Figs $2 \mathrm{~J}, 25-27$

\section{Material examined}

BRAZIL - Ceará State • [1] spec.; Praia da Pedra Rachada, Paracuru; 16 May 2003; L.R. Simone leg.; MZSP 36450. - Alagoas State • [1] spec.; Praia da Ponta Verde, Maceió; 0940'05" S, 3541'35" W; $1 \mathrm{~m}$ depth; M.D. Correia leg.; MZSP 102113. - Bahia State • [1] spec.; Forte Santa Maria, Salvador; $13^{\circ} 00^{\prime} 15^{\prime \prime} \mathrm{S}, 38^{\circ} 32^{\prime} 03^{\prime \prime} \mathrm{W}, 0-10 \mathrm{~m}$ depth; 18 Feb. 2016; M.R. Fernandes leg.; MNRJ 35062. - Espírito

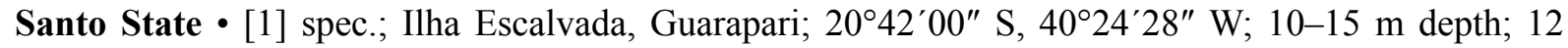
Oct. 2014; M.R. Fernandes and L.S. Souza leg.; MNRJ 33983. - Rio de Janeiro State • [4, 3 d] specs; 


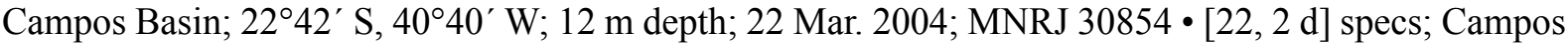

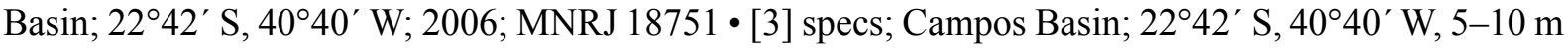
depth; 2007; MNRJ 15402 • [65, 1 d] specs; same data as for preceding; MNRJ 29763 • [1] spec.; same data as for preceding; MNRJ 32962 • [4] specs; same data as for preceding; MNRJ 33136 • [2, 2 d] specs; Prainha, Arraial do Cabo; 14 Mar. 2015; M.R. Fernandes and L.S. Souza leg.; MNRJ 26840 • [1] spec.; Praia do Forno, Arraial do Cabo; 14 Mar. 2015; M.R. Fernandes and L.S. Souza leg.; MNRJ 26830 •[2, 2 d] specs; Enseada do Cardeiro, Arraial do Cabo; 6 m depth; 12 Sep. 2015; M.R. Fernandes and L.S. Souza leg.; MNRJ 34616 • [1] spec.; Ilhas Maricás, Maricá; 8 m depth; 12 Feb. 2015; M.R. Fernandes and L.S. Souza leg.; MNRJ 34242.

\section{Description of basic anatomy}

EXTERNAL MORPHOLOGY. Body white, head and anterior/lateral portions of foot mainly black, cephalic tentacles and ventral part of the foot entirely white; pedal slit covering $65-80 \%$ of foot length.

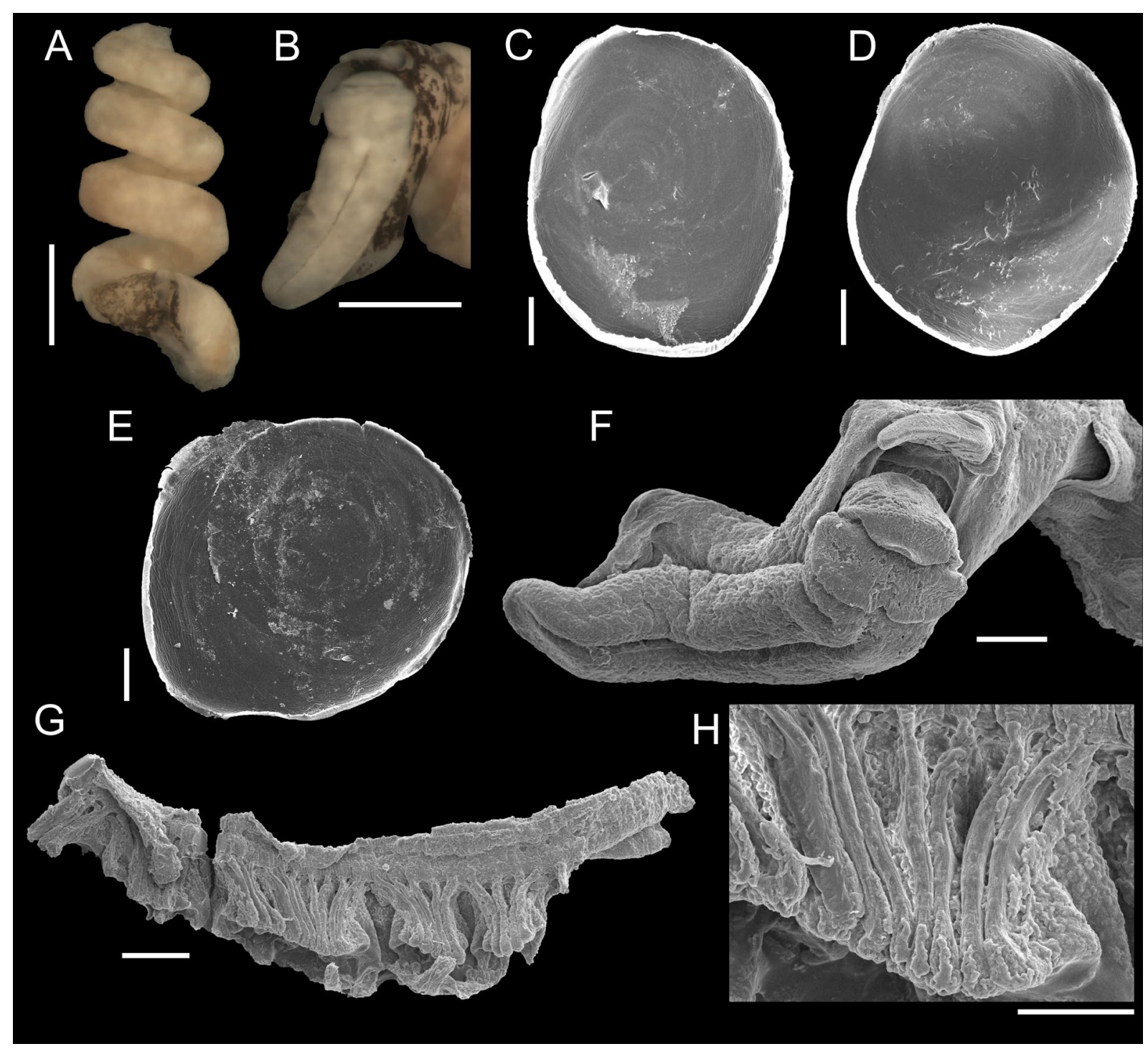

Fig. 25. Similiphora intermedia (C.B. Adams, 1850). A-C, F-H. MNRJ 30854. D. MNRJ 18751. E. MNRJ 29763. A-B. External morphology. C-E. Operculum. F-H. Head-foot (F) and ctenidium $(\mathrm{G}-\mathrm{H})$ critical-point dried. Scale bars: $A-B=500 \mu \mathrm{m} ; \mathrm{C}-\mathrm{G}=100 \mu \mathrm{m} ; \mathrm{H}=50 \mu \mathrm{m}$. 
OperCulum. Ovate, thin, semi-transparent, membranous, multispiral, $\sim 4.25$ whorls, nucleus subcentral, dislocated $22-26 \%$ from center toward margin.

$\mathrm{J}_{\mathrm{AW}}$. Wing-shaped; outer side with scales rectangular/squared, rectangular-bilobed (resembling tiles), bone-shaped or occasionally acute-lanceolate; scales with micro-pores up to $400 \mathrm{~nm}$ in diameter; inner side with scales oblong-lanceolate or hexagonal/gem-like, surface smooth; scales of outer side 10.0 $13.2 \mu \mathrm{m}$ long, 3.4-6.2 $\mu \mathrm{m}$ wide, ratio length/width 2.0-3.0 (rectangular scales), 10.0-11.5 $\mu \mathrm{m}$ long, 2.7-6.0 $\mu \mathrm{m}$ wide, ratio length/width 1.9-3.8 (rectangular-bilobed), 11.5-12.7 $\mu \mathrm{m}$ long, 3.4-3.8 $\mu \mathrm{m}$ wide, ratio length/width 3.2-3.4 (bone-shaped); scales of inner side usually 12.4-15.3 $\mu \mathrm{m}$ long, 5.4-7.1 $\mu \mathrm{m}$ wide, ratio length/width 2.1-2.6 (oblong-lanceolate scales), 12.5-13.0 $\mu \mathrm{m}$ long, 7.0-7.4 $\mu \mathrm{m}$ wide, ratio length/width 1.7-1.8 (hexagonal).

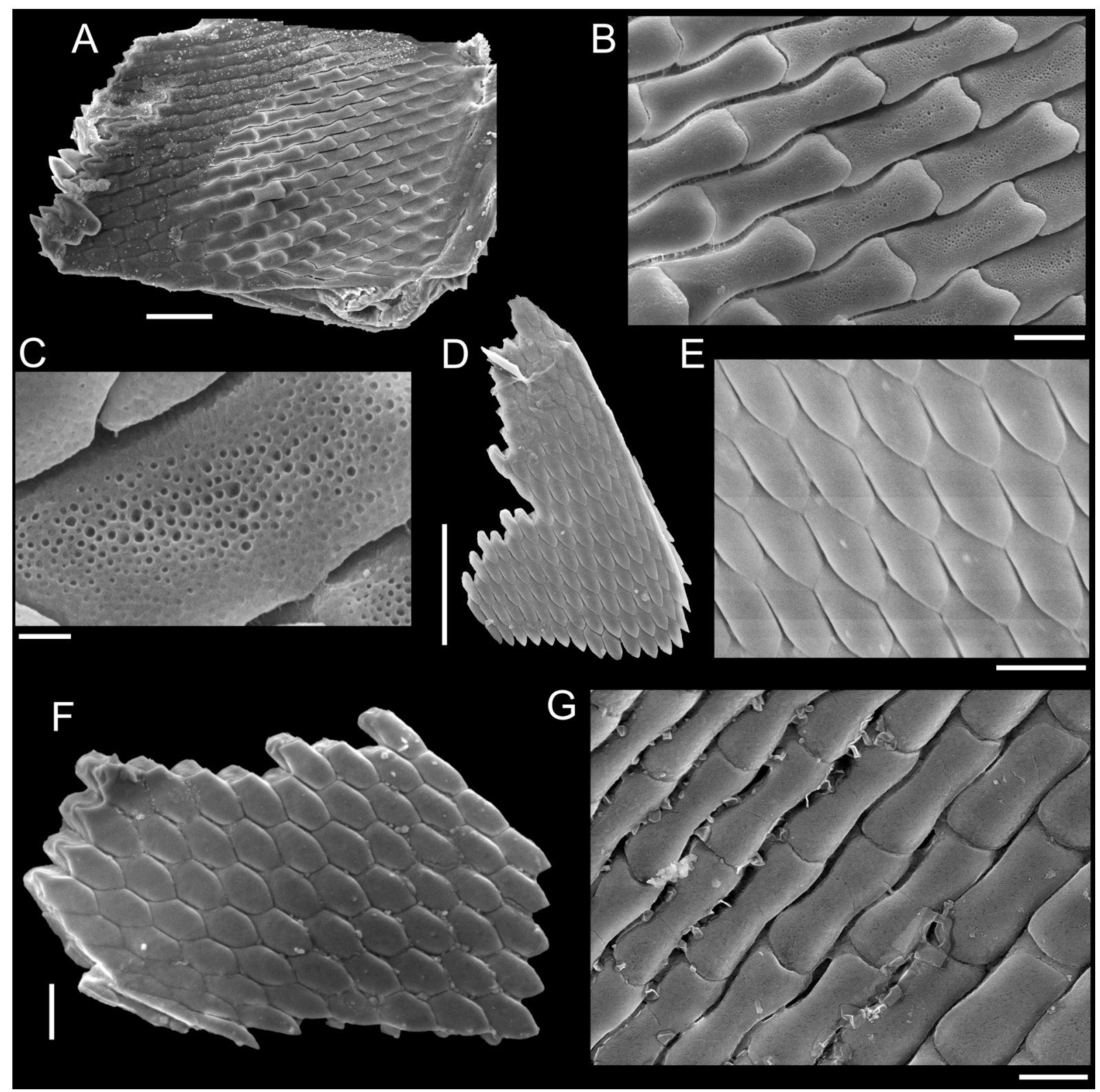

Fig. 26. Similiphora intermedia (C.B. Adams, 1850). A-C, F. MNRJ 18751. D-E. MNRJ 30854. G. MNRJ 29763. A-G. Jaw, outer (A-C, G) and inner (D-F) sides. Scale bars: A $=20 \mu \mathrm{m} ; \mathrm{B}, \mathrm{G}=5 \mu \mathrm{m}$; $\mathrm{C}=1 \mu \mathrm{m} ; \mathrm{D}=50 \mu \mathrm{m} ; \mathrm{E}-\mathrm{F}=10 \mu \mathrm{m}$. 
RADULA. Formula 14-1-1-1-14; central and lateral teeth with three cusps similarly sized, with a parrotbeak appearance, outer cusps slightly oriented outwards and slightly broader and more prominent than median cusp; a very small process may appear on the side of cusp 1 of lateral teeth; marginal teeth with three cusps, median one much thinner and elongated (1.6-2.9× longer than outer cusps),

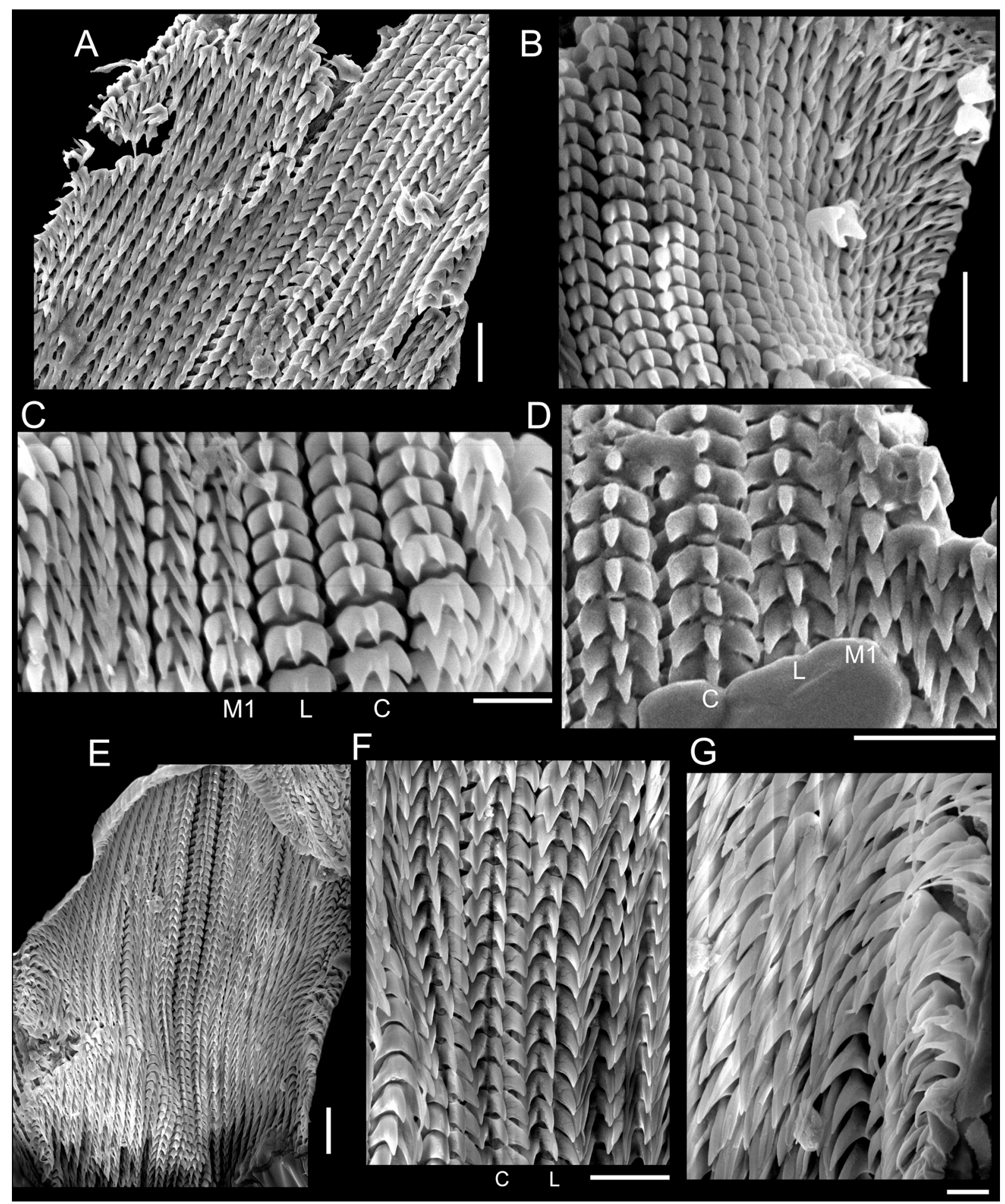

Fig. 27. Similiphora intermedia (C.B. Adams, 1850), radula. A-D. MNRJ 30854. E-G. MNRJ 29763. Scale bars: A-B, D-E $=10 \mu \mathrm{m} \mathrm{C,} \mathrm{F}=5 \mu \mathrm{m} ; \mathrm{G}=2 \mu \mathrm{m}$. 
resembling a malleable filament, outer cusps curved in inner teeth (somewhat similar to outer cusps of central and lateral teeth, but not oriented outwards as the latter) but more triangular and elongated in outer teeth; median cusp of marginal teeth develops in the lower half of tooth, outer cusps develop in the top of tooth; base of marginal teeth more developed than that of central and lateral teeth; central tooth 3.5-5.7 $\mu \mathrm{m}$ wide, lateral teeth 3.1-5.4 $\mu \mathrm{m}$ wide, inner marginal teeth $2.0-3.9 \mu \mathrm{m}$ wide, outer marginal teeth $1.6-3.4 \mu \mathrm{m}$ wide.

\section{Remarks}

Despite being one of the commonest triphorids in the western Atlantic, S. intermedia has its external morphology, operculum, jaw and radula firstly illustrated in the present study. Just like its congeneric species from the eastern Atlantic, the anterior portion of the animal has a dark pigmentation even after stored in ethanol (Fig. 25A-B). The operculum of $S$. intermedia, with a subcentral nucleus (Fig. 25C-E), is similar to that of S. triclotae Bouchet, 1997 (Bouchet 1997: fig. 9A). The tooth morphology of $S$. intermedia is also very similar to those of $S$. similior (Bouchet \& Guillemot, 1978) and S. triclotae, with all teeth bearing three cusps but the marginal teeth showing a median cusp much elongated, 1.6-2.9 $\times$ longer than outer cusps in S. intermedia (two times longer in S. triclotae; two to four times longer in S. similior). The number of marginal teeth is also slight conservative in the genus, with 14 in S. intermedia, 15 in S. triclotae and 13-16 in S. similior.

Genus Strobiligera Dall, 1924

\section{Type species}

Triforis ibex Dall, 1881. Original designation. Recent, Gulf of Mexico.

Strobiligera gaesona (Dall, 1927)

Figs 2K, 28-29

\section{Material examined}

BRAZIL - Ceará State: [2, 1 d] specs; Canopus Bank; 02 ${ }^{\circ} 14^{\prime} 25^{\prime \prime}$ S, 38 22 $22^{\prime} 50^{\prime \prime}$ W; 240-260 m depth; 2005; MZSP 53685 • [1, d] spec. same data as for preceding; MZSP 53697.

\section{Description of basic anatomy}

EXTERNAL MORPHOLOGY. Body yellowish-white, covered by minute white dots in the posterior whorl adjacent to head-foot.

Operculum. Yellowish, elliptical, moderately thin but rigid, semi-transparent, 3.25 distinct whorls, nucleus slightly eccentric, dislocated $\sim 32 \%$ from center towards margin; diameter of operculum does not significantly exceed diameter of opercular pouch.

JAW. Outer side with robust scales, rhombus-shaped, rectangular or rectangular-lanceolate, covered by micro-pores up to $380 \mathrm{~nm}$ in diameter; scales of outer side 14.9-21.2 $\mu \mathrm{m}$ long, 7.9-9.5 $\mu \mathrm{m}$ wide, ratio length/width 1.6-2.4 (rhombus-shaped), 10.3-11.3 $\mu \mathrm{m}$ long, 4.4-4.8 $\mu \mathrm{m}$ wide, ratio length/width $2.3-2.4$ (rectangular), 11.8-17.6 $\mu \mathrm{m}$ long, 4.2-6.4 $\mu \mathrm{m}$ wide, ratio length/width 2.7-3.3 (rectangular/lanceolate).

RADULA. Formula not discernible, without clear differentiation of central, lateral and marginal teeth, but at least 30 scissor-like teeth per row, frequently overcrowded in its central portion; teeth typically with three cusps, two elongated/curved ones and a smaller marginal cusp positioned sometimes on the left margin, other times on the right margin, with the change of side of the marginal cusp being prone to occur more than once in the same row; the length of marginal cusp greatly varies, often $25-70 \%$ of length of main cusps, but it can be reduced until totally disappear or even reach same size of other 
cusps; rare teeth with two cusps have one cusp longer than the other; rare teeth with four cusps have inner cusps more elongated than outer ones (which reach $43-85 \%$ of length of inner cusps), in some cases with an internal diastema between inner cusps; abnormal teeth of three cusps with a much reduced size may be present in a central portion of row; teeth with three cusps typically $2.0-3.9 \mu \mathrm{m}$ wide, but abnormally reduced teeth as little as $1.5 \mu \mathrm{m}$ wide may occur; teeth with two cusps $1.1-1.5 \mu \mathrm{m}$ wide; teeth with four cusps $2.3-3.5 \mu \mathrm{m}$ wide.

\section{Remarks}

Even being an upper bathyal species, S. gaesona possesses distinct eyes (Fig. 28A). The elliptical operculum seems to be a common feature of the genus, with the nucleus of $S$. gaesona being apparently not as eccentric as in S. lubrica (Bouchet \& Warén, 1993). The operculum of $S$. gaesona is yellowish (Fig. 28B), similar to the 'light tan' color described for S. lubrica (Bouchet \& Warén 1993).

The scissor-like tooth morphology of $S$. gaesona is peculiar, with undifferentiated teeth and a typical tooth bearing three claw-like cusps, two longer and one external (right or left) smaller cusp, with rare

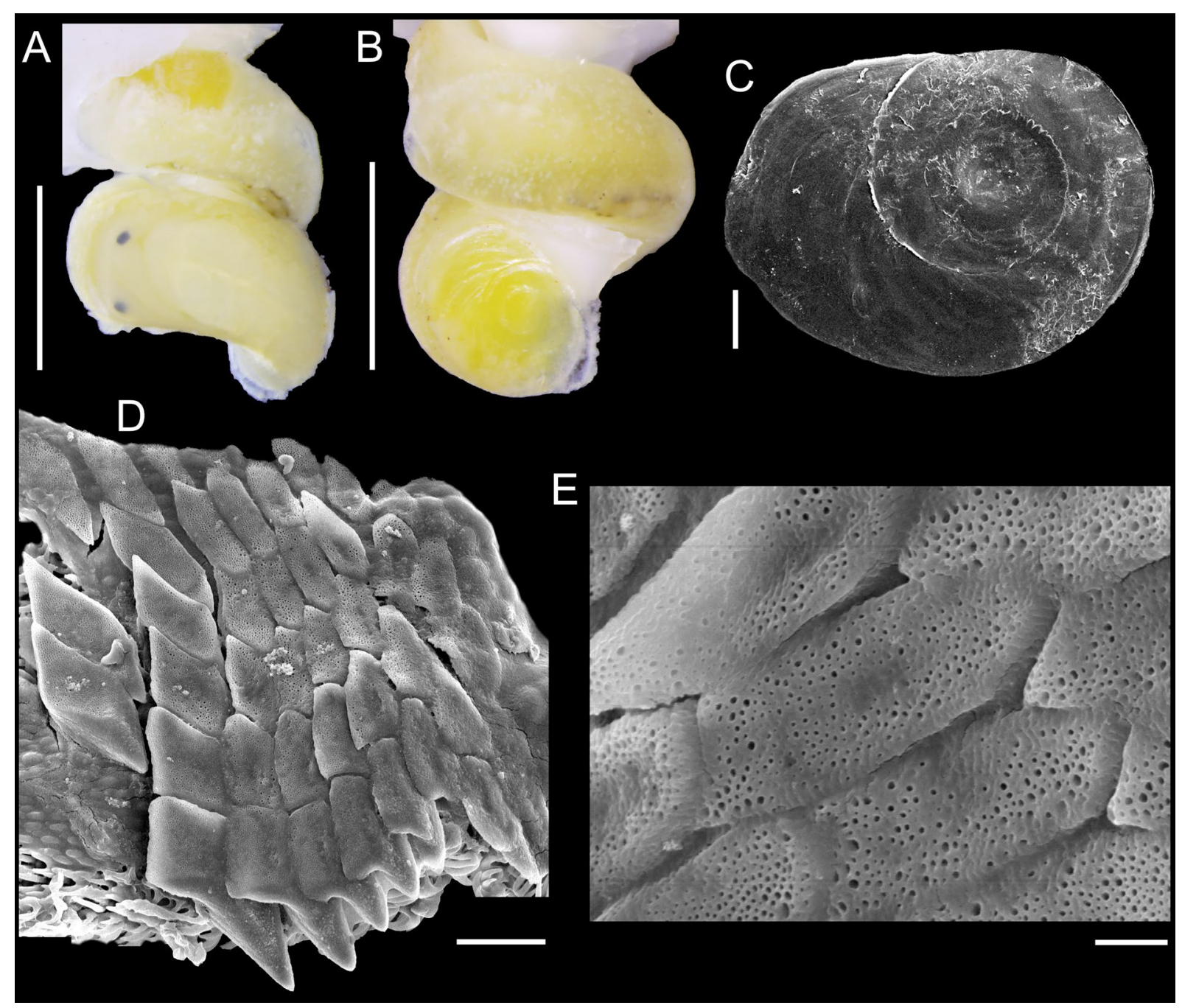

Fig. 28. Strobiligera gaesona (Dall, 1927). A-E. MZSP 53697. A-B. External morphology. C. Operculum. D-E. Jaw, outer side. Scale bars: A-B $=1 \mathrm{~mm} ; \mathrm{C}=100 \mu \mathrm{m} ; \mathrm{D}=10 \mu \mathrm{m} ; \mathrm{E}=2 \mu \mathrm{m}$. 
variations of two or four cusps (Fig. 29). This radula is nearly identical to those of S. brychia (Bouchet \& Guillemot, 1978) and S. lubrica, although the total number of teeth per row could not be determined in S. gaesona. The radula of S. brychia also shows teeth with two to four cusps, and teeth with three cusps

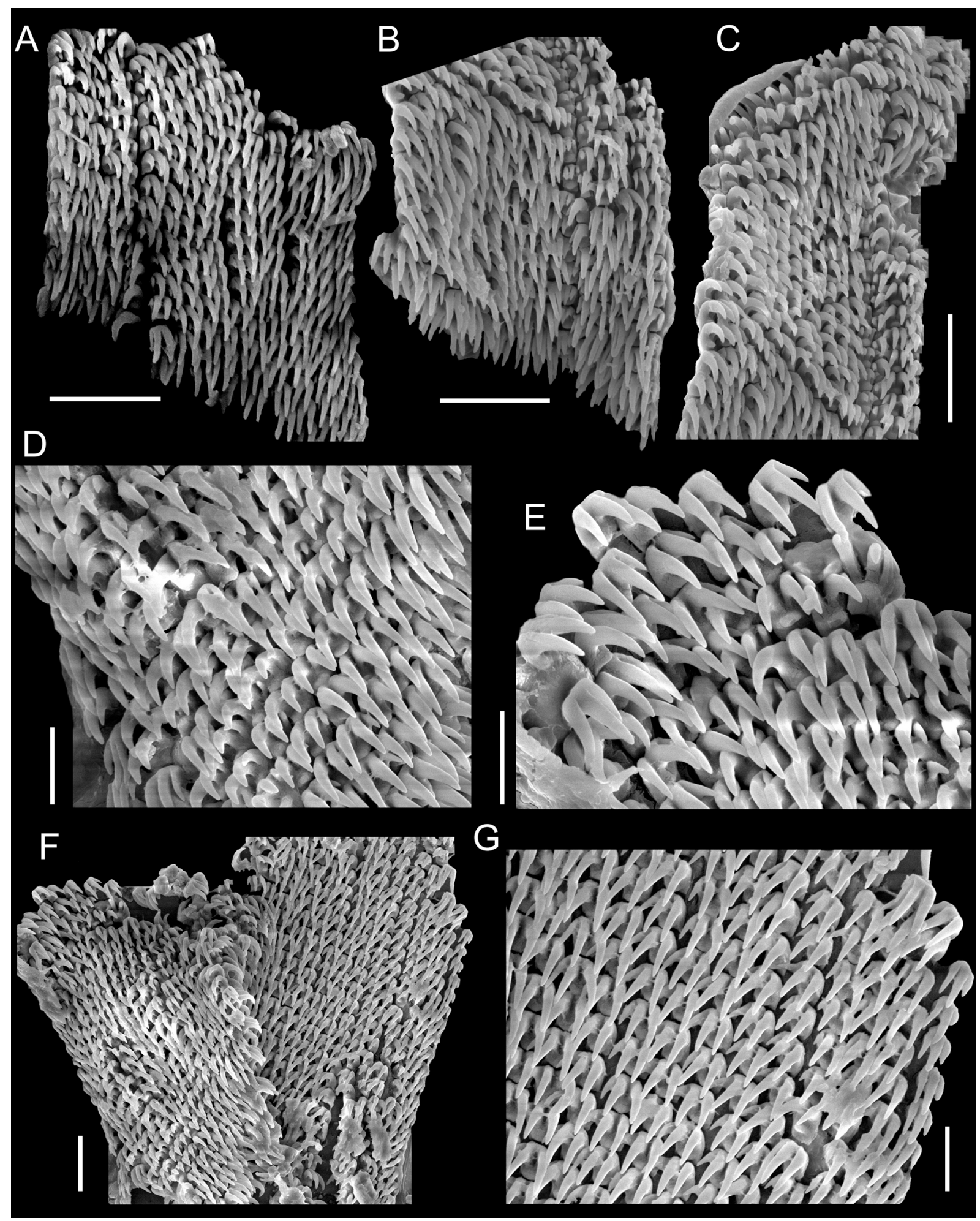

Fig. 29. Strobiligera gaesona (Dall, 1927), radula. A-C. MZSP 53685. D-G. MZSP 53697. Scale bars: A-C, $\mathrm{F}=10 \mu \mathrm{m}$; D-E, $\mathrm{G}=5 \mu \mathrm{m}$. 
having the smaller cusp positioned to the left or to the right (Bouchet 1985), although the reduced cusp in $S$. brychia seems to be even shorter than in S. gaesona. The radula of $S$. lubrica was described as possessing teeth mainly with two claw-like cusps, but outer marginal teeth with a third cusp; however, teeth with two and three cusps (two long, one small cusp) can be found together (Bouchet \& Warén 1993: fig. 1284).

The great similarities of operculum and radula between species of Strobiligera with paucispiral (S. gaesona) and multispiral (S. brychia and S. lubrica) protoconchs eliminate any suspicion that both groups could belong to different genera (Fernandes \& Pimenta 2014).

\section{A digression: soft parts of a species from the northwestern Atlantic}

“Inella” harryleei Rolán \& Fernández-Garcés, 2008

Figs 2L, 30-32

\section{Material examined}

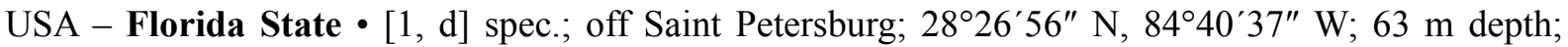
24 May 2012; G. Paulay leg.; FLMNH 450495.

\section{Description of basic anatomy}

Operculum. Yellowish, ovate, flat, moderately thin but rigid, semi-transparent, 3.25 distinct whorls, nucleus slightly eccentric, dislocated $\sim 37 \%$ from center toward margin; diameter of operculum does not exceed diameter of opercular pouch.

JAW. Wing-shaped; outer side with $\sim 30$ rows of scales, each scale often rhombus-shaped/squared, occasionally puzzle-shaped, rectangular or irregular; micro-pores in the posterior region, up to $380 \mathrm{~nm}$ in diameter; inner side with scales gem-like or leaf-shaped, surface smooth; scales of outer side 10.9$16.5 \mu \mathrm{m}$ long, 9.1-11.0 $\mu \mathrm{m}$ wide, ratio length/width 1.0-1.6 (rhombus-shaped/squared), 7.9-11.8 $\mu \mathrm{m}$ long, 4.5-6.1 $\mu \mathrm{m}$ wide, ratio length/width 1.3-2.6 (puzzle-shaped), 8.0-9.9 $\mu \mathrm{m}$ long, 2.9-4.3 $\mu \mathrm{m}$ wide, ratio length/width 2.1-3.3 (rectangular); scales of inner side 11.8-19.4 $\mu \mathrm{m}$ long, $4.5-7.4 \mu \mathrm{m}$ wide, ratio length/width 2.3-2.9 (gem-like), 15.1-17.7 $\mu \mathrm{m}$ long, 4.2-6.6 $\mu \mathrm{m}$ wide, ratio length/width 2.3-4.2 (leafshaped).

RADULA. Up to 37 overcrowded and undifferentiated teeth per row, comb-like and usually with five elongated cusps, but occasionally four or six/seven cusps, outermost cusps $39-77 \%$ of length of inner cusps; last marginal teeth with four to five triangular and pointed cusps, outer ones and median cusp (cusps 1, 3 and 5, when five cusps present) usually 53-74\% of length of larger cusps; teeth with four cusps 4.4-4.7 $\mu \mathrm{m}$ wide, teeth with five cusps 3.7-5.5 $\mu \mathrm{m}$ wide (teeth in the center of row slightly wider than marginal teeth), teeth with six/seven cusps $6.0-6.6 \mu \mathrm{m}$ wide, last marginal teeth $3.0-4.2 \mu \mathrm{m}$ wide.

\section{Remarks}

"Inella" harryleei has a different radular morphology when compared to Inella obliqua (May, 1915), which is the single species with illustrated soft parts of Inella s.s. (Marshall 1983). The operculum of " $P$ ". harryleei is slightly eccentric (Fig. 30C), similarly to I. obliqua and S. gaesona.

The undifferentiated and overcrowded teeth of " $P$ ". harryleei resemble those of Monophorus olivaceus (Figs 17-18) and M. erythrosoma, with a typical tooth bearing five comb-like cusps, in spite of slight variations in the number of cusps. Just like M. olivaceus, the last marginal teeth of " $P$ ". harryleei are considerably reduced in size. Species of Monophorus are usually sampled at mid-low depths of the continental shelf (Fernandes \& Pimenta 2017a), considering that " $P$ ". harryleei similarly inhabits depths 
of 63-90 m (Rolán \& Fernández-Garcés 2008; present study). However, " $I$ ". harryleei shows significant differences in the shell (e.g., abapical spiral cord of teleoconch much developed) and operculum (with an ovoid shape, almost elliptical, and nucleus more eccentric) compared to Monophorus. Although it seems premature to reallocate " $P$ ". harryleei in Monophorus, " $P$ ". harryleei is certainly related to the informal "Inella group" (Marshall 1983).

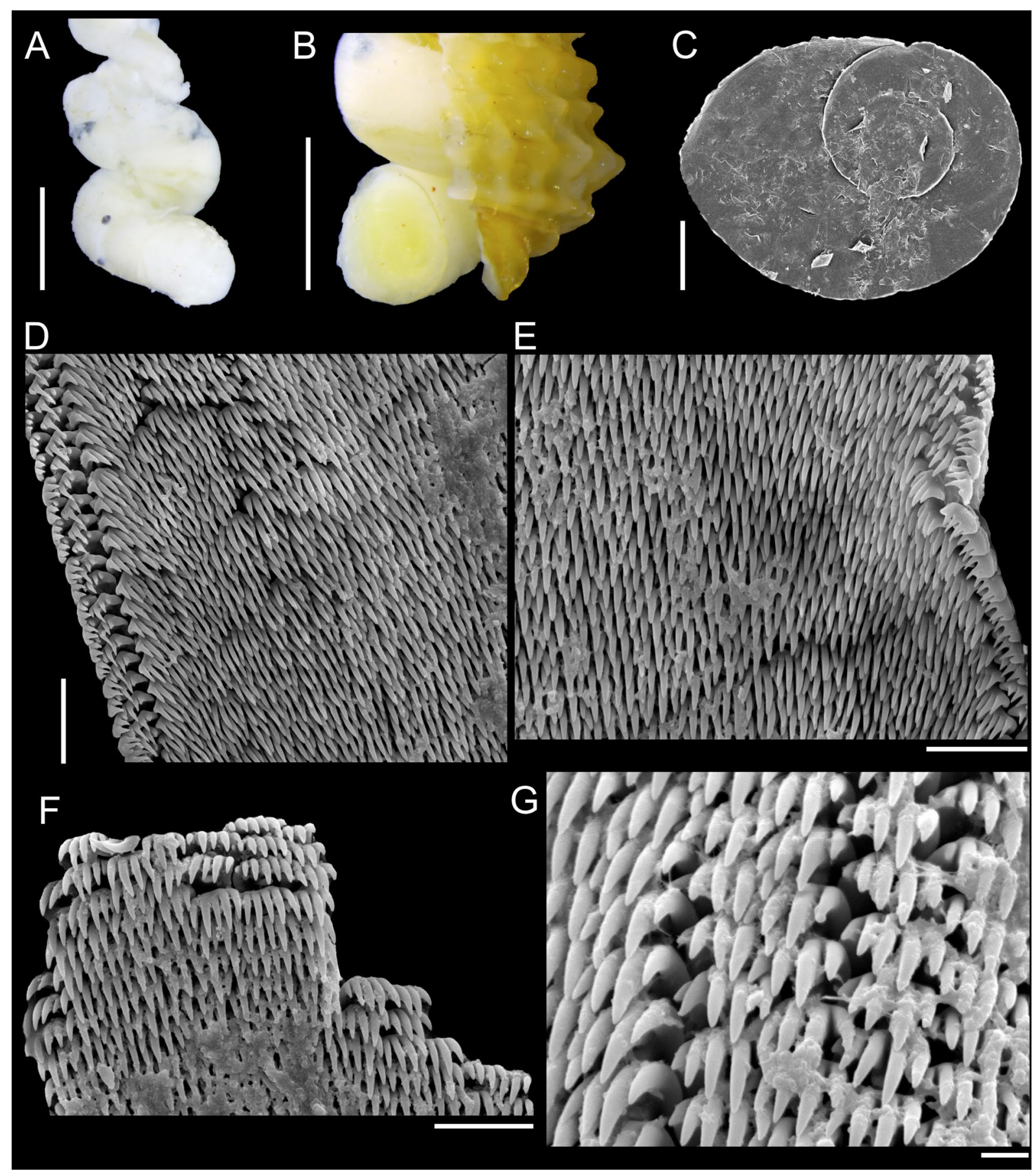

Fig. 30. "Inella" harryleei Rolán \& Fernández-Garcés, 2008. A-G. FLMNH 450495. A-B. External morphology. C. Operculum. D-G. Radula. Scale bars: A-B $=1 \mathrm{~mm}$; C $=200 \mu \mathrm{m}$; D-F = $10 \mu \mathrm{m} ; \mathrm{G}=2 \mu \mathrm{m}$. 


\section{Discussion}

The present section is divided according to the main morphological structures herein analysed (operculum, jaw and radula), in order to fully explore their taxonomic aspects and relevance to the study of Triphoridae on a global scale.

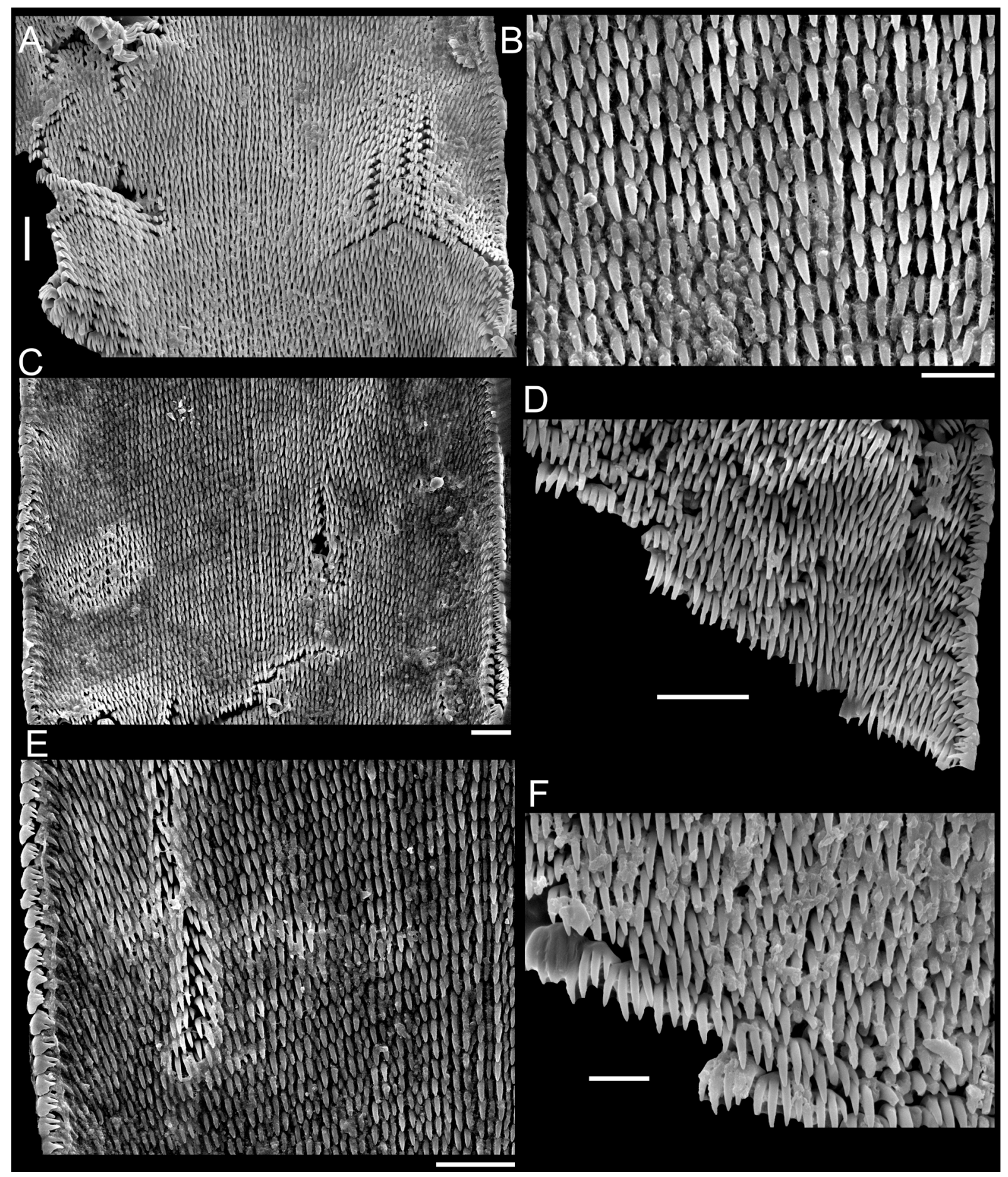

Fig. 31. "Inella" harryleei Rolán \& Fernández-Garcés, 2008, radula. A-F. FLMNH 450495. Scale bars: $\mathrm{A}, \mathrm{C}-\mathrm{E}=10 \mu \mathrm{m} ; \mathrm{B}, \mathrm{F}=5 \mu \mathrm{m}$. 


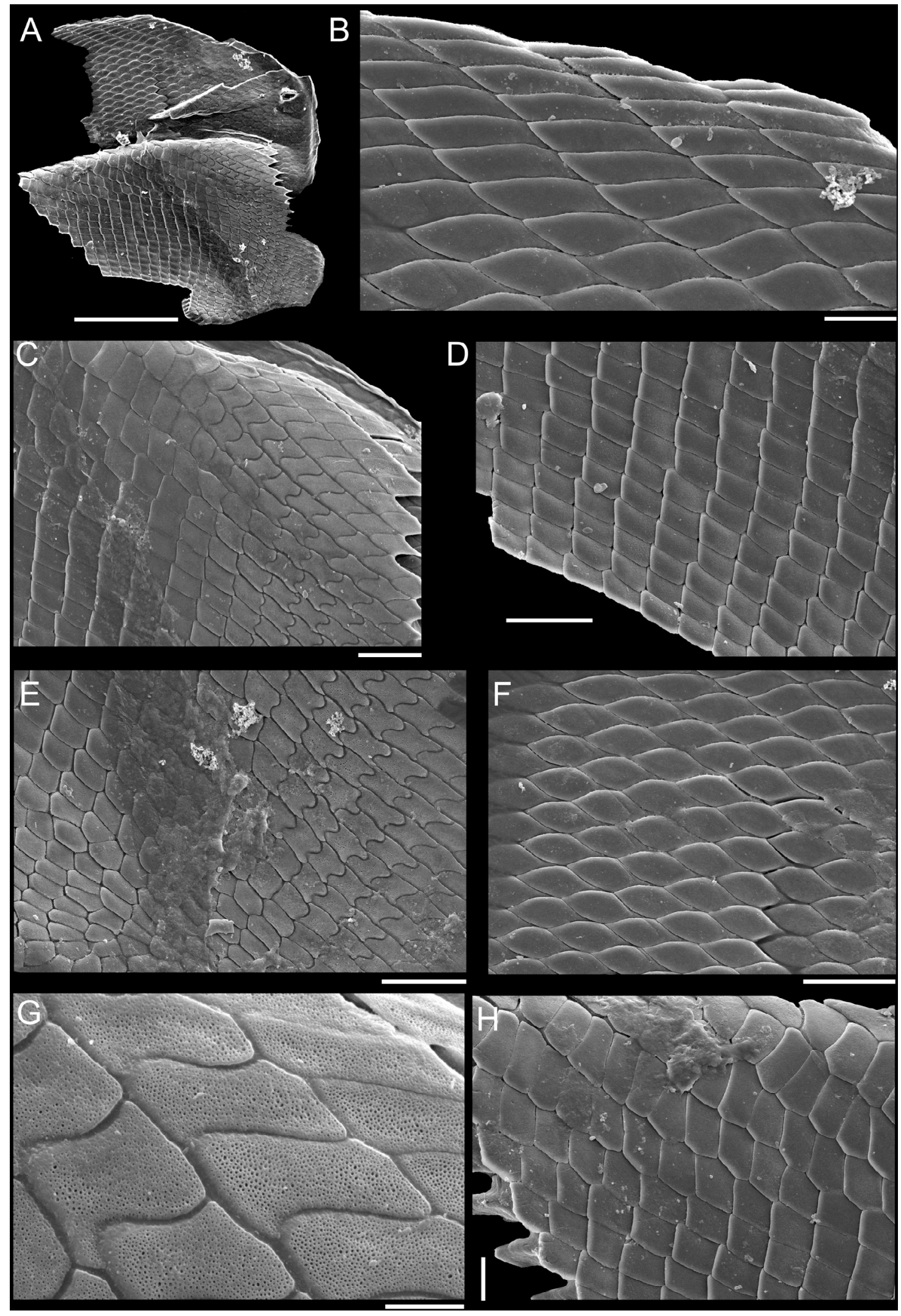

Fig. 32. "Inella" harryleei Rolán \& Fernández-Garcés, 2008. A-H. FLMNH 450495. A-H. Jaw, inner (B, F) and outer (C-E, G-H) sides. Scale bars: A $=100 \mu \mathrm{m} ; \mathrm{B}, \mathrm{H}=10 \mu \mathrm{m} ; \mathrm{C}-\mathrm{F}=20 \mu \mathrm{m} ; \mathrm{G}=5 \mu \mathrm{m}$. 


\section{Operculum}

Despite the considerable variation in the opercular morphology of triphorids, closely related genera and species tend to have similar opercula (Marshall 1983). The most common pattern observed in Triphorinae is a circular operculum bearing a central or subcentral nucleus, with a thin consistency, and a simple attachment to the foot, with both multispiral and paucispiral opercula being usual (Marshall 1983). Evidently, several groups deviated from this trend in different ways. The thick consistency of the operculum of Latitriphora (Fig. 12C) and Nototriphora (Fig. 21C-E), resulting in an easy removal and cleaning of this structure when compared to fragile opercula, is probably homologous. Some genera of Triphoridae, regarded as advanced by Marshall (1983), have the insertion of the operculum into the opercular pouch modified into a small ornament or even a prominent peg, which can be conical or honeycomb-like (Nützel 1998). Only Coriophora Laseron, 1958, Iniforis, Cheirodonta and Nanaphora seem to present such a modification in the operculum, although pegs or ornaments were not identified in the inner part of the operculum in I. pseudothomae, C. dupliniana comb. nov. and N. verbernei, despite the small projection seen in the former (Fig. 9E). It is worthy to mention that Coriophora and Iniforis may be closely related, just like Cheirodonta and Nanaphora (Marshall 1983), suggesting that the unusual modification of the insertion of the operculum into the opercular pouch may have evolved only a few times in Triphoridae.

The operculum of Metaxia rugulosa (Fig. 4B), just like that of other congeneric species, has a considerably eccentric nucleus and is somewhat similar to some species possessing the so-called operculum 'type 2' of Cerithiopsidae/Newtoniellidae (Marshall 1978), as also noted by Nützel (1998: 63). In the present study, Strobiligera gaesona (Fig. 28C) and "Inella" harryleei (Fig. 30C) showed a slightly eccentric nucleus, with Monophorus olivaceus (Fig. 14E-F) having a subcentral to slightly dislocated nucleus. A slightly eccentric nucleus also appears in the southwestern Pacific species Monophorus nigrofuscus (A. Adams, 1854), which is supposedly related to an ancient lineage in this genus (Marshall 1983). Following the proposition that Metaxiinae and the "Inella group" (in which Strobiligera, Monophorus and "I." harryleei are included) are primitive in Triphoridae (Marshall 1983), the considerably or slightly eccentric nucleus in this family may be a hint of that. Monophorus, as a very derived genus in the "Inella group" (Marshall 1983), would constitute a transition from a slightly eccentric to a typical subcentral nucleus, which is most common in the remaining genera of Triphorinae. Some species of Aclophora Laseron, 1958 and Aclophoropsis Marshall, 1983 also have an eccentric nucleus (Marshall 1983), possibly still showing a primitive condition or being a result of convergence. Kosuge (1966), in contrast, argued that the number of whorls and not the position of the nucleus had some meaning in the evolution of Triphoridae, with a derived paucispiral condition.

\section{Jaw}

The extremely long proboscis of triphorids, adapted to penetrate deeply into the osculum of sponges, renders the jaw and radula to be situated in a very far position from the mouth when the animal is not feeding. During jaw/radula extraction, most individuals can present these structures situated at one whorl posteriorly to the mouth, and up to two whorls in large specimens (like those of Strobiligera gaesona). All observed jaws have a golden or light-golden color, usually bright, whereas the radula is whitish or even slightly iridescent under a high intensity illuminator (Fig. 14D).

Risbec (1943: 103) was presumably the first author to substantially describe the jaw of Triphoridae, in this case, of one species from the southwestern Pacific. He described five or six rows of scales per jaw, each scale with an enlarged base and a triangular, erect and spine-like projection (Fig. 33A). Fretter (1951: 577) did not illustrate or describe the scales of the jaw, but instead described the general shape of the jaw and its positioning in a northeastern Atlantic triphorid. Kosuge (1966) illustrated the jaw of four species from Japan (Fig. 33B-E), very briefly describing some of them. The single type of scale he detected was of "elongate-quadrangular scales with aculeated tops" (Kosuge 1966: 303), although it is possible to see types of scales other than the common squared/rectangular ones in his drawings, 
like rhombus-shaped and irregular scales at the margin of the jaw (Fig. 33B). Kosuge (1966) apparently illustrated only the outer side of the jaw.

Marshall (1977: 112) cited the presence of elongate-quadrangular scales in the jaw of Metaxia exaltata. Bouchet (1985) examined the jaws of six species from four genera under SEM, and found no differences among them, having illustrated the jaw of a single species (Fig. 33F), apparently the inner side; this notion of supposed morphological homogeneity of the jaw would last for the following decades. Nützel (1998) illustrated the outer side of the jaw of an undescribed species of Metaxia (Fig. 33G-H), citing the existence of diamond-like or puzzle-like scales for Triphoridae (also seen in Fig. 1). He considered that the jaw of Metaxiinae is much more similar to Triphorinae than to Cerithiopsidae, being the first author to interpret this structure as having some degree of taxonomical relevance.

In contrast to the much more frequent study of the radula for taxonomical purposes in most families of Gastropoda, several authors interpret the jaw of gastropods as a conservative structure, not being rare to see illustrations of one side of the jaw of a single specimen (and consequently of a single species) generalized to an entire family. After several SEM micrographs obtained in the present study, it is clear that the jaw of Triphoridae is not uniform. For example, the outer and inner sides of the jaw bear several types of scales, some of them present in both sides (e.g., lanceolate and rhombus-shaped scales), but others are restricted to the outer (e.g., squared/rectangular, puzzle-like and bone-shaped scales) or inner sides (e.g., gem-like scales). Another peculiar distinction is the presence of micro-pores: the inner jaw is always smooth, whereas the outer jaw is smooth in an anterior region (away from the radula) but remarkably porous in the posterior region (close to the radula). There seems to be no transition zone between porous and smooth scales in the outer jaw, with adjacent scales being of one or the other condition (Fig. 16E), although the shape of the scale is usually not abruptly altered between adjacent scales, but instead showing intermediate/transition forms.

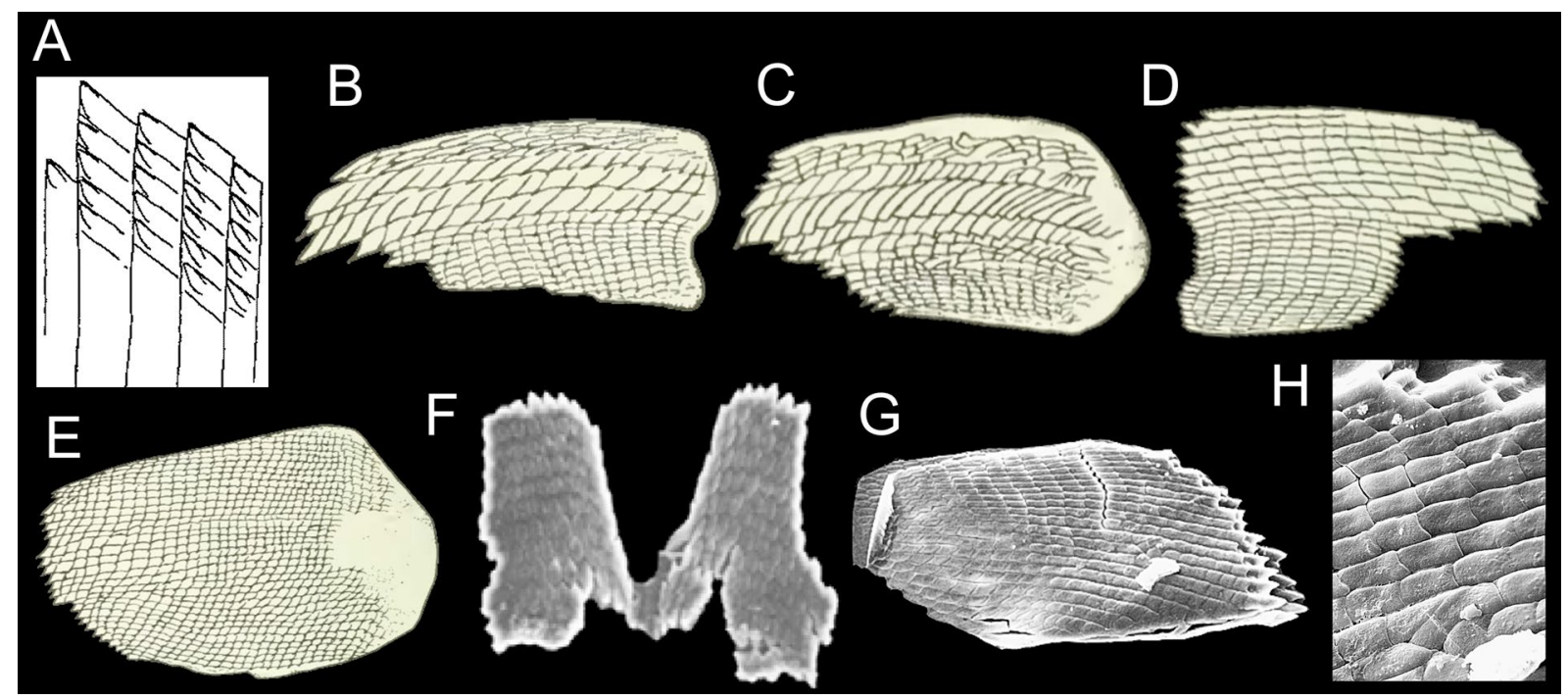

Fig. 33. Drawings and SEM micrographs of the jaw of triphorids in previous works. All permissions were obtained from authors and journals (see 'Acknowledgments'). A. Differoforis montrouzieri (Hervier, 1898); obtained from Risbec (1943: fig. 68). B-E. Obtained from Kosuge (1966: figs 5-8), following updated specific names: B. Mastoniaeforis albogranosa (Kosuge, 1961). C. Viriola tricincta (Dunker, 1882). D. Coriophora fusca (Dunker, 1860). E. Cautotriphora alveolata (A. Adams \& Reeve, 1850). F. Marshallora adversa (Montagu, 1803); obtained from Bouchet (1985: fig. 4). G-H. Metaxia sp.; obtained from Nützel (1998: fig. 7P-Q). 
Certainly more variation of jaw scales per species has yet to be revealed, because few individuals per species were herein examined. With the present and limited knowledge, it is unwise to affirm about the importance of types of jaw scales to distinguish genera of Triphoridae (Table 2). One suspicion is that Metaxiinae has a limited variation of jaw scales (only rectangular and rhombus-shaped scales in the outer side) if compared to Triphorinae, albeit very few micrographs of Metaxiinae are currently available (Figs 2B, D, 4C-D; Nützel 1998: fig. 7P-Q). Micro-pores in the jaw of triphorids are not exclusive of the family, being also seen in the newtoniellid Retilaskeya Marshall, 1978 (unpublished data) and perhaps in all Triphoroidea. The jaw of other gastropods may also present micro-pores, such as the inner and outer sides of the jaw of Epitoniidae (Gittenberger \& Gittenberger 2005; Zelaya \& Güller 2017), possibly providing a rougher surface and more abrasion to process the food.

\section{Radula}

A primary objective of the present study was to compare the radulae of Brazilian specimens with Caribbean ones previously illustrated in the series of papers by Rolán \& Fernández-Garcés (e.g., 1993, 1994, 1995, 2008), also providing detailed descriptions and measurements of teeth and cusps. The radulae of seven species are herein studied for the first time: Metaxia excelsa, Metaxia rugulosa, Cheirodonta dupliniana comb. nov., Iniforis pseudothomae, Similiphora intermedia, Strobiligera gaesona and "Inella" harryleei.

Although subjective, the phylogeny of Kosuge (1966) was the first attempt to clarify the systematics of Triphoridae. He defined three subfamilies mainly based on radular differences, namely Triphorinae, Iniforinae and Mastoniinae, also claiming that radulae with few cusps per teeth represent the derived condition. Marshall (1983) considered inadequate the subdivision of Kosuge, assuming that Iniforinae and Mastoniinae are synonyms of Triphorinae and sustaining the validity of Metaxiinae and Adelacerithiinae as dextrally-coiled triphorids with a rhinioglossate radula (i.e., with several marginal teeth). He agreed with Kosuge's view that advanced genera show a reduction in the number of cusps per teeth and that the many-toothed condition is of very early origin, although several events of reduction or multiplication of teeth may have evolved in the family, and that no single or combined radular characters can confidently split the subfamily Triphorinae. Marshall (1983) suggested that tooth/cusp elongation may have been originated in outer marginal teeth and progressively proceeded towards the central tooth in derived species, and properly stated that sometimes it is difficult or impossible to ascertain the radular morphology of a species based on a single individual.

Bandel (1984) proposed that triphorids have two types of radula: one would have a prior multiplication of cusps in central and lateral teeth, with a subsequent splitting of these teeth into a few or numerous new teeth; the second group would have an increase in the number of elongated marginal teeth. According to him, the primitive radula of Triphoridae followed a taenioglossate pattern, citing species currently allocated in Marshallora Bouchet, 1985 as an example, which actually agrees with Kosuge's view owing to his strong reliance on species currently in Marshallora to define his supposed primitive Triphorinae (Kosuge 1966). To Ponder \& Warén (1988), the rhinioglossate condition of triphorids was obtained from the multiplication of marginal teeth, what was rejected by Marshall (1983) and Nützel (1998) by a lack of homology. The latter author correctly considered that species bearing many teeth are particularly prone to present considerable intraspecific variation in the total number of teeth. He also stated that undifferentiated teeth and teeth with elongated hair-like cusps are not rare in this family, and that the huge variation in the radular formula of triphorids was the major aspect of its diversity. Finally, Nützel (1998) mentioned that the great morphological diversity of the triphorid radula appeared in a short time frame, with a probable accelerated evolution.

Nützel (1998) suggested that planctotrophic species in the subfamily Metaxiinae and in Strobiligera have very similar embryonic shells and nearly undifferentiated teeth, reflecting a probable phylogenetic 
proximity between these genera. The similarity of Metaxiinae with the "Inella group" was previously pointed by Marshall (1983: 15) because of their rather generalized radula. Due to the poor fossil record of the Metaxiinae, Nützel (1998: 85) regarded that it is more probable that this group is advanced rather than primitive among triphorids, recognizing an alternative scenario in which Metaxiinae and Triphorinae independently emerged from a third group.

Agreeing with Bouchet \& Warén (1993: 611), "the rhinioglossate type of radula may have evolved several times from taenioglossate cerithiopsids" or newtoniellids, merely by evolutive parallelism. Thus, tooth multiplication in Triphoroidea would render not a triphorid radula, but instead a nontaenioglossate radula, observed in the removal of Adelacerithiinae from Triphoridae by Nützel (1998). A molecular phylogeny of the group may reveal Metaxiinae being placed outside Triphoridae but inserted in other dextral Triphoroidea lineages, and the rarity of fossil forms in the former may be indeed related to a recent origin, but not necessarily within Triphoridae. Considering that the spongivory of Triphoroidea was probably the main driver of the radical evolution of the radula in this group, we acknowledge that the release from the taenioglossate pattern allowed Triphoridae to obtain several new radular morphologies (and perhaps more sponge hosts) than observed for typical cerithiopsids, a group that explored a great variation within the usual seven teeth per row (Marshall 1978). However, this does not mean that triphorids were the single lineage of Triphoroidea that deviated from this pattern.

In the present study, all species related to the "Inella group", i.e., Monophorus olivaceus (Figs 1718), Strobiligera gaesona (Fig. 29) and "Inella" harryleei (Figs 30D-G, 31) showed the primitive pattern of several overcrowded and mainly undifferentiated teeth. Iniforis (Fig. 11) and Isotriphora Cotton \& Godfrey, 1931 (Marshall 1983: fig. 5F-G) also have undifferentiated teeth and are possibly related (Marshall 1983). The theoretical radular formula of n-1-1-1-n of triphorids (Marshall, 1983) cannot be applied for such groups (Table 2), because it is impossible to define central or lateral teeth. Monophorus shows a tendency for a discrete tooth differentiation, albeit possible ancient groups like M. olivaceus still show a primitive condition, once again reinforcing the possibility of this genus to be a transition taxon. Similarly, related genera to Iniforis such as Coriophora and Mastonia also have an already differentiated tooth morphology, suggesting they are derived genera compared to Iniforis. Inella (s.s.) obliqua, otherwise, has a slightly differentiated tooth morphology (Marshall 1983), which could represent a new derivation of the primitive radula along the evolution of the "Inella group". Both the "Inella group" and Iniforis/Isotriphora may be ancestral lineages of Triphoridae, sharing a primitive radula and originating different main groups or subfamilies (Fernandes \& Pimenta in prep.). In fact, when the rhinioglossate condition emerged (whether in Triphorinae, Metaxiinae or Adelacerithiinae), the basic initial pattern seemed to follow teeth multiplication, with subsequent tooth differentiation being moderately (Metaxiinae and Adelacerithiinae) or considerably (Triphorinae) developed.

The study of the radula of western Atlantic species revealed problems in the delimitation of some genera. As mentioned previously, Nanaphora and Sagenotriphora are probably polyphyletic or present an astonishing variation in the composition of the radula, although triphorid genera are usually defined by typical and (more or less) restricted morphology patterns to each genus. "Inella" harryleei, although probably closely related to Monophorus both in teleoconch and radular morphology, may be worthy of a new genus. Minor conflicts of divergent radula were also detected in Cheirodonta and Latitriphora.

The typical cusp elongation of many derived genera in Triphoridae can be observed, for example, in marginal teeth of western Atlantic species of Marshallora, Cosmotriphora (Fig. 8), Latitriphora (Fig. 13), Nototriphora (Figs 22-23) and Similiphora (Fig. 27) - Table 2. Marshall (1983) noted that with the elongation of one cusp, the bordering cusps would loose the function of rasping the food and serve only to maintain the alignment of the main cusp, with some species even entirely loosening 
Table 2 (continued on next page). Summary of the main features of the jaw and the radula of species analyzed in the present study, not including other references. Asterisks (*) indicate length instead of width, i.e., in some cases of cusp elongation.

\begin{tabular}{|c|c|c|c|c|c|c|}
\hline \multirow[b]{2}{*}{ Species } & \multicolumn{2}{|c|}{ Jaw scales } & \multicolumn{4}{|c|}{ Radula } \\
\hline & Outer & Inner & Formula & Cusps/tooth & $\begin{array}{c}\text { Cusp } \\
\text { elongation }\end{array}$ & $\begin{array}{l}\text { Width of teeth } \\
\quad \text { (in } \mu \mathrm{m})\end{array}$ \\
\hline Metaxia excelsa & $\begin{array}{l}\text { Rectangular/squared; } \\
\text { rhombus-shaped; } \\
\text { oblong-lanceolate }\end{array}$ & Not studied & $4-1-1-1-4$ & $\begin{array}{c}\text { C: } 4 / 5 \\
\text { L: } 4 \\
\text { M1-M2: } 4 \\
\text { M3-M4: } 3\end{array}$ & No & $\begin{array}{c}\text { C: } 6.4-9.2 \\
\text { L: } 7.1-9.9 \\
\text { M1-M2: 4.1-8.7 } \\
\text { M3-M4: } 2.3-4.4\end{array}$ \\
\hline Metaxia rugulosa & $\begin{array}{c}\text { Rectangular; } \\
\text { rhombus-shaped }\end{array}$ & Not studied & $3-1-1-1-3$ & $\begin{array}{c}\text { C: } 4 / 5 \\
\text { L: } 4 \\
\text { M1-M2: } 3 / 4 \\
\text { M3: } 3\end{array}$ & No & $\begin{array}{c}\text { C: } 7.7-8.7 \\
\text { L: } 6.7-7.4 \\
\text { M1-M2: } 4.0-7.6 \\
\text { M3: } 2.1-3.0\end{array}$ \\
\hline $\begin{array}{c}\text { Cheirodonta } \\
\text { dupliniana }\end{array}$ & $\begin{array}{l}\text { Rectangular/squared; } \\
\text { rectangular-bilobed; } \\
\text { acute-lanceolate; } \\
\text { puzzle-like }\end{array}$ & Not studied & $8-1-1-1-8$ & $\begin{array}{c}\text { C: } 7 \\
\text { L: } 8 \\
\text { M1: } 8 / 9 \\
\text { M2-M8: } 9 / 10\end{array}$ & No & $\begin{array}{c}\text { C: } 4.9-5.0 \\
\text { L: } 4.1-4.6 \\
\text { M1: } 4.1-4.9 \\
\text { M2-M8: } 4.8-5.4\end{array}$ \\
\hline $\begin{array}{c}\text { Cosmotriphora } \\
\text { melanura }\end{array}$ & $\begin{array}{l}\text { Rectangular; } \\
\text { rectangular-bilobed; } \\
\text { acute-lanceolate }\end{array}$ & Hexagonal & $\begin{array}{c}\text { Not } \\
\text { discernible }\end{array}$ & $\begin{array}{c}\text { C: } 4 \\
\text { L: } 4 \\
\text { M1-M5: } 3 \\
\geq \text { M6: } 2\end{array}$ & $\begin{array}{l}\text { Marginal } \\
\text { teeth }\end{array}$ & $\begin{array}{c}\text { C: } 2.9-3.5 \\
\text { L: } 2.9-3.6 \\
\text { M1-M5: } 1.7-2.7 \\
\text { —M6: } 6.0-10.6^{*}\end{array}$ \\
\hline "Inella" harryleei & $\begin{array}{l}\text { Rhombus-shaped; } \\
\text { puzzle-shaped; } \\
\text { rectangular }\end{array}$ & $\begin{array}{l}\text { Gem-like; } \\
\text { leaf-shaped }\end{array}$ & $\begin{array}{l}37 \text { similar } \\
\text { teeth/row }\end{array}$ & $\begin{array}{l}\text { Usually } 5 \text { cusps, } \\
\text { but even } 4,6 \text { or } 7\end{array}$ & No & $3.0-6.6$ \\
\hline $\begin{array}{c}\text { Iniforis } \\
\text { pseudothomae }\end{array}$ & $\begin{array}{l}\text { Acute-lanceolate; } \\
\text { rectangular/squared; } \\
\text { rectangular-bilobed }\end{array}$ & $\begin{array}{c}\text { Lanceolate; } \\
\text { hexagonal; } \\
\text { rhombus-shaped }\end{array}$ & $\begin{array}{l}41 \text { similar } \\
\text { teeth/row }\end{array}$ & 3 & No & $1.3-1.8$ \\
\hline Latitriphora albida & $\begin{array}{l}\text { Rectangular/squared; } \\
\text { leaf-shaped; } \\
\text { rectangular-bilobed; } \\
\text { bone-shaped }\end{array}$ & $\begin{array}{l}\text { Lanceolate; } \\
\text { fusiform; } \\
\text { hexagonal }\end{array}$ & $12-1-1-1-12$ & $\begin{array}{c}\text { C: } 3 / 4 \\
\text { L: } 5 / 6 \\
\text { M1: } 4 \\
\text { M2-M12: } 3\end{array}$ & $\begin{array}{l}\text { Marginal } \\
\text { teeth }\end{array}$ & $\begin{array}{c}\text { C: } 4.3-4.8 \\
\text { L: } 4.6-5.2 \\
\text { M1: } 3.3-3.6 \\
\text { M2-M12: } 1.9-2.9\end{array}$ \\
\hline $\begin{array}{c}\text { Monophorus } \\
\text { olivaceus }\end{array}$ & $\begin{array}{l}\text { Rectangular/squared; } \\
\text { rectangular-bilobed; } \\
\text { bone-shaped; hexag- } \\
\text { onal; } \\
\text { acute-lanceolate; } \\
\text { X-shaped; } \\
\text { puzzle-shaped }\end{array}$ & $\begin{array}{l}\text { Lanceolate; } \\
\text { hexagonal; } \\
\text { gem-like; } \\
\text { rhombus-shaped }\end{array}$ & $\begin{array}{l}43 \text { similar } \\
\text { teeth/row }\end{array}$ & $\begin{array}{l}\text { Usually } 5 \text { to } 6 \\
\text { cusps, but even } \\
2,3,4 \text { or } 7\end{array}$ & No & $1.7-5.1$ \\
\hline $\begin{array}{c}\text { Nanaphora } \\
\text { verbernei }\end{array}$ & Not studied & Not studied & $8-1-1-1-8$ & $\begin{array}{c}\text { C: } 5 \\
\text { L: } 4 \text { to } 6 \\
\text { M1-M7: } 3 / 4 \\
\text { M8: } 3\end{array}$ & No & $\begin{array}{c}\text { C: } 3.6-3.8 \\
\text { L: } 3.8-4.1 \\
\text { M1-M7: } 2.4-9.2 \\
\text { M8: } 2.9-3.3\end{array}$ \\
\hline $\begin{array}{c}\text { Nototriphora } \\
\text { decorata }\end{array}$ & $\begin{array}{l}\text { Boomerang-shaped; } \\
\text { rectangular; } \\
\text { rhombus-shaped; } \\
\text { X-shaped; puz- } \\
\text { zle-shaped }\end{array}$ & Lanceolate & $18-1-1-1-18$ & $\begin{array}{c}\text { C: } 3 \\
\text { L: } 5 \\
\text { M1: } 4 \\
\text { M2-M18: } 3\end{array}$ & $\begin{array}{l}\text { Marginal } \\
\text { teeth }\end{array}$ & $\begin{array}{l}\mathrm{C}: 3.1-4.1 \\
\mathrm{~L}: 3.4-4.7 \\
\mathrm{M}: 1.8-3.7\end{array}$ \\
\hline
\end{tabular}


Table 2 (continued). Summary of the main features of the jaw and the radula of species analyzed in the present study.

\begin{tabular}{|c|c|c|c|c|c|c|}
\hline \multirow[b]{2}{*}{ Species } & \multicolumn{2}{|c|}{ Jaw scales } & \multicolumn{4}{|c|}{ Radula } \\
\hline & Outer & Inner & Formula & Cusps/tooth & $\begin{array}{c}\text { Cusp } \\
\text { elongation }\end{array}$ & $\begin{array}{l}\text { Width of teeth } \\
\quad \text { (in } \mu \mathrm{m})\end{array}$ \\
\hline $\begin{array}{c}\text { Similiphora } \\
\text { intermedia }\end{array}$ & $\begin{array}{l}\text { Rectangular/squared; } \\
\text { rectangular-bilobed; } \\
\text { bone-shaped; } \\
\text { acute-lanceolate }\end{array}$ & $\begin{array}{l}\text { Oblong- } \\
\text { lanceolate; } \\
\text { hexagonal; } \\
\text { gem-like }\end{array}$ & $14-1-1-1-14$ & 3 & $\begin{array}{l}\text { Marginal } \\
\text { teeth }\end{array}$ & $\begin{array}{l}\text { C: } 3.5-5.7 \\
\text { L: } 3.1-5.4 \\
\text { M: } 1.6-3.9\end{array}$ \\
\hline $\begin{array}{l}\text { Strobiligera } \\
\text { gaesona }\end{array}$ & $\begin{array}{l}\text { Rhombus-shaped; } \\
\text { rectangular; } \\
\text { rectangular-lanceolate }\end{array}$ & Not studied & $\begin{array}{l}>30 \text { similar } \\
\text { teeth }\end{array}$ & $\begin{array}{c}\text { Usually } 3 \text { cusps, } \\
\text { but even } 2 \text { or } 4\end{array}$ & No & $1.1-3.9$ \\
\hline
\end{tabular}

adjacent cusps and having the elongated cusp solely sustained by a broadened base. Considering the emergence of elongated cusps initially at the marginal teeth and progressively towards the central tooth in some cases (Marshall 1983), it seems plausible that these filiform, hair-like cusps without serrated margins may not have any function to rasp sponges, but instead may serve exclusively to gather food particles. The progressive modification of all radular teeth/cusps into elongated ones in a few genera may be related to an increasingly importance of the jaw as the responsible to weaken the soft parts of the sponge, and the evolution of the morphology of the jaw in triphorids may exemplify it. Conversely, this trend of cusp elongation may have initially appeared in outer marginal teeth owing to the common sense that marginal teeth are often not involved to rasp, but to collect food particles in several mollusks (Hickman 1980).

The concentration of force into fewer points is mechanically prone to rasp harder substrates (Padilla 1985; Reid \& Mak 1999). Species of Marshallora and Sagenotriphora, for example, possess only three teeth per row with evident rasping function, the former with a long and common base for the multicuspid teeth (similar to a rachiglossate radula) and the latter with central and lateral teeth with a globose shape (broad base) and being adhered into a central axis (Fig. 24A-D). These seem to be adaptations for a diet based on hard substrates (i.e., sponges with thick internal walls), reducing risks of teeth or cusps dislodgement during feeding. Cusps in both genera are sharp, which may be more useful to cut tissues (Padilla 2004).

The knowledge of species-specific associations of triphorids with sponges, still far from satisfactory, may allow a correlation between the texture of sponges and the related radular apparatus of the triphorid, regarding that divergent radular morphology not always translate into divergent feeding preference (Hickman 1980; Raffaelli 1985). Mechanical tests and the examination of gut content may also clarify these questions (Raffaelli 1985; Hawkins et al. 1989; Padilla 2004). The inference of the existence of distinct species solely based on radular morphology is also questionable in triphorids; differences in the habitat or food environment may promote great phenotypical plasticity in the radula, in addition to natural variation among individuals (Padilla 2004). This reinforces the importance of conducting SEM for more than one individual when studying a triphorid radula (Marshall 1983).

\section{Other structures}

The pedal slit of Triphoroidea is traditionally recognized as responsible to produce mucus in the sole (Kosuge 1966), enabling these snails to climb even smooth vertical surfaces, and the slit is much more evident after a correct relaxation (Fig. 25F; Nützel 1998: fig. 12E-F). Otherwise, it becomes shrunken and imperceptible under stereo microscopy. The foot and the cephalic tentacles are very affected when 
specimens are not properly relaxed, being completely elongated with hydrostatic pressure (i.e., only in live specimens). Because of the scarcity of observations of live animals in this study, mantle tentacles, which may have taxonomic significance (Nützel 1998), were not distinguished herein.

Another feature that desirably requires photographs of live animals is the coloration of the head-foot. Prolonged periods of storage in ethanol alter the original coloration of soft parts, especially light colors, like in the readily fading of red pigmentation in Nanaphora verbernei (Fig. 19A-D). In contrast, dark colors seem to persist longer, as observed in Similiphora intermedia (Fig. 25A-B) and in the unusual black stripe typical of Cosmotriphora melanura (Fig. 7A-B).

A rare record in this study was the presence of black fecal pellets in the intestine of Nanaphora verbernei (Fig. 19D), assuming a vesicular shape and being $82-100 \mu \mathrm{m}$ long. Fretter (1951) indicated that spicules compose the great amount of triphorid faeces, being presumably wrapped by the mucus secreted by the epithelium of the mid-intestine (Fretter 1951). Kosuge (1966) described the fecal pellets of Coriophora fusca (Dunker, 1860) (under the name Mastonia limosa Jousseaume, 1884) as being spindle-shaped, also containing sponge spicules. The first images of fecal pellets of triphorids were provided by Nützel (1998: fig. 9P-R) for two species of Coriophora and for an unidentified genus, all showing a more or less vesicular-shape, but one showing spicule needles covering the surface of the pellet and another vesicle being externally constituted by small spheroids; according to him, the color of pellets is clearly species-specific. The black fecal pellets of a species of Monophorus from Chile are vesicular, but distinctly anteriorly rounded and posteriorly acute, measuring 87-115 $\mu \mathrm{m}$ long (Fernandes \& Araya in prep.). Well-formed black fecal pellets of Marshallora were recorded with a length of 164-215 $\mu \mathrm{m}$, also vesicular-shaped (Fernandes et al. in prep.); the double-sized fecal pellets of Marshallora compared to Nanaphora and Monophorus are not related to shell size, which is similar among the three species. Thus, coloration, external surface, size and shape of fecal pellets may slightly vary between species, although more intra- and interspecific comparisons are required to confirm it. Fecal morphology seems to reflect the internal structure of the rectum (Geiger et al. 2008), thus possibly having taxonomic importance.

\section{Final considerations}

The present study aimed at shedding light on the basic anatomy (mainly internal hard structures) of triphorids from Brazil, having furnished a solid basis of comparison of operculum and radula with previously illustrated Caribbean specimens and with species from other regions of the world, but raising concerns about some generic allocations. A significant contribution was developed to understand the morphology of the jaw, a previously meaningless structure in the taxonomy of triphorids. Aspects of the basic anatomy are now known for only 13 species of Triphoridae occurring in Brazil, representing $\sim 20 \%$ of the 66 species (Fernandes \& Pimenta in prep.). More sampling is required to fill this important gap in our knowledge.

Histological analyzes will be particularly important for the study of triphorids as it would be to any other animal with a specialized feeding mode, enabling the evaluation of the presence of spicules of different sponges in their stomach content. Micro-tomography and histological serial sections with subsequent $3 \mathrm{D}$ reconstructions are another exciting procedures to the study of micromollusks (Geiger et al. 2007).

More studies of the soft parts of triphorids must be conducted around the world, and a thorough investigation of the internal anatomy of different genera will certainly reveal many surprises related to digestive, reproductive, nervous and other systems. A similar anatomical comparison with other groups of Triphoroidea will also provide new substantial insights. Lastly, a molecular phylogeny of Triphoridae is needed to integrate the evolution of internal hard structures with the evolution of monophyletic lineages. 


\section{Acknowledgements}

We are very grateful to: Dr José H. Leal (BMSM), Dr Ellen Strong (NMNH), Dr Flávio Passos (UNICAMP), Dr Luiz Simone (MZUSP), Dr Amanda Bemis and Dr John Slapcinsky (FLMNH), for the loan of some specimens; Dr Alexander Nützel (LMU), Dr Charles Lydeard (Morehead State University), Dr Paolo Russo and Dr Philippe Bouchet (MNHN) allowed us to reproduce images of previous works (Fig. 33); Camila Messias (MNRJ) helped with SEM micrographs; Dr Bruce Marshall (Museum of New Zealand Te Papa Tongarewa), Dr Emilio Rolán (Museo de Historia Natural de la Universidad de Santiago de Compostela, Spain) and an anonymous reviewer made great suggestions for this study; Conselho Nacional de Desenvolvimento Científico e Tecnológico (CNPq) and The Conchological Society of Great Britain and Ireland respectively provided a doctorate fellowship and a research grant to the first author. All samplings in Brazil were conducted under license number 45410 of SISBIO (Sistema de Autorização e Informação em Biodiversidade).

\section{References}

Albano P.G., Sabelli B. \& Bouchet P. 2011. The challenge of small and rare species in marine biodiversity surveys: microgastropod diversity in a complex tropical coastal environment. Biodiversity and Conservation 20: 3223-3237. https://doi.org/10.1007/s10531-011-0117-x

Bandel K. 1984. The radulae of Caribbean and other Mesogastropoda and Neogastropoda. Zoologische Verhandelingen 214: 1-188.

Bouchet P. 1985. Les Triphoridae de Méditerranée et du proche Atlantique (Mollusca, Gastropoda). Lavori della Società Italiana di Malacologia 21: 5-58.

Bouchet P. 1997. Nouvelles observations sur la systematique des Triphoridae de Méditerranée et du proche Atlantique. Bollettino Malacologico 31: 205-220.

Bouchet P. \& Guillemot H. 1978. The Triphora perversa-complex in Western Europe. Journal of Molluscan Studies 44: 344-356.

Bouchet P. \& Warén A. 1993. Revision of the northeast Atlantic bathyal and abyssal Mesogastropoda. Bollettino Malacologico 3: 579-840.

Bouchet P., Lozouet P., Maestrati P. \& Héros V. 2002. Assessing the magnitude of species richness in tropical marine environments: exceptionally high numbers of molluscs at a New Caledonia site. Biological Journal of the Linnean Society 75: 421-436. https://doi.org/10.1046/j.1095-8312.2002.00052.x

Bouchet P., Marshall B. \& Gofas S. 2017. Metaxia Monterosato, 1884. MolluscaBase. Available from http://www.molluscabase.org/aphia.php?p=taxdetails\&id=138572 [accessed 14 Nov. 2017].

Cossmann M. 1906. Essais de paléoconchologie comparée, 7. Published by the author, Paris. https://doi.org/10.5962/bhl.title.52314

Fernandes F. \& Rolán E. 1988. A família Triphoridae (Mollusca: Gastropoda) no Arquipélago de Cabo Verde. Publicações Ocasionais da Sociedade Portuguesa de Malacologia 11: 17-32.

Fernandes M.R. \& Pimenta A.D. 2014. Two species of the genus Strobiligera (Caenogastropoda: Triphoridae) with a multispiral protoconch in Southeastern Brazil. American Malacological Bulletin 32: 165-172. https://doi.org/10.4003/006.032.0207

Fernandes M.R. \& Pimenta A.D. 2015. Five new species and two records of Triphorinae(Caenogastropoda, Triphoridae) from Brazil. Zootaxa 4012: 493-513. https://doi.org/10.11646/zootaxa.4012.3.5

Fernandes M.R. \& Pimenta A.D. 2017a. Synopsis of the deep-sea groups of Triphoroidea (Gastropoda). Journal of Natural History 51: 853-865. https://doi.org/10.1080/00222933.2017.1293181 
Fernandes M.R. \& Pimenta A.D. 2017b. A study of triphorid larvae and post-larvae at the Campos Basin deep-sea floor, southeastern Brazil (Gastropoda: Triphoroidea). Journal of Natural History 51: 867-881. https://doi.org/10.1080/00222933.2017.1293178

Fretter V. 1951. Observations on the life history and functional morphology of Cerithiopsis tubercularis (Montagu) and Triphora perversa (L.). Journal of the Marine Biological Association of the United Kingdom 29: 567-586. https://doi.org/10.1017/S0025315400052784

García M.T. \& Luque A.A. 1986. Contribución al conocimiento de los gasterópodos prosobranquios de la Isla de la Juventud y del Archipiélago de los Canarreos (Cuba). Revista de Investigaciones Marinas 7: $31-52$.

Geiger D.L., Marshall B.A., Ponder W.F., Sasaki T. \& Warén A. 2007. Techniques for collecting, handling, preparing, storing, and examining small molluscan specimens. Molluscan Research 27: 1-50.

Geiger D.L., Nützel A. \& Sasaki T. 2008. Vetigastropoda. In: Ponder W.F. \& Lindberg D.R. (eds) Phylogeny and Evolution of the Mollusca: 297-330. University of California Press, Berkeley.

Gittenberger A. \& Gittenberger E. 2005. A hitherto unnoticed adaptive radiation: epitoniid species (Gastropoda: Epitoniidae) associated with corals (Scleractinia). Contributions to Zoology 74: 125-203.

Golding R.E., Ponder W.F. \& Byrne M. 2009. The evolutionary and biomechanical implications of snout and proboscis morphology in Caenogastropoda (Mollusca: Gastropoda). Journal of Natural History 43: 2723-2763. https://doi.org/10.1080/00222930903219954

Haszprunar G. 1985. The fine morphology of the osphradial sense organs of the Mollusca. 1. Gastropoda, Prosobranchia. Philosophical Transactions of the Royal Society B 307: 457-496.

https://doi.org/10.1098/rstb.1985.0003

Hawkins S.J., Watson D.C., Hill A.S., Harding S.P., Kyriakides M.A., Hutchinson S. \& Norton T.A. 1989. A comparison of feeding mechanisms in microphagous, herbivorous, intertidal, prosobranchs in relation to resource partitioning. Journal of Molluscan Studies 55: 151-165.

https://doi.org/10.1093/mollus/55.2.151

Healy J.M. 1990. Systematic importance of spermatozeugmata in triphorid and cerithiopsid gastropods (Caenogastropoda: Triphoroidea). Journal of Molluscan Studies 56: 115-118.

https://doi.org/10.1093/mollus/56.1.115

Hickman C.S. 1980. Gastropod radulae and the assessment of form in evolutionary paleontology. Paleobiology 6: 276-294. https://doi.org/10.1017/S0094837300006801

Houston R.S. 1985. Genital ducts of the Cerithiacea (Gastropoda: Mesogastropoda) from the Gulf of California. Journal of Molluscan Studies 51: 183-189.

https://doi.org/10.1093/oxfordjournals.mollus.a065899

Johansson J. 1953. On the genital organs of some mesogastropods: Cerithium vulgatum Brug. Triphora perversa (L.) and Melanella (Eulima) intermedia (Cantr.). Zoologiska Bidrag fran Uppsala 30: 1-23.

Kosuge S. 1966. The family Triphoridae and its systematic position. Malacologia 4: 297-324.

Marcus E. \& Marcus E. 1963. Mesogastropoden von der Küste São Paulos. Abhandlungen der Mathematisch-Naturwissenschaftlichen Klasse 1: 1-105.

Marshall B.A. 1977. The dextral triforid genus Metaxia (Mollusca: Gastropoda) in the south-west Pacific. New Zealand Journal of Zoology 4: 111-117.

Marshall B.A. 1978. Cerithiopsidae (Mollusca: Gastropoda) of New Zealand and a provisional classification of the family. New Zealand Journal of Zoology 5: 47-120. 
Marshall B.A. 1983. A revision of the recent Triphoridae of Southern Australia (Mollusca: Gastropoda). Records of the Australian Museum, suppl. 2: 1-119.

Nützel A. 1998. Ueber die Stammesgeschichte der Ptenoglossa (Gastropoda). Berliner Geowissenschaftliche Abhandlungen, ser. E (Palaeobiologie) 26: 1-229.

Padilla D.K. 1985. Structural resistance of algae to herbivorous - a biomechanical approach. Marine Biology 90: 103-109. https://doi.org/10.1007/BF00428220

Padilla D.K. 2004. Form and function of radular teeth of herbivorous molluscs: focus on the future. American Malacological Bulletin 18: 163-168.

Ponder W.F. \& Warén A. 1988. Classification of the Caenogastropoda and Heterostropha - a list of the family-group names and higher taxa. In: Ponder W.F. (ed.) Prosobranch Phylogeny. Malacological Review, suppl. 4: 288-328.

Raffaelli D. 1985. Functional feeding groups of some intertidal molluscs defined by gut contents analysis. Journal of Molluscan Studies 51: 233-239. https://doi.org/10.1093/oxfordjournals.mollus.a065912

Redfern C. 2013. Bahamian Seashells: 1161 Species from Abaco, Bahamas. Bahamian Seashells Inc., Boca Raton.

Reid D. \& Mak Y.M. 1999. Indirect evidence for ecophenotypic plasticity in radular dentition of Littoraria species (Gastropoda: Littorinidae). Journal of Molluscan Studies 65: 355-370. https://doi.org/10.1093/mollus/65.3.355

Risbec J. 1943. Recherches anatomiques sur les Prosobranches de Nouvelle-Calédonie. (Quatrième partie). Annales des Sciences Naturelles, Zoologie 11 (5): 89-107.

Rolán E. \& Fernández-Garcés R. 1993. The family Triphoridae (Mollusca, Gastropoda) in Cuba. 2. The genus Iniforis Jousseaume, 1884. Apex 8: 95-105.

Rolán E. \& Fernández-Garcés R. 1994. The family Triphoridae (Mollusca, Gastropoda) in Cuba. 4. The genera Monophorus, Nototriphora, Cosmotriphora and Cheirodonta, with the description of three new species. Apex 9: 17-27.

Rolán E. \& Fernández-Garcés R. 1995. The family Triphoridae (Mollusca, Gastropoda) in Cuba. 5. The genera Marshallora, Mesophora, Similiphora, Eutriphora, Latitriphora, Aclophora and other species without generic affiliation. Apex 10: 9-24.

Rolán E. \& Fernández-Garcés R. 2008. New data on the Caribbean Triphoridae (Caenogastropoda, Triphoroidea) with the description of 26 new species. Iberus 26: 81-170.

Rolán E. \& Peñas A. 2001. Two new species of the genus Monophorus (Gastropoda, Triphoridae) in the east Atlantic and Mediterranean Sea. Iberus 19: 31-40.

Romani L. 2015. A new Mediterranean Monophorus species (Gastropoda: Triphoridae). Bollettino Malacologico 51: 3-8.

Stephens L.D. \& Vafiadis P. 2015. The genus Eutriphora - notes on four species of Triphoridae from southeastern Australia. The Malacological Society of Australasia Newsletter 153: 4-5.

Wells F.E. 1998. Superfamily Triphoroidea. In: Beesley P.L., Ross G.J.B. \& Wells A. (eds) Mollusca: the Southern Synthesis. Fauna of Australia. Part B: 808-811. Vol. 5. CSIRO Publishing, Melbourne.

WoRMS Editorial Board. 2018. World Register of Marine Species. Available from http://www.marinespecies.org [accessed 28 May 2018].

Zamudio K.R., Kellner A., Serejo C., Britto M.R., Castro C.B., Buckup P.A., Pires D.O., Couri M., Kury A.B., Cardoso I.A., Monné M.L., Pombal Jr. J., Patiu C.M., Padula V., Pimenta A.D., Ventura C.R.R., 
Hajdu E., Zanol J., Bruna E.M., Fitzpatrick J., Rocha L.A. 2018. Lack of Science support fails Brazil. Science 361: 1322-1323. https://doi.org/10.1126/science.aav3296

Zelaya D.G. \& Güller M. 2017. Undercover speciation of wentletraps (Caenogastropoda: Epitoniidae) in the Southwestern Atlantic. Zootaxa 4286: 41-69. https://doi.org/10.11646/zootaxa.4286.1.2

Manuscript received: 31 August 2018

Manuscript accepted: 28 February 2019

Published on: 17 April 2019

Topic editor: Rudy Jocqué

Desk editor: Pepe Fernández

Printed versions of all papers are also deposited in the libraries of the institutes that are members of the EJT consortium: Muséum national d'Histoire naturelle, Paris, France; Meise Botanic Garden, Belgium; Royal Museum for Central Africa, Tervuren, Belgium; Royal Belgian Institute of Natural Sciences, Brussels, Belgium; Natural History Museum of Denmark, Copenhagen, Denmark; Naturalis Biodiversity Center, Leiden, the Netherlands; Museo Nacional de Ciencias Naturales-CSIC, Madrid, Spain; Real Jardín Botánico de Madrid CSIC, Spain; Zoological Research Museum Alexander Koenig, Bonn, Germany. 